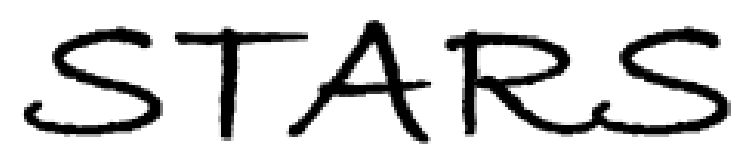

University of Central Florida

STARS

2013

\title{
Combustion Synthesis And Characterization Of Porous Niti Intermetallic For Structural Application
}

Jessica Vanterpool

University of Central Florida

Part of the Mechanical Engineering Commons

Find similar works at: https://stars.library.ucf.edu/etd

University of Central Florida Libraries http://library.ucf.edu

This Masters Thesis (Open Access) is brought to you for free and open access by STARS. It has been accepted for inclusion in Electronic Theses and Dissertations, 2004-2019 by an authorized administrator of STARS. For more information, please contact STARS@ucf.edu.

\section{STARS Citation}

Vanterpool, Jessica, "Combustion Synthesis And Characterization Of Porous Niti Intermetallic For Structural Application" (2013). Electronic Theses and Dissertations, 2004-2019. 2590.

https://stars.library.ucf.edu/etd/2590

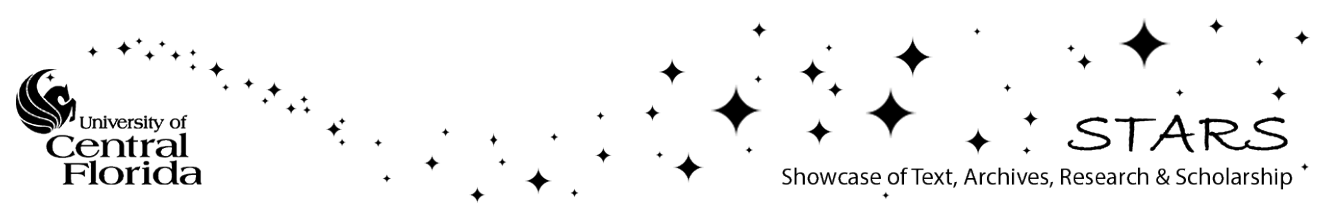




\title{
COMBUSTION SYNTHESIS AND CHARACTERIZATION OF POROUS NITI
} INTERMETALLIC FOR STRUCTURAL APPLICATION

by

\section{JESSICA DANIELLE VANTERPOOL \\ B.S Florida State University, 2009}

\begin{abstract}
A thesis submitted in partial fulfillment of the requirements for the degree of Master of Science in the Department of Mechanical, Materials and Aerospace Engineering in the College of Engineering and Computer Science at the University of Central Florida Orlando, Florida
\end{abstract}

Spring Term

2013 


\begin{abstract}
This thesis describes experimental investigation of thermal and combustion phenomena as well as structure for self- propagating combustion synthesis of porous $\mathrm{Ni}$ - Ti intermetallic aimed for structural biomedical application. The control parameters for the porosity distribution have been investigated experimentally through varying the preheat temperature, initial porosity, initial elemental particle size, and applied pressure during the fabrication process. $\mathrm{Ni}$ and $\mathrm{Ti}$ elemental powders are mixed using a 1:1 ratio. The mixture is compressed using several different compression forces to produce cylindrical samples of $1.1 \mathrm{~cm}$ diameter and $2-3 \mathrm{~cm}$ length, with initial porosity ranging from $30 \%$ to $40 \%$. The samples are preheated to various initial temperatures and ignited from the top surface such that the flame propagates axially downwards. The combustion reaction is recorded with a motion camera. An infrared sensor is used to record the temperature profile during the combustion process. The samples are then cut using a diamond saw in both longitudinal and transverse directions. Image analysis software is then used to analyze the porosity distribution in each sample.
\end{abstract}


Dedicated to my family and friends 


\section{ACKNOWLEDGMENTS}

First I would like to express my gratitude to my advisor Dr. Olusegun Ilegbusi for allowing me the opportunity to carry out this thesis study. Dr. Ilegbusi's tutelage and mentorship has allowed me to extend the boundaries of both my research and dreams. His drive and ability to think outside of the box has been a tremendous example of how I myself would like to further my career in the field of engineering. I would also like to thank Dr. Zhiliang Li of whom I was

his understudy. Dr. Li patiently taught me how to fabricate NiTi samples as well as how to carry out the combustion synthesis process. I am truly grateful for the time he took to get me better acclimated with my research.

Thank you to Jeanine Clements who is the MMAE Graduate Admissions Specialist. Jeanine guided me many times during my confusion as a graduate student. No matter how busy or preoccupied she became she would always find time to help me in a timely manner.

Thank you to NSF for funding my research. Without the support of NSF my research would not be possible.

Thank you to my family and friends for their endless support. Most importantly thank you to my mother for her countless prayers and words of encouragement. I truly would not get very far without her.

Finally thank you to God for I would be nothing without him. One scripture that has always stuck with me through the course of graduate school is: Philippians 4:13 I can do all things through Christ which strengthened me. 


\section{TABLE OF CONTENTS}

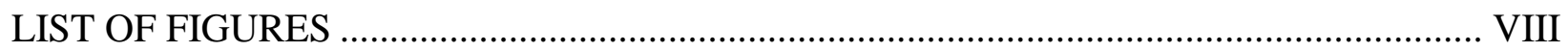

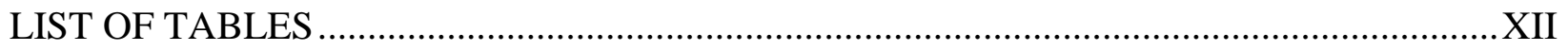

LIST OF ABBREVIATIONS/NOMENCLATURE/ACRONYMS .................................... XIII

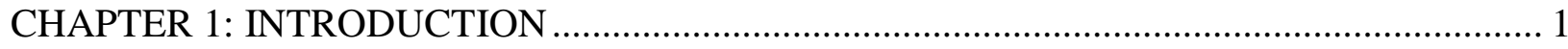

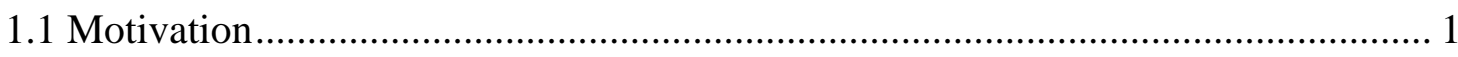

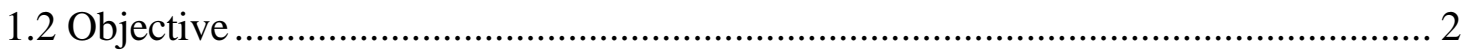

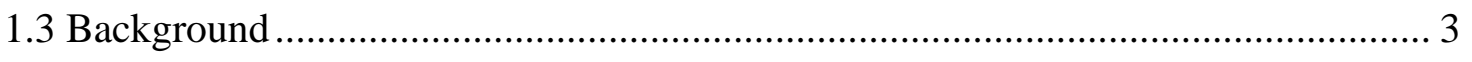

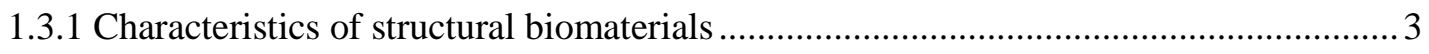

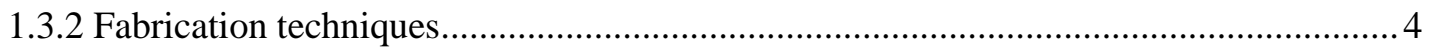

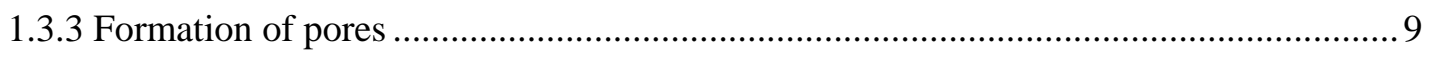

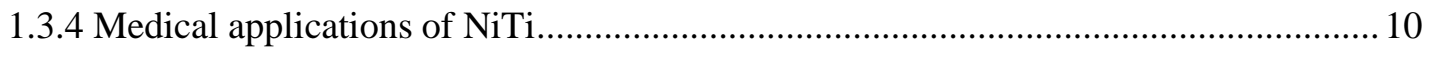

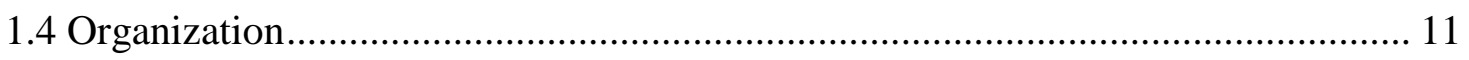

CHAPTER 2: LITERATURE REVIEW ......................................................................... 12

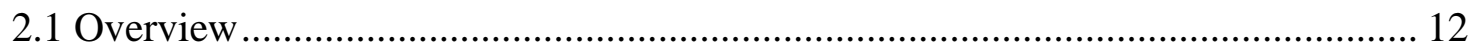

2.2 Important Characteristics of Structural Biomaterials ...................................... 12

2.3 Fabrication Methods .................................................................................... 14

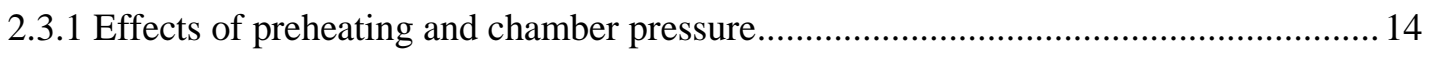

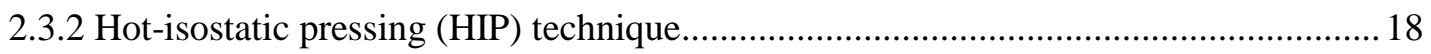

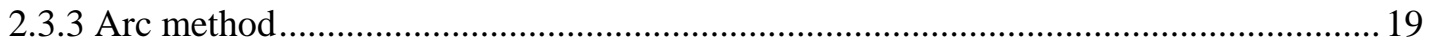




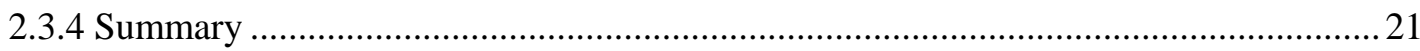

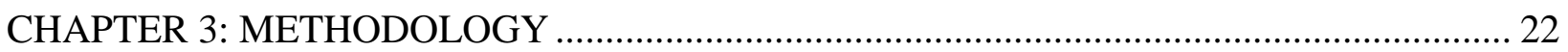

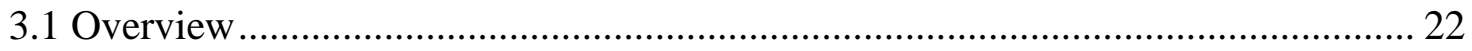

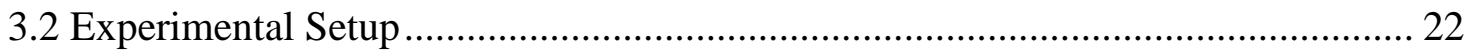

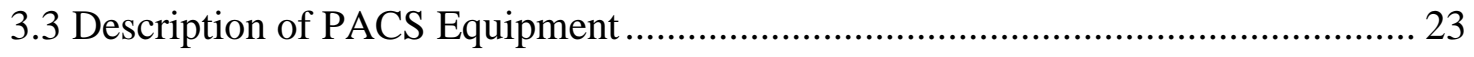

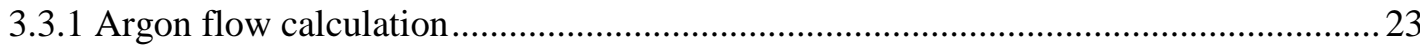

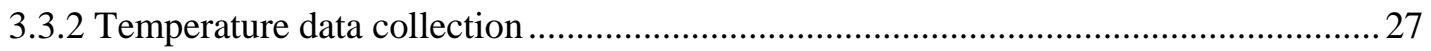

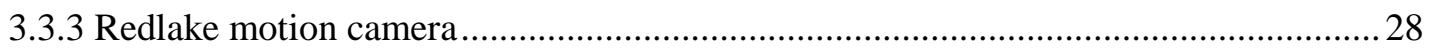

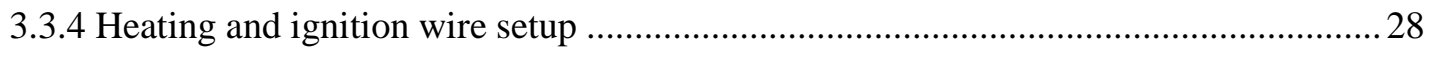

3.3.5 Two-dimensional (2D) porosity calculation software (ImageJ) ................................ 30

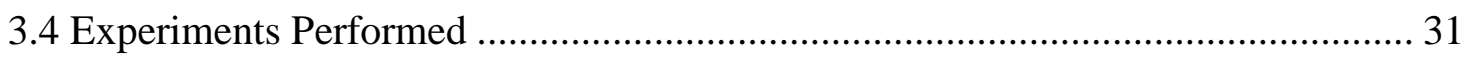

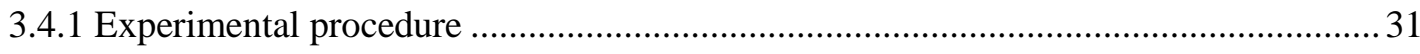

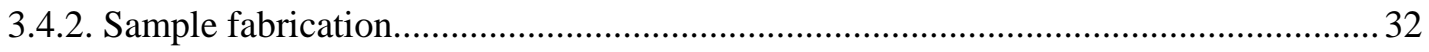

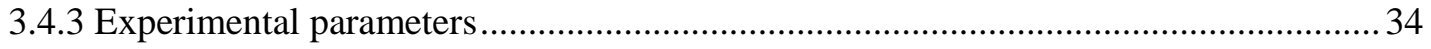

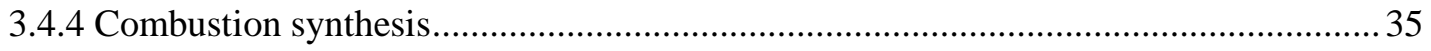

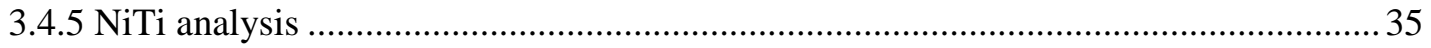

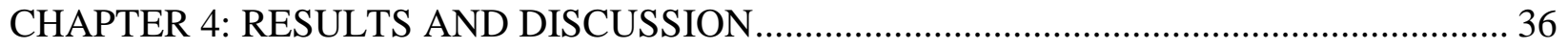

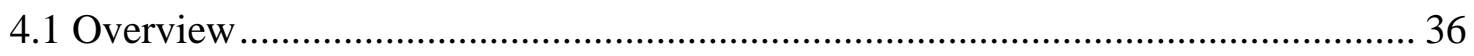

4.2 Effect of Processing Parameters …………………........................................... 36

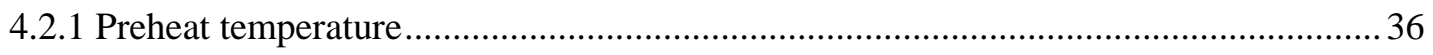

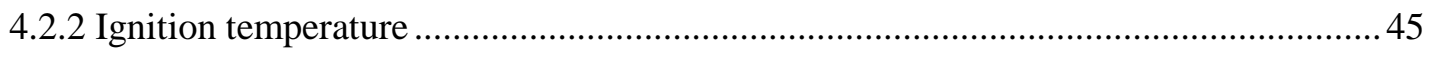

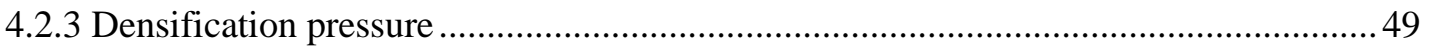




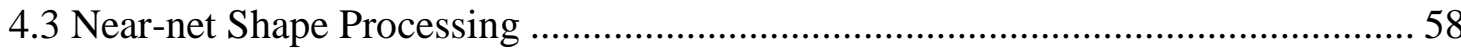

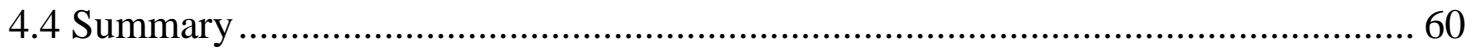

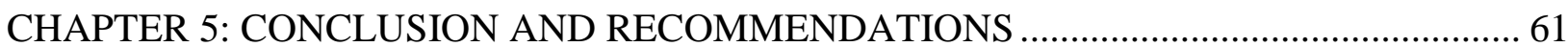

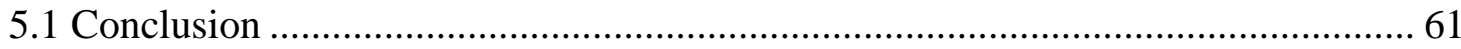

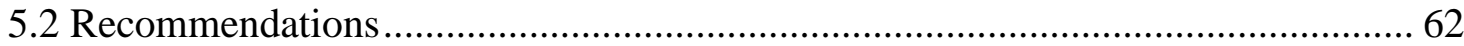

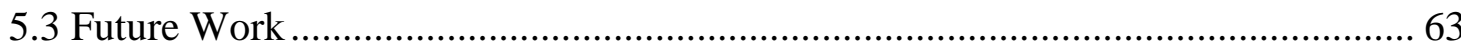

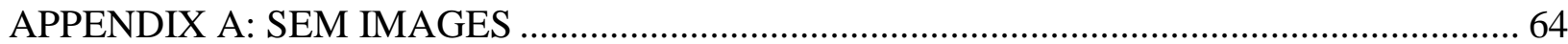

APPENDIX B: REFERENCE [35] PERMISSION LETTER .............................................. 74

APPENDIX C: REFERENCE [37] PERMISSION LETTER .............................................. 77

APPENDIX D: REFERENCE [41] PERMISSION LETTER ............................................. 79

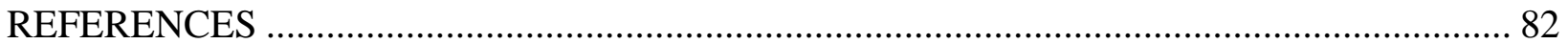




\section{LIST OF FIGURES}

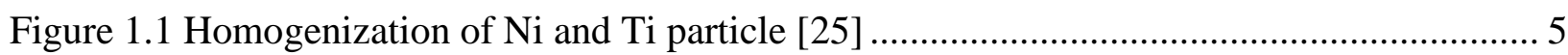

Figure 1.2 Schematic sketch of the PACS process. (a) Mixture of Ni and Ti particles, (b) pressure being applied to particles, and (c) Combustion synthesis [24] ................................ 6

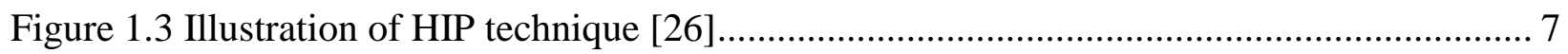

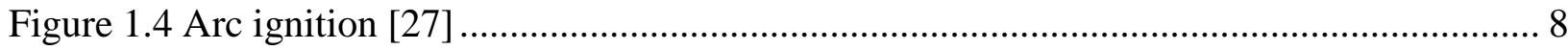

Figure 1.5 Illustration of semi-solid matrix in 3 dimensional scales [8] .................................. 9

Figure 2.1: (a) NiTi implant showing tissue growth, (b) Ti scaffold showing growth, (c)

Magnified view of bone tissues growth into the peripheral pores of porous NiTi, and (d)

Magnified view of bone tissue growth into the peripheral pores of porous $\mathrm{Ti}$ [35].

Figure 2.2 Open and closed pore figuration. The left pore demonstrates an open pore while the right pore represents a closed pore

Figure 2.3: Longitudinal views of SHS synthesized parts at different preheating temperatures and different chamber pressures: (a) $200^{\circ} \mathrm{C}, 138 \mathrm{kPa}$, (b) $250^{\circ} \mathrm{C}, 138 \mathrm{kPa}$, (c) $300^{\circ} \mathrm{C}, 138 \mathrm{kPa}$, (d) $200^{\circ} \mathrm{C}, 201 \mathrm{kPa},(\mathrm{e}) 250^{\circ} \mathrm{C}, 201 \mathrm{kPa}$, (f) $300^{\circ} \mathrm{C}, 201 \mathrm{kPa}[37] \ldots$

Figure 2.5 Macrographs of porous NiTi synthesized by igniting at different locations at $350{ }^{\circ} \mathrm{C}$.

(a)ignited from the top, (b) ignited at an angle, (c) ignited perpendicular to side surface [41] ... 20

Figure 3.1 Schematic of the experimental apparatus [24] 23

viii 
Figure 3.2 Contours of mole fraction of oxygen for $\mathrm{V} 0=2 \mathrm{~cm} / \mathrm{s}$ and $3 \mathrm{~cm} / \mathrm{s}$ in low preheating state [24]

Figure 3.3 Contours of mole fraction of oxygen for $\mathrm{V} 0=2 \mathrm{~cm} / \mathrm{a}$ and $3 \mathrm{~cm} / \mathrm{s}$ in high preheating state [24]. 26

Figure 3.4 Micro Epsilon infrared sensor 27

Figure 3.5 Heating wire placed inside insulation walls 29

Figure 3.6 Ignition wire setup 30

Figure 3.7: Ni-Ti cylindrical die 33

Figure 3.8: Ni-Ti sample after initial densification process 33

Figure 4.1 SEM micrographs for sample A2 (densification force $=22241 \mathrm{~N}$ ) in the X-direction $\left(\mathrm{A}=\right.$ preheat temp. $\approx 600^{\circ} \mathrm{C}, \mathrm{B}=$ preheat temp. $\approx 500^{\circ} \mathrm{C}, \mathrm{C}=$ preheat temp. $\left.\approx 350^{\circ} \mathrm{C}\right)$ 37

Figure 4.2 SEM micrographs for sample A2 (densification force $=22241 \mathrm{~N}$ ) in the Y-direction $\left(\mathrm{A}=\right.$ preheat temp. $\approx 600^{\circ} \mathrm{C}, \mathrm{B}=$ preheat temp. $\approx 500^{\circ} \mathrm{C}, \mathrm{C}=$ preheat temp. $\left.\approx 350^{\circ} \mathrm{C}\right)$ 38

Figure 4.3 SEM micrographs for sample A3 (densification force $=26689 \mathrm{~N}$ ) in the X-direction $\left(\mathrm{A}=\right.$ preheat temp. $\approx 600^{\circ} \mathrm{C}, \mathrm{B}=$ preheat temp. $\approx 500^{\circ} \mathrm{C}, \mathrm{C}=$ preheat temp. $\left.\approx 350^{\circ} \mathrm{C}\right)$ 38

Figure 4.4 SEM micrographs for sample A3 (densification force $=26689 \mathrm{~N}$ ) in the Y-direction $\left(\mathrm{A}=\right.$ preheat temp. $\approx 600^{\circ} \mathrm{C}, \mathrm{B}=$ preheat temp. $\approx 500^{\circ} \mathrm{C}, \mathrm{C}=$ preheat temp. $\left.\approx 350^{\circ} \mathrm{C}\right)$ 39

Figure 4.5 Pore frequency analysis of sample A2 in the X-direction

Figure 4.6 Pore frequency analysis of sample A2 in the Y-direction 41 ix 
Figure 4.7 Pore frequency analysis of sample A3 in the X-direction

Figure 4.8 Pore frequency analysis of sample A3 in the Y-direction 43

Figure 4.13 SEM micrographs forces applied are A1(13344N), A2(22241N) and A3(26689N)

$\left(\mathrm{X}\right.$-direction) $\left(\right.$ preheat temp. $\approx 600^{\circ} \mathrm{C}$ ignition temp. $\left.\approx 1100^{\circ} \mathrm{C}\right)$

Figure 4.14 SEM micrographs forces applied are A1 (13344N), A2 (22241N) and A3 (26689N)

(Y-direction) (preheat temp. $\approx 600^{\circ} \mathrm{C}$ ignition temp. $\approx 1100{ }^{\circ} \mathrm{C}$ ).

Figure 4.15: Pore intensity for sample in the $\mathrm{x}$-direction (Samples processed at preheat temp. $\approx$ $600{ }^{\circ} \mathrm{C}$, ignition temp. $\approx 1100{ }^{\circ} \mathrm{C}$ )

Figure 4.16: Pore intensity for sample set 1 in the Y-direction(Samples processed at preheat

temp. $\approx 600{ }^{\circ} \mathrm{C}$, ignition temp. $\approx 1100{ }^{\circ} \mathrm{C}$ ) 53

Figure 4.17 SEM micrographs of samples A2 and A2.1 in the X-direction processed at a preheat temp. of $500{ }^{\circ} \mathrm{C}$ and ignition temp of $1000{ }^{\circ} \mathrm{C}$. 54

Figure 4.18 SEM micrographs of samples A2 and A2.1 in the X-direction processed at a preheat temp. of $500{ }^{\circ} \mathrm{C}$ and ignition temp of $1000^{\circ} \mathrm{C}$. 55

Figure 4.19 Pore distribution for samples A2 and A2.1 in the X-direction (Samples processed at preheat temp. $\approx 500^{\circ} \mathrm{C}$ and ignition temp. $\approx 1050^{\circ} \mathrm{C}$ ) 56

Figure 4.20 Pore distribution for samples A2 and A2.1 in the Y-direction (Samples processed at preheat temp. $\approx 500^{\circ} \mathrm{C}$ and ignition temp. $\approx 1050^{\circ} \mathrm{C}$ ) 57

Figure 4.21: Ni-Ti molds 58 


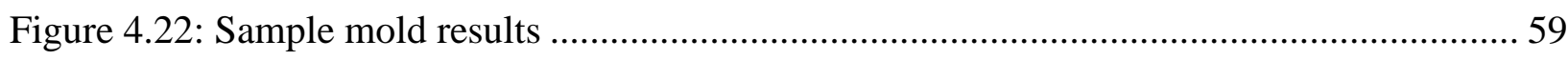




\section{LIST OF TABLES}

Table 2.1: Effect of preheating temperature and chamber pressure on the combustion temperature of sample compacts at $8 \mathrm{MPa}$ [37] 15

Table 2.2: Total porosity, open porosity and open porosity ratio of synthesized samples at different SHS conditions [37] 16

Table 2.3 Displays values for the ultimate compression strengths and Young's modulus [41] ... 20

Table 3.1 Boundary conditions used in simulation cases [24].... 24

Table 3.2 Ni and Ti powder specifications 32

Table 3.3 Input process parameters used for sample densification pressures of $13345 \mathrm{~N}, 26689 \mathrm{~N}$, $22241 \mathrm{~N}$ 34

Table 4.1 Area porosity data for sample A2 with ignition temperature $\approx 1100^{\circ} \mathrm{C}$ 44

Table 4.2 Area porosity data for sample A3 with ignition temperature $\approx 1100^{\circ} \mathrm{C}$ 45

Table 4.3 Area porosity data for sample A2 processed at preheat temp. $600^{\circ} \mathrm{C}$ 48 Table 4.4: Area porosity data for samples A1, A2 (Samples processed at preheat temp. $\approx 600{ }^{\circ} \mathrm{C}$, ignition temp. $\approx 1100^{\circ} \mathrm{C}$ ) 51

Table 4.5 Area porosity for A2 and A2.1 (Samples processed at preheat temp. $\approx 500{ }^{\circ} \mathrm{C}$ and ignition temp. $\approx 1050{ }^{\circ} \mathrm{C}$ ) 55 


\section{LIST OF ABBREVIATIONS/NOMENCLATURE/ACRONYMS}

$\begin{array}{ll}\text { CS } & \text { Combustion synthesis } \\ \text { HIP } & \text { Hot-Isostatic Pressing } \\ \text { NSF } & \text { National Science Foundation } \\ \text { PACS } & \text { Pressure assisted combustion synthesis } \\ \text { SEM } & \text { Scanning electron microscopy } \\ \text { SHS } & \text { Self-propagating high temperature synthesis } \\ \text { SMA } & \text { Shape memory alloy }\end{array}$

xiii 


\section{CHAPTER 1: INTRODUCTION}

\subsection{Motivation}

Self-propagating high-temperature synthesis or SHS has received considerable attention due to the many benefits over common methods used for producing metal matrix composites. The benefits of SHS include low cost/energy requirements, and ease of application to produce homogeneous product [1-5]. Due to the increasing popularity of the process, it has recently been extensively investigated numerically and experimentally [1-7].

The motivation for this study is the potential to apply the SHS technique to produce intermetallic NiTi material for biomedical applications. The perfect material for biomedical applications such as bone replacement must exhibit excellent biocompatibility, mechanical properties matching the adjoining tissue, and a surface structure/composition that encourages its incorporation into the body $[8,9]$. This is mainly because existing materials, used because of their good biocompatibility, typically exhibit undesirable mechanical properties such as high elastic moduli $[8,9]$.

The mechanical properties of porous NiTi match closely to that of the human bone [9]. The non-corrosive, biocompatibility, and strength properties make porous NiTi a good candidate for bone replacement. Since the porosity of the human bone varies throughout the body. Several variables are being analyzed as control parameters for porosity variables in the finished $\mathrm{NiTi}$ product. The objective of this research is discussed in further detail in the next section. 


\subsection{Objective}

The objective of this study is to quantify the effect of processing conditions on the thermal profile as well as the porosity distribution in the final porous NiTi product. Specifically this study will focus on the following key objectives:

- Validate PACS process: Specimens of porous NiTi will be synthesized under various processing conditions and micro-structurally analyzed for porosity and pore morphology. Heating temperature, ignition temperature, particle size and sample densification pressure will be used as control parameters in each experiment.

- Determine structure-property correlation for porous NiTi material: The data obtained from experiments will be analyzed and used to identify relationships between porosity/pore morphology.

- Validate near net shape capabilities of porous NiTi: Cylindrical samples of porous NiTi will be placed in molds of different shapes and undergo the combustion synthesis process. The shape of the resulting sample will be examined relative to that of the mold. Micrographs of the final product will also be taken and analyzed. 


\subsection{Background}

This section discusses important characteristics needed for structural biomaterials as well as characteristics of NiTi. The different fabrication techniques used to make NiTi and other intermetallics will be identified. These fabrication techniques are used to alter the mechanical properties and pore morphology.

\subsubsection{Characteristics of structural biomaterials}

Materials used for structural biomedical application within the human body must exhibit mechanical properties similar to that of the bone. Specifically they must exhibit the following characteristics [10-12]:

- Biocompatibility (allows tissue growth through material)

- High strength and low stiffness(significant in preventing deformation or fracture, and stress shielding effects)

- High toughness (essential to avoid brittle failure)

- Shape-recovery behavior (promotes mechanical stability within the host tissue)

NiTi has exhibited potential in all the aforementioned qualities to be a good candidate for biomedical structural material. Its high biocompatibility allows blood flow and tissue growth throughout the sample. Two other important characteristics of porous NiTi are high recoverable strain and low elastic modulus [11]. These characteristics are very important for loading 
purposes. In addition to the mechanical properties that mimic hard tissue in the human body, NiTi has good imaging characteristics being quite visible on MRIs [10]. Porous NiTi has thus received considerate attention from the medical field due to these characteristics. The next section discusses some fabrication techniques used to produce porous NiTi and other metal composites.

\subsubsection{Fabrication techniques}

Self-propagating high-temperature synthesis (SHS) or Combustion Synthesis (CS)

SHS or CS is a technique used for fabricating metal matrix composites through an exothermic chemical reaction. The process generally consists of compressing two or more metal species together and preheating the specimen to a prescribed temperature. The sample is immediately ignited, initiating a chemical reaction that causes a wave to propagate and sustain through the sample. The final product is largely determined by the processing parameters such as the material properties, preheat temperature and ignition temperatures as well as particle size [3, $4,14,17-22]$. The effects of these parameters have been widely investigated and found to have a significant impact on the final product [3, 4, 14, 17-22].

Pressure Assisted Combustion Synthesis (PACS)

Pressure-assisted combustion synthesis or the PACS [18] process is a derivative of the standard combustion synthesis (CS). Specifically, it combines densification or cold pressing of Ni and Ti particles with CS. Densification of the mixture decreases the overall porosity of the 
sample as well as increases the total area for direct contact between Ni and Ti particles [15]. The desired outcome of compressing $\mathrm{Ni}$ and $\mathrm{Ti}$ particles is to create a homogeneous phase composition and promote a more uniform and isotropic pore distribution. Figure 1.1 illustrates a transient liquid phase joint when the surfaces of two particles completely touch and join together resulting in isothermal solidification [24, 25]. Densification is enforced to achieve complete liquid phase.

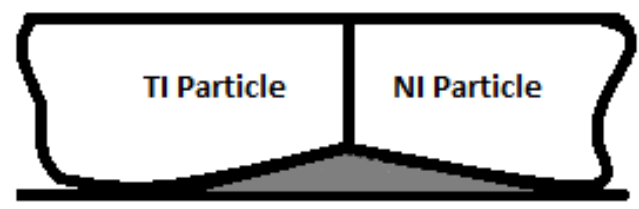

Figure 1.1 Homogenization of Ni and Ti particle [25]

Fig. 1.2 is a schematic illustration of PACS. The particles are first mixed together and then compressed. The cylindrical sample is then heated and ignited causing the flame (shown in (c)) to propagate through the material. 


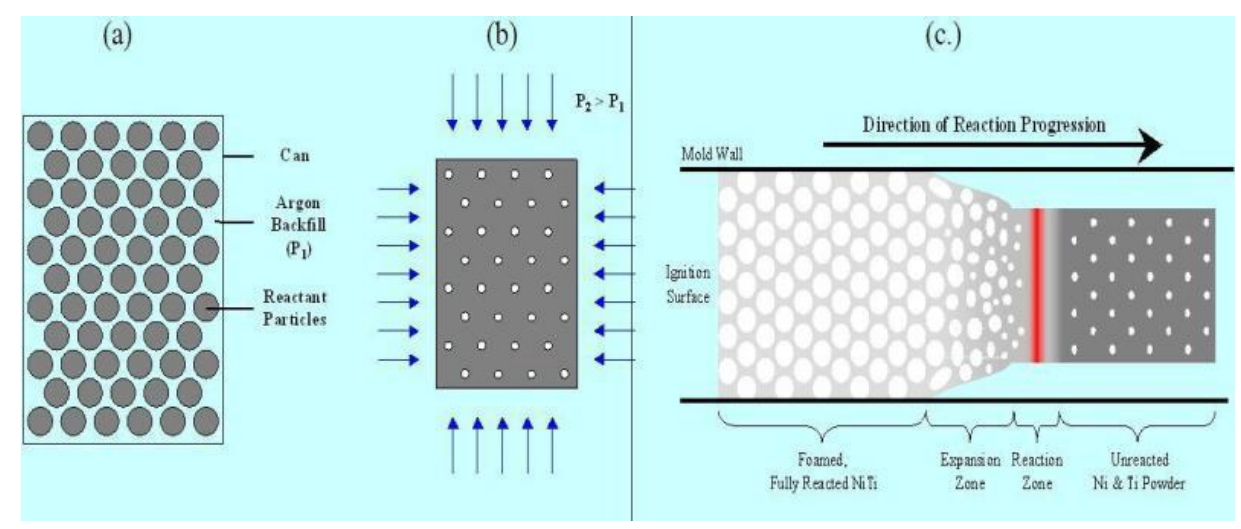

Figure 1.2 Schematic sketch of the PACS process. (a) Mixture of Ni and Ti particles, (b) pressure being applied to particles, and (c) Combustion synthesis [24]

Hot-Isostatic Pressing (HIP)

Hot Isostatic Pressing or HIP is a technique used for fabrication of metal matrix composites. The process involves applying pressure on the sample in all directions during combustion synthesis. Initially particles of two or more metals are pressed together creating a compressed sample. The sample is then placed inside of a HIP furnace which is evacuated and backfilled with Argon [26]. Heat is applied and gradually increased which in return increases the pressure applied to the sample. The increase in temperature triggers a chemical reaction allowing combustion synthesis to take place. Figure 1.4 is a schematic sketch of the HIP process. 


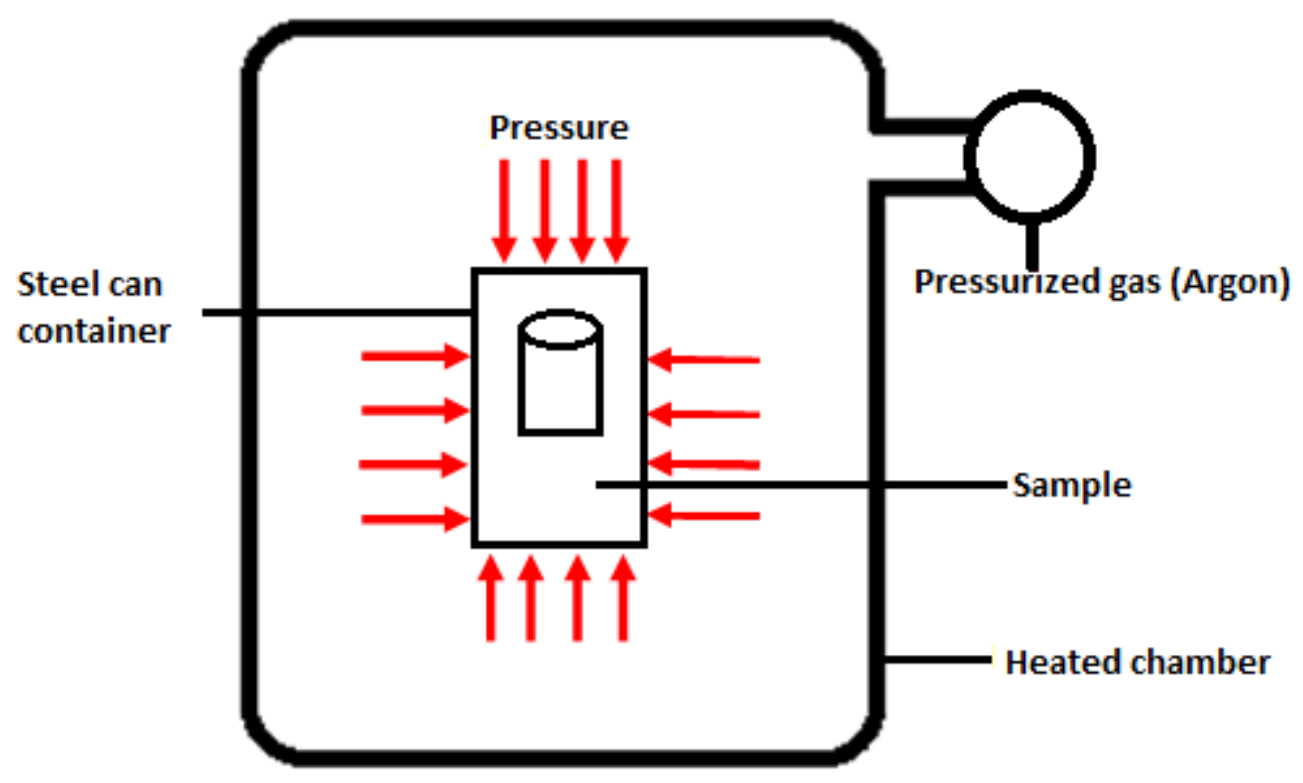

Figure 1.3 Illustration of HIP technique [26]

\section{Ignition techniques}

Various ignition methods are often used during combustion synthesis of metal particle mixtures in order to change the sample structure. Two different ignition methods are described below.

Arcing

In the arcing method samples are usually heated to a specific heating temperature as done in any SHS process. The sample is then ignited using a high voltage electric arc. The sample is typically placed under the arcing flame. Figure 1.4 illustrates the arcing technique. Chapter 2 discusses a study which applies the arcing method during fabrication of NiTi to change the 
direction of the sample combustion channels. The various combustion channels were found to change the mechanical properties of each sample.

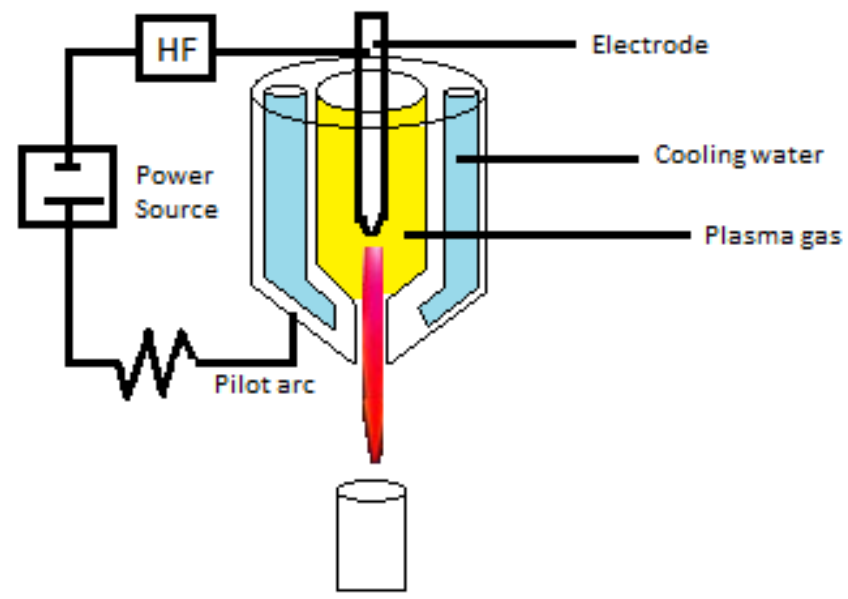

Figure 1.4 Arc ignition [27]

\section{Selective laser sintering (SLS)}

Selective laser sintering combines SHS and laser application to produce porous metal composites [28]. SLS is used as a rapid prototyping method for metal composites [28]. Unlike most SHS processes SLS does not start off with compressed samples. Instead SLS involves laser sintering for several different layers [28]. The metal composite powder is shaped and layered using a prototyping device. Once the first layer is created a chemical reaction is initiated through use of a laser. This process is completed for each layer created. The necessary laser voltage is determined based on the thickness of the layer [28]. This particular ignition technique is attractive for biomedical structural materials because of its ability to shape a sample into a specific shape. 


\subsubsection{Formation of pores}

In the fabrication process of porous NiTi the formation of pores may be attributed to a particular fabrication method or process parameter. Tay et. al. [29] explains that the formation of pores could be due to high pressure argon trapped in initial pores, original pores in pressed compact, or diffusion rates of $\mathrm{Ni}$ and $\mathrm{Ti}$ ( $\mathrm{Ni}$ diffusion rate $>\mathrm{Ti}$ diffusion rate). Other sources of pore formation may be due to the behavior of the liquid phase during the segment of which the flame propagates down from the ignition surface causing Ni and Ti particles to melt and merge together [8]. During this process a liquid and solid solution or semi-solid matrix is produced from different $\mathrm{Ni}$ and $\mathrm{Ti}$ diffusion rates [8]. Figure 1.5 illustrates the semi-solid matrix on three dimensional scales.

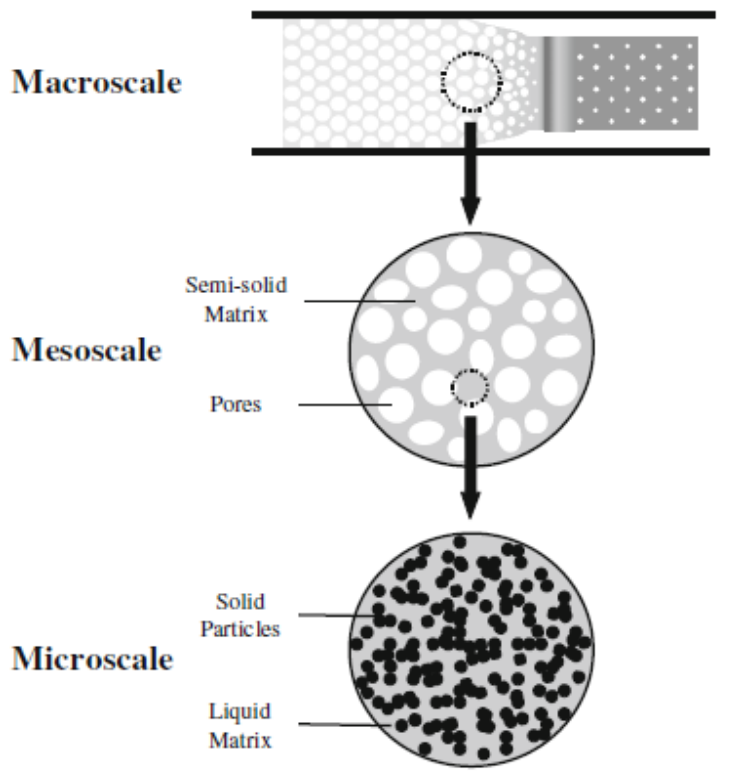

Figure 1.5 Illustration of semi-solid matrix in 3 dimensional scales [8] 
When the slurry consist of a lower liquid fraction the original pores of the compacted sample are the main source of pore formation. However when the liquid fraction is higher new pores are able to form and the liquid can flow with less resistance. The liquid fraction can be altered through changing the combustion temperature of the process.

\subsubsection{Medical applications of NiTi}

In the medical field porous NiTi can be used for hard tissue replacement, surgical tools, wire support, etc. Below are several different medical applications for porous NiTi along with a brief description for each application [30-33].

- Intervertebral fusion devices: Utilized for spinal support to persons with back pain, or certain deceases (lumbar spinal stenosis, intermittent neurogenic claudication, etc.).

- Vascular Stents: Vascular stents are utilized to provide flow in the arteries and veins within the body. Lack of flow within the veins and arteries may occur due to certain deceases such as atherosclerosis that block the fluid vessels or may cause irregular flow within the veins and arteries.

- Guide wire: Guide wires are used to clear plaque from the arteries. A catheter is inserted into the arteries, next a thin guide wire is placed in the catheter and positioned to the plaque segment of the artery. A balloon and stent are slid down the guide wire which is used to open up the blocked segment of the artery. 
- Braces: NiTi wires are used for orthodontic wire application to keep braces aligned and tight.

- Dental implants: NiTi is used as a tool for root canals.

- NiTi wire bone support: NiTi wire is sometimes used to hold bones together in order for them to reconnect with one another.

\subsection{Organization}

This thesis is organized into 5 chapters of which this chapter is the first. Chapter 2 describes current or existing fabrication methods for producing NiTi. This chapter will also describe the unique mechanical properties NiTi and the applications that take advantage of these properties. Chapter 3 discusses the methodology used in this study. The results from the procedure are analyzed and discussed in chapter 4 . Chapter 5 is the conclusion, summarizing the major findings of the study. It also includes recommendations for further study. 


\section{CHAPTER 2: LITERATURE REVIEW}

\subsection{Overview}

NiTi also referred to as Nitinol was first discovered for its shape memory alloy (SMA) abilities in 1962 by William Beuhler [34]. Beuhler worked at the US Naval labs and discovered this rare characteristic in the process of developing a heat and corrosive resistant alloy [34]. In recent years NiTi has become a major contender in the biomedical field. With mechanical properties that mimic bone, control of the alloy has been investigated in many ways. A variety of combustion methods have been used in efforts to control the mechanical and physical features of porous NiTi. This section will discuss important mechanical properties which structural biomaterials should have. The chapter will also describe several studies in which the characteristics and mechanical properties of porous NiTi are altered through various fabrication techniques. Lastly this chapter will discuss implant applications of porous NiTi.

\subsection{Important Characteristics of Structural Biomaterials}

Porous NiTi is a strong candidate for bone replacement and other structural biomedical materials due to its corrosion resistance, wear resistance and mechanical properties [10]. The porous structure of metallic NiTi promotes biocompatibility which is highly desirable for applications within the human body [35]. A study was completed in which porous NiTi, porous Ti, dense Ni and dense Ti scaffolds were implanted into 5mm holes of a rabbit's femur for 15 
weeks [35]. Figure 2.1 shows the results of the study with the images showing tissue growth within the scaffolds [35]. However, the porous NiTi scaffold was found to bond best with the rabbit's body [35].
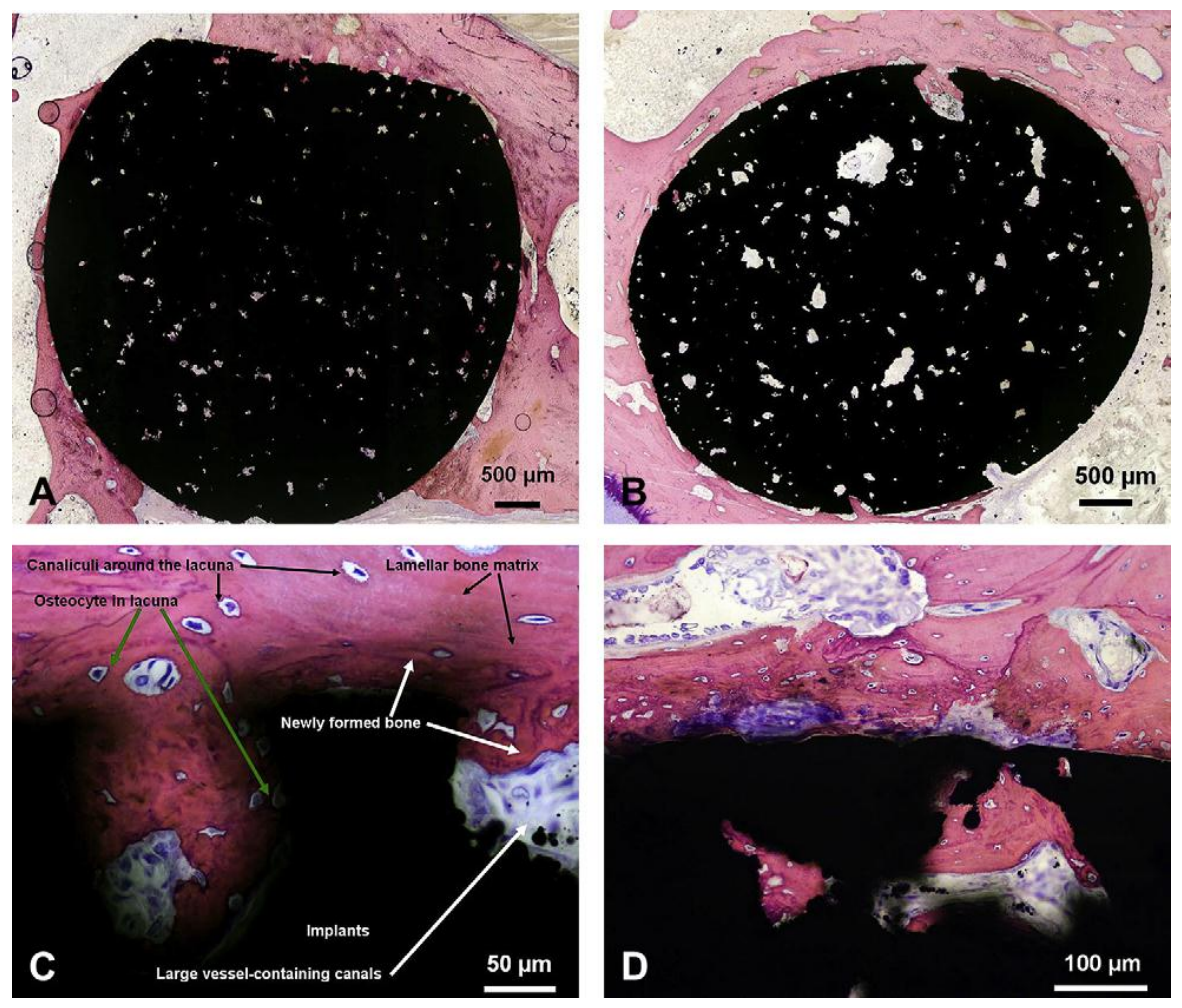

Figure 2.1: (a) NiTi implant showing tissue growth, (b) Ti scaffold showing growth, (c) Magnified view of bone tissues growth into the peripheral pores of porous NiTi, and (d) Magnified view of bone tissue growth into the peripheral pores of porous Ti [35].

Another important factor when considering metallic implants for orthopedic surgery is the elastic modulus [36]. A sufficiently higher or lower elastic modulus will result in stress-shielding or improper loading of the bone $[11,36]$. The Young's modulus value of most metallic biomaterials 
is usually considerably higher than those of hard tissue or cortical bone (below $20 \mathrm{GPa}$ ) such as stainless steel (210 GPA) [36]. NiTi alloy has an elastic modulus of $48 \mathrm{GPa}$ which is much closer to the elastic modulus of bone. The next section discusses different techniques used to alter the mechanical properties and pore morphology of porous NiTi.

\subsection{Fabrication Methods}

\subsubsection{Effects of preheating and chamber pressure}

The effects of preheating and chamber pressure during the SHS process have been investigated by Wisutmethangoon et al. [37]. Ni and Ti powders were mixed using a 1:1 ratio, and then cold pressed at $8 \mathrm{MPa}$ into cylindrical samples. SHS experiments were carried out in a reaction chamber using varying chamber pressure and preheating temperature values. Argon was passed throughout the chamber at $138 \mathrm{kPa}$ and $201 \mathrm{kPa}$. The following preheating temperatures were used: $200{ }^{\circ} \mathrm{C}, 250{ }^{\circ} \mathrm{C}$, and $300{ }^{\circ} \mathrm{C}$. A type $\mathrm{K}$ thermocouple was placed on the top portion of the sample to record the combustion temperature. Samples were ignited from the top using a Tungsten coil. Preheat temperature and chamber pressure were utilized as control parameters on the effects of product composition and pore morphology which was analyzed through scanning electron microscopy (SEM) micrographs [37].

The effects of chamber pressure and preheating temperature on the combustion temperature are showing below in Table 2.1. The results exhibit an increasing combustion temperature with increasing preheating temperature. Li et al [38] used thermodynamic equations to explain the increase in combustion temperature due to increasing preheating temperature. The 
increase in chamber pressure has an opposite effect on the combustion temperature. This can be explained by the decrease in the adiabatic combustion temperature and the enthalpy of formation $[37,38]$.

Table 2.1: Effect of preheating temperature and chamber pressure on the combustion temperature of sample compacts at $8 \mathrm{MPa}[37]$

\begin{tabular}{|c|c|c|}
\hline $\begin{array}{c}\text { Preheating temperature } \\
\left({ }^{\circ} \mathrm{C}\right)\end{array}$ & $\begin{array}{c}138 \mathrm{kPa} \text { Combustion } \\
\text { temperature }\left({ }^{\circ} \mathrm{C}\right)\end{array}$ & $\begin{array}{c}201 \mathrm{kPa} \text { Combustion } \\
\text { temperature }\left({ }^{\circ} \mathrm{C}\right)\end{array}$ \\
\hline 200 & $703 \pm 13$ & $696 \pm 13$ \\
\hline 250 & $730 \pm 18$ & $723 \pm 13$ \\
\hline 300 & $749 \pm 11$ & $744 \pm 10$ \\
\hline
\end{tabular}

Table 2.2 shows the final pore morphology obtained as a function of the chamber pressure and preheat temperature [37]. The results indicate a decrease in both the total and open porosity with increasing preheat temperature. Figure illustrates the difference between closed and open pore figuration. However, the total and open porosity does increase with increasing chamber pressure except at preheat temperature of $300{ }^{\circ} \mathrm{C}$. It can be seen from the results of Table 2.2 that the chamber pressure has little effect on the porosity, as also evidenced in pore morphology micrographs shown in Fig. 2.1 [37]. 


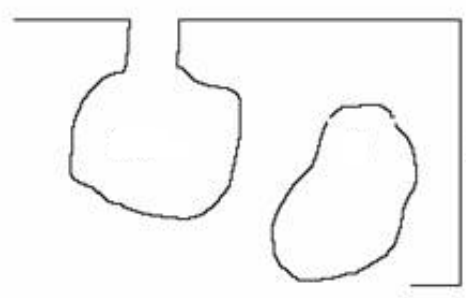

Figure 2.2 Open and closed pore figuration. The left pore demonstrates an open pore while the right pore represents a closed pore.

Table 2.2: Total porosity, open porosity and open porosity ratio of synthesized samples at different SHS conditions [37]

\begin{tabular}{|c|c|c|c|}
\hline $\begin{array}{c}\text { Preheating } \\
\text { temperature }\left({ }^{\circ} \mathrm{C}\right)\end{array}$ & $\begin{array}{c}\text { Argon gas } \\
\text { pressure in } \\
\text { reactor (KPa) }\end{array}$ & $\begin{array}{c}\text { Total porosity } \\
(\text { vol.\%) }\end{array}$ & $\begin{array}{c}\text { Open porosity } \\
(\text { vol.\%) }\end{array}$ \\
\hline \multirow{2}{*}{200} & 138 & 57.9 & 55.8 \\
& 201 & 58.0 & 56.9 \\
\hline \multirow{2}{*}{250} & 138 & 56.8 & 55.4 \\
& 201 & 57.2 & 55.6 \\
\hline \multirow{2}{*}{300} & 138 & 56.2 & 52.4 \\
& 201 & 56.1 & 50.2 \\
\hline
\end{tabular}

Figure 2.3 shows the synthesized sample micrographs for chamber pressures of $138 \mathrm{KPa}(\mathrm{a}, \mathrm{b}, \mathrm{c})$ and $201 \mathrm{KPa}(\mathrm{d}, \mathrm{e}, \mathrm{f})$. [37] The images confirm that chamber pressure has little effect on pore morphology. However, the images do indicate a change in pore morphology orientation at higher preheat temperatures. 


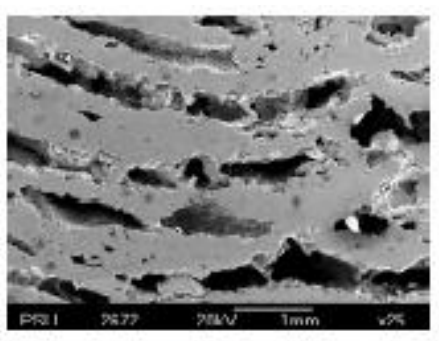

(a)

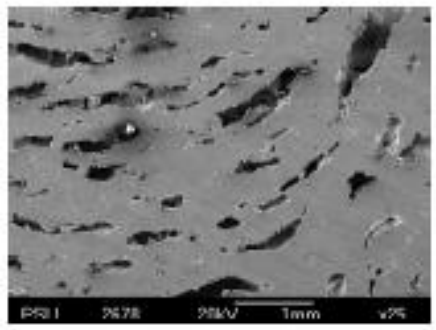

(c)

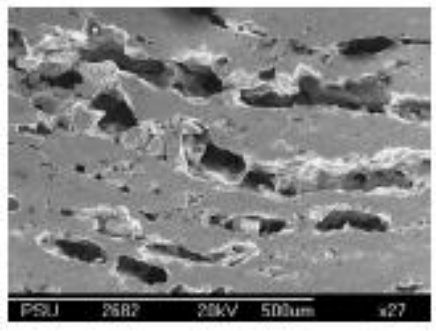

(e)

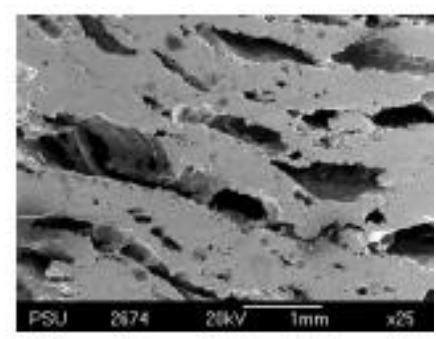

(b)

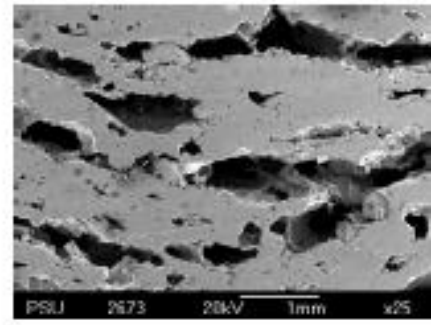

(d)

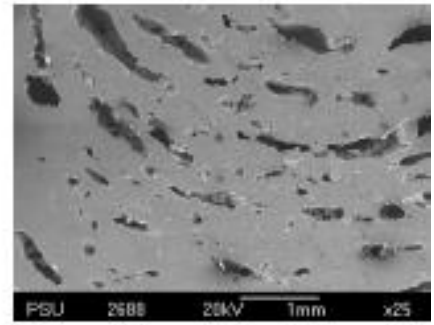

(f)

Figure 2.3: Longitudinal views of SHS synthesized parts at different preheating temperatures and different chamber pressures: (a) $200^{\circ} \mathrm{C}, 138 \mathrm{kPa}$, (b) $250^{\circ} \mathrm{C}, 138 \mathrm{kPa}$, (c) $300^{\circ} \mathrm{C}, 138 \mathrm{kPa}$, (d) $200^{\circ} \mathrm{C}, 201 \mathrm{kPa}$, (e) $250^{\circ} \mathrm{C}, 201 \mathrm{kPa}$, (f) $300^{\circ} \mathrm{C}, 201 \mathrm{kPa}$ [37]

The main conclusion that could be drawn from this study is that chamber pressure has a small effect on pore morphology and combustion temperature in addition the preheat temperature has a larger impact on the combustion temperature and pore morphology than the chamber pressure [37]. 
2.3.2 Hot-isostatic pressing (HIP) technique

Liu et al. [39] discusses a variation of the HIP method: Capsule Free (CF) - HIP. "Capsule free" refers to the elemental powders being cold pressed and not packed (without using pressure) inside of a stainless steel container $[39,40]$. In this particular study three different types of samples were fabricated by CF-HIP to evaluate the effects of the densification pressure, $\mathrm{TiH}_{2}$, and $\mathrm{NH}_{4} \mathrm{HCO}_{3}$ on the final pore morphology [39]. One sample set (A) was fabricated using different compaction pressures, while another sample set (B) was made by mixing $\mathrm{Ni}$, Ti and 9.0 wt. $\% \mathrm{TiH}_{2}$ powders with atomic ratio of $1: 1$ and cold pressed at $200 \mathrm{MPa}$. The third sample set (C) was fully mixed with $\mathrm{Ni}$ and Ti powders, and $30 \mathrm{wt} \% \mathrm{NH}_{4} \mathrm{HCO}_{3}$ with atomic ratio of 1:1 compacted at the same pressure as the second set B.

Experiments were performed in a HIP chamber which was evacuated with a vacuum. Once the chamber was evacuated it was filled with argon. Initially the argon pressure was set to $100 \mathrm{MPa}$ at room pressure [39]. The argon pressure and temperature were then increased to $150 \mathrm{MPa}$ and $1050{ }^{\circ} \mathrm{C}$ [39] for a total of $3 \mathrm{~h}$. An optical microscope was used to analyze the microstructure of each sample. Compression tests were carried out to obtain mechanical properties for each sample.

The results from this study prove CF-HIP to be a promising method for controlling pore shape and size. This method also demonstrates capability to improve the mechanical properties of porous NiTi. The results from the study show that the final porosity stays in the range of 20 28 vol\% demonstrating that compaction pressure has a significant impact on final porosity [39]. 
From this study it is shown that the final porosity distribution is significantly lower than the green porosity. This was attributed to pore shrinkage during the CF-HIP process [39].

It was found that the addition of $\mathrm{TiH}_{2}$ in sample set $\mathrm{B}$ produced interconnected pores. The compression strength decreased due to this pore morphology. The results for compression strength of each sample obtained and analyzed in this study. The compressive strain and residual strain values of sample sets $\mathrm{A}$ and $\mathrm{C}$ are closes to that of bone and would be most beneficial for use of structural support within the human body.

This study shows that the densification pressure on green compacts or addition of $\mathrm{TiH}_{2}$, or $\mathrm{NH}_{4} \mathrm{HCO}_{3}$ can be used as control parameters for final porosity [38]. Overall this study proves CF-HIP to be a promising method of controlling pore size shape and strength of porous NiTi.

\subsubsection{Arc method}

Kaya et al. [41] explores the effect of combustion channels on the compressive strength of porous NiTi. Synthesized NiTi samples were fabricated using the SHS process; however ignition was by means used of a high voltage electric arc. The samples were ignited at different locations to change the orientation of the combustion channels. Figure 2.5 shows some results obtained indicating the ignition point and resulting combustion channel orientation. 


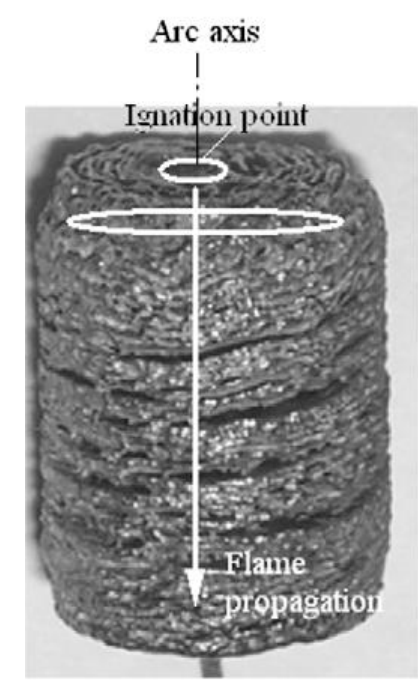

(a)

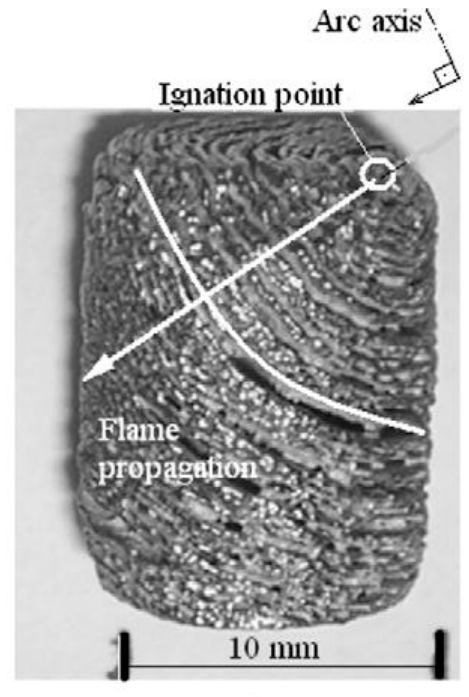

(b)

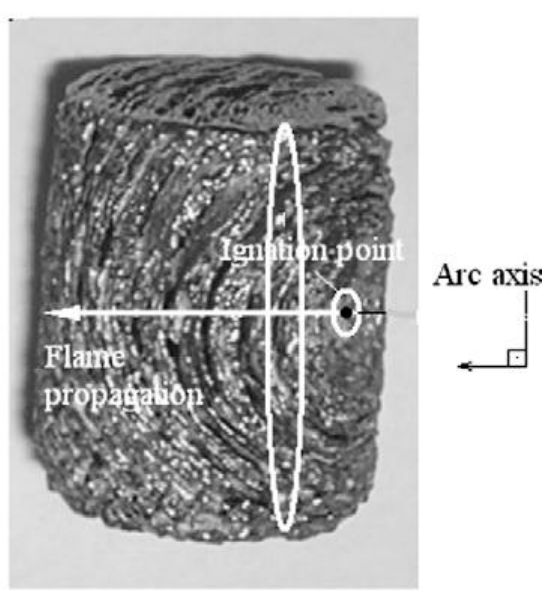

(c)

Figure 2.5 Macrographs of porous NiTi synthesized by igniting at different locations at $350{ }^{\circ} \mathrm{C}$. (a)ignited from the top, (b) ignited at an angle, (c) ignited perpendicular to side surface [41].

Compression tests were carried out for three samples a, b and c. The results from the compression test are displayed in Table 2.3. An increase in compression strength is observed in the cases resulting in longitudinal combustion channels (sample b and c) [41]. The results prove that the combustion channel orientation has a major effect on the compression strength of porous NiTi [41].

Table 2.3 Displays values for the ultimate compression strengths and Young's modulus [41]

\begin{tabular}{lll}
\hline Specimens & Compressive strength (Mpa) & Young's modulus (GPa) \\
\hline (a) & 317 & 3.05 \\
(b) & 455 & 3.75 \\
(c) & 462 & 4.6 \\
\hline
\end{tabular}


The arcing method proved to be an effective way of altering compression strength for porous NiTi. Ignition methods that occur through the use of heating coil lack the ability to vary the ignition location which is a major advantage of using the arcing method.

\subsubsection{Summary}

The fabrication processes described above are illustrative of the variety of processes that are being tested or utilized to alter the mechanical or physical features of porous NiTi. The other

methods not include selective laser sintering (SLS), electron beam melting, Quasi-isostatic pressing (QIP), Spark Plasma sintering (SPS) and more [10, 22-42]. The present chapter reflects the progress that is being made in controlling the structure and properties of porous NiTi 


\section{CHAPTER 3: METHODOLOGY}

\subsection{Overview}

Chapter 3 describes the experimental procedure used to fabricate porous NiTi in this study. The equipment setup, sample fabrication and process procedure are described in detail. The methodology utilized, is the pressure-assisted combustion synthesis (PACS) technique [8] which is derived from the standard SHS technique.

\subsection{Experimental Setup}

Figure 3.1 illustrates the experimental apparatus utilized for the study. It comprises of a heating wire, a stainless steel iso-velocity argon flow controller, an insulator, a motion camera and infrared sensor. All test were carried out in an open air environment in which argon flowed. Footage of each experiment was recorded with a Redlake Motion camera. An infrared sensor (MICRO EPSILON, thermometer CTM-2) was used to monitor thermal changes during each experiment. Data from the Redlake motion camera and infrared sensor were obtained through a data acquisition system. Elemental Ni-Ti particles were mixed together using an atomic ratio of 1:1 and cold pressed at $13344 \mathrm{~N}, 22241 \mathrm{~N}$, and $26689 \mathrm{~N}$. Samples were set on top of insulation and then heated with a Nichrome heating coil (controlled by a DC power supply (HY3030E)). Samples were then ignited from the top with a zigzag Nichrome wire (controlled by a DC power supply (HY3050E)). Synthesized samples remained in argon flow until complete thermal cooldown was achieved. 


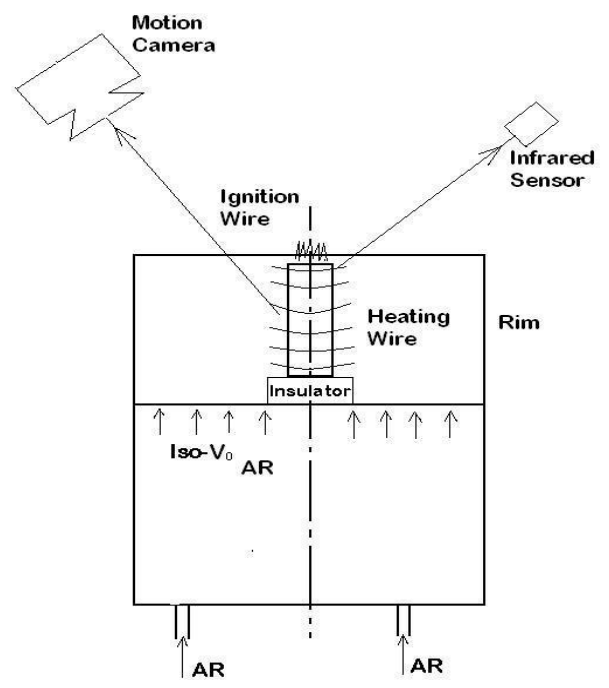

Figure 3.1 Schematic of the experimental apparatus [24]

\subsection{Description of PACS Equipment}

\subsubsection{Argon flow calculation}

Figure 3.1 illustrates the experimental setup for this study. As mentioned in a previous section 3.2, the experiments were carried out in an open air environment to allow easy monitoring of the process through camera and temperature sensor. An inert gas (argon) is thus used to continuously purge the system to prevent the sample from being in contact with oxygen. A Computational Fluid Dynamics (CFD) model was developed in a previous study [24] to estimate the optimal argon flow velocity $V_{0}$ required for that purpose. For each experimental process the preheating sample typically lasted 8-10mins, while the ignition segment lasted for 
10-60sec. The flame front wave typically took three seconds to propagate down the sample. Due to the long duration of the preheat phase there is ample chance for oxidation to occur. Thus the CFD model was focused on the preheat segment and utilized to determine $V_{o}$ under two steady state conditions. Table 3.1 shows the two boundary conditions utilized for the model.

The results from the simulations are presented in Fig. 3.2 (low preheat temperature) and 3.3 (high preheat temperature) [24]. The figure shows the predicted distribution of oxygen mole fraction around the sample as a function of the axial(x) and radial(r) positions respectively. From the results it was found that the maximum oxygen mole fraction will be less than $0.01 \%$ when $V_{O}$ $=3 \mathrm{~cm} / \mathrm{s}$ for both low and high preheat temperatures. Thus $V_{0}=3 \mathrm{~cm} / \mathrm{s}$ was used as the flow rate for argon for all the experiments.

Table 3.1 Boundary conditions used in simulation cases [24]

\begin{tabular}{|c|c|c|}
\hline & $\begin{array}{c}\text { Low preheating } \\
\text { temperature }\end{array}$ & $\begin{array}{c}\text { High preheating } \\
\text { temperature }\end{array}$ \\
\hline Heating wire & $630^{\circ} \mathrm{C}$ & $930{ }^{\circ} \mathrm{C}$ \\
\hline $\begin{array}{c}\mathrm{Ni}-\mathrm{Ti} \text { Cylinder } \\
\text { surface }\end{array}$ & $330{ }^{\circ} \mathrm{C}$ & $550{ }^{\circ} \mathrm{C}$ \\
\hline Insulator surface & $130{ }^{\circ} \mathrm{C}$. & $230{ }^{\circ} \mathrm{C}$ \\
\hline
\end{tabular}




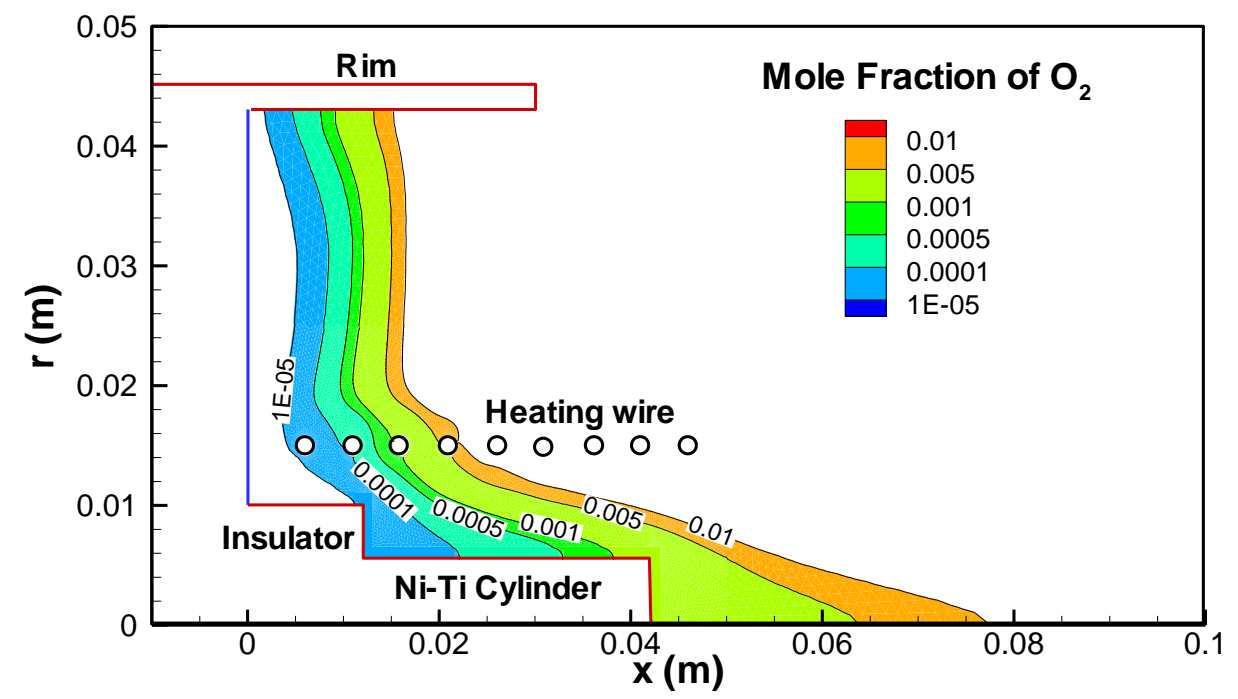

A. $\mathrm{V}_{0}=2 \mathrm{~cm} / \mathrm{s}$

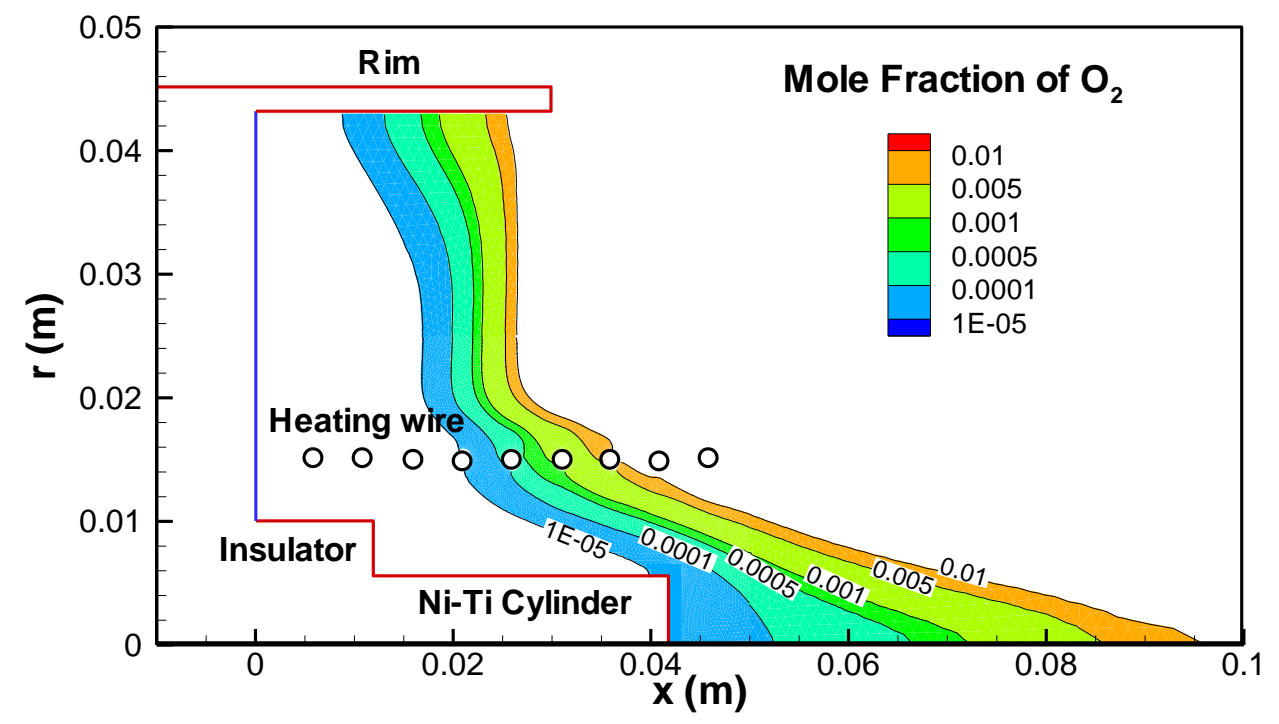

A. $V_{0}=3 \mathrm{~cm} / \mathrm{s}$

Figure 3.2 Contours of mole fraction of oxygen for $\mathrm{V} 0=2 \mathrm{~cm} / \mathrm{s}$ and $3 \mathrm{~cm} / \mathrm{s}$ in low preheating state [24] 


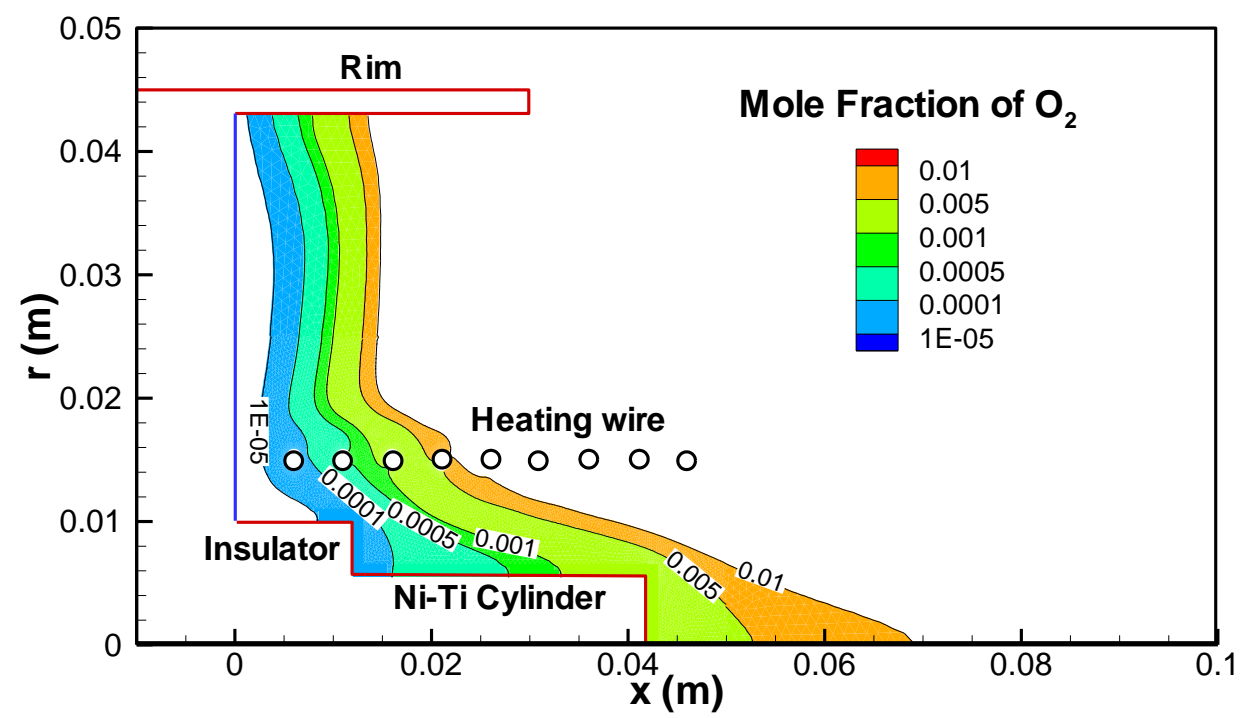

A. $V_{0}=2 \mathrm{~cm} / \mathrm{s}$

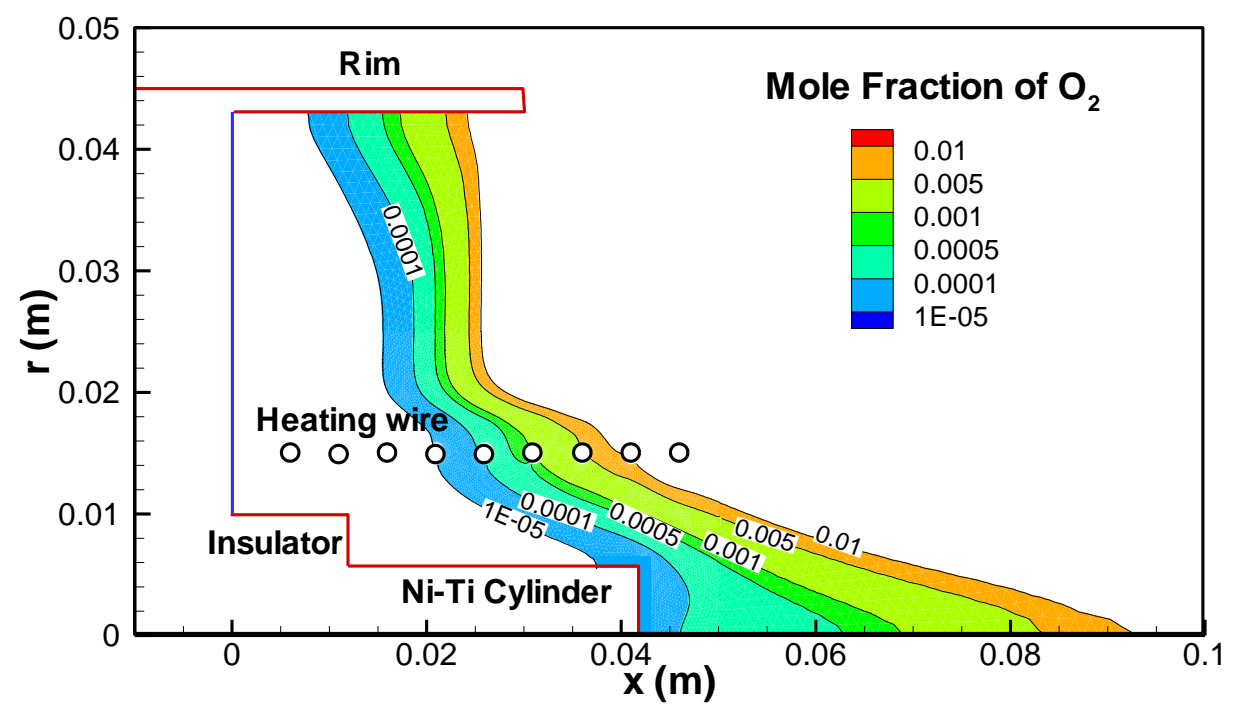

A. $V_{0}=3 \mathrm{~cm} / \mathrm{s}$

Figure 3.3 Contours of mole fraction of oxygen for $\mathrm{V} 0=2 \mathrm{~cm} / \mathrm{a}$ and $3 \mathrm{~cm} / \mathrm{s}$ in high preheating state [24] 


\subsubsection{Temperature data collection}

An infrared sensor (MICRO EPSILON, thermometer CTM-2) was utilized to obtain the thermal profile for each experiment. This sensor allowed monitoring of the preheat and combustion temperatures. The data from the sensor was gathered through a data attainment system at an interval of $10 \mathrm{~ms}$ through a USB interface. During the preheat process each sample was probed with a thermocouple (OMEGA, K type, bead size $0.12 \mathrm{~mm}$ and response time of about $10 \mathrm{~ms}$ ) many times to assure precision of the temperature sensor and also to adjust the material emissivity coefficient (emissivity for $\mathrm{Ni}-\mathrm{Ti}$ is .55). Figure 3.4 shows the infrared sensor at the top left section of the photograph. The output of the sensor can be analyzed on the sensor box (shown at the bottom right hand side of the figure) or through computer connection.

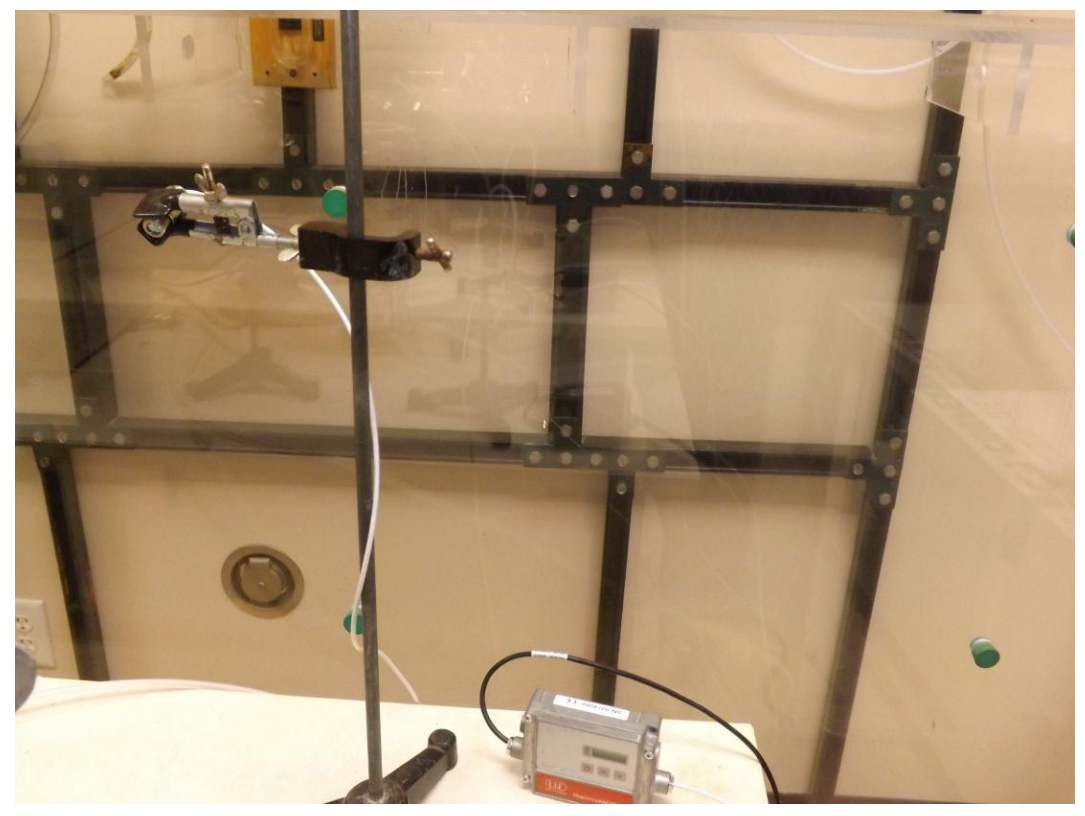

Figure 3.4 Micro Epsilon infrared sensor 
Due to thermal variances during the combustion synthesis the emissivity value changed with the $\mathrm{Ni}$-Ti surface temperature. The error in the recorded combustion temperature was set to $20^{\circ} \mathrm{C}$.

\subsubsection{Redlake motion camera}

All experiments were captured using a Redlake motion camera. The camera was placed approximately 5 inches vertically from the top of the insulation material, and then positioned to have complete viewing range of the Ni-Ti sample. The Redlake motion camera settings were

manipulated (such as frames per second, and color) through a data acquisition system. Camera focus and lighting were controlled and set directly on the camera. The combustion process was configured to be viewed and analyzed at any speed.

\subsubsection{Heating and ignition wire setup}

The Nichrome heating wire shown in Fig. 3.5 below was placed within the insulation walls of the equipment. The heating wire was made with $7-8$ coils $(0.5 \mathrm{~mm}$ outer diameter). Each coil was carefully spaced to prevent wire burnout. The wire was controlled by a DC power supply (HY3030E) with the capability to uniformly preheat the sample to any prescribed temperature of up to $700^{\circ} \mathrm{C}$ within 10 minutes. 


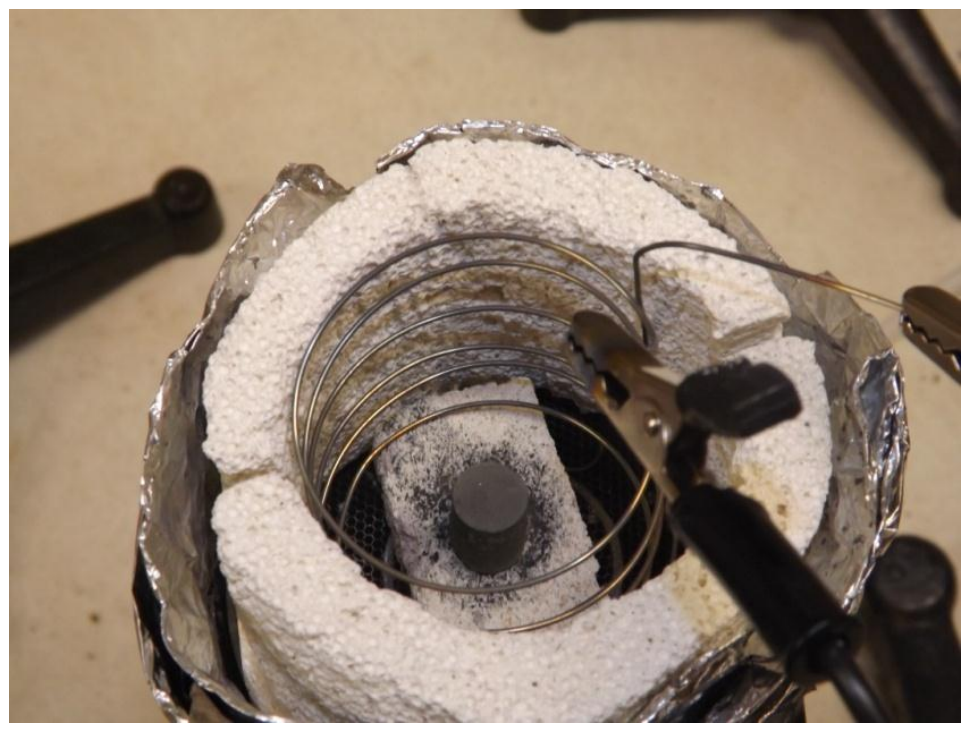

Figure 3.5 Heating wire placed inside insulation walls

Nichrome was also used as the ignition wire $(0.5 \mathrm{~mm}$ diameter $)$ as shown in Fig.3.6. The ignition current was controlled by another DC power supply (HY3050E). The ignition wire was set up approximately $2 \mathrm{~mm}$ above the top surface of the sample. Due to the $1400{ }^{\circ} \mathrm{C}$ melting point of Nichrome, heating temperature had to be decreased once ignition took place. 


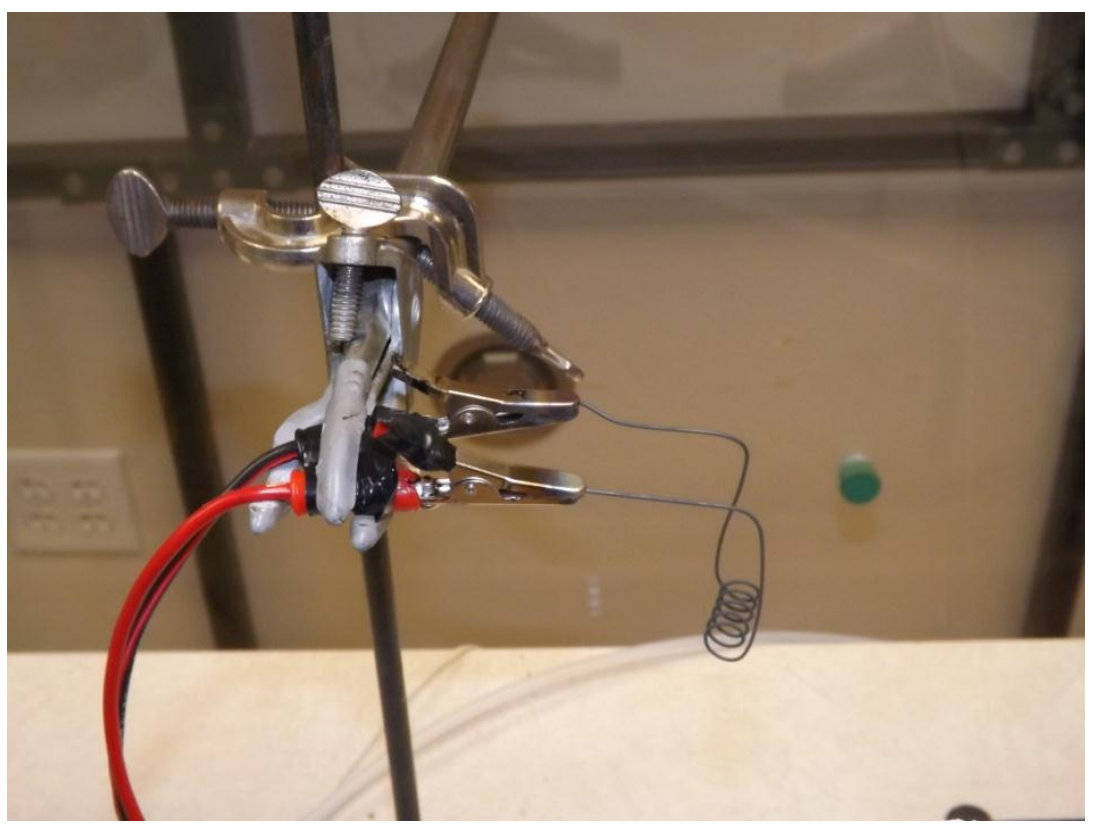

Figure 3.6 Ignition wire setup

3.3.5 Two-dimensional (2D) porosity calculation software (ImageJ)

The ImageJ software [44] was used to configure and analyze micrographs of NiTi samples produced. The program was utilized to calculate 2D area porosity, sample histograms, and range variations of pore size and shapes. In addition the program was used for visualization of porosity distribution for the samples produced.

The program calculated area porosity as a percent by dividing the total pore area by the entire area analyzed (area measured in pixels). The program is able to decipher the difference between a pore and non-pore formation by color. Generally pores appear darker than the surface allowing the program to calculate measurements based on the size of darker shades. 


\subsection{Experiments Performed}

\subsubsection{Experimental procedure}

Figure 3.1 in a previous section illustrates the experimental set-up used for the study. It consists of a stainless steel iso-velocity Argon flow controller, an insulator, a heating wire, an ignition wire, a motion camera and an infrared sensor. Ni-Ti cylindrical samples were made through cold pressing $\mathrm{Ni}$ and $\mathrm{Ti}$ particles together. Each sample was fabricated using a 1:1 mixture. All the tests were carried out in an open air environment in which argon flowed. The test were monitored using a Redlake Motion camera and an infrared temperature sensor. Each $\mathrm{Ni}$ - Ti sample was set on top of an insulator situated within a solenoid Nichrome heating coil [24].

As described earlier in a previous section 3.2 the ignition wire was placed approximately $2 \mathrm{~mm}$ from the top surface of the Ni-Ti surface. The ignition energy was delivered by radiation heat transfer through the $2 \mathrm{~mm}$ gap between the ignition wire and sample surface [24]. The combustion front propagation speed was then analyzed from the images of the reaction front position, which was recorded by the motion camera system at a frequency of $50 \mathrm{f} / \mathrm{sec}$. The proceeding sections describe in detail the Ni-Ti fabrication method, process parameters and SHS process used in this study. 


\subsubsection{Sample fabrication}

Two sample sets were produced using $37 \mu \mathrm{m} \mathrm{Ni}$ and $\mathrm{Ti}$ particle sizes and $2.5 \mu \mathrm{m} \mathrm{Ni}$ and $5 \mu \mathrm{m}$ Ti particle sizes. The following procedure was used in preparing each sample: $\mathrm{Ni}$ and $\mathrm{Ti}$ particles were weighed separately using a 1:1 ratio. The specifications shown in table 3.2 and equations 3.1-3.4 were used in calculating the ratio weights.

Table 3.2 Ni and Ti powder specifications

\begin{tabular}{|l|c|c|}
\hline & $\mathrm{Ni}(99.9 \%$ purity) & $\mathrm{Ti}(99.9 \%$ purity) \\
\hline Atomic weight & 58.71 & 47.90 \\
\hline Density $\left(\mathrm{g} / \mathrm{cm}^{\wedge} 3\right)$ & 8.908 & 4.506 \\
\hline
\end{tabular}

Ti-Ni mass ratio $=47.9: 58.71=1: 1.2257$

Ti mass percent $=1 / 2.2257=44.93 \%$

Ni mass percent $=55.07 \%$

Once the Ni and Ti particles were measured they were then thoroughly mixed. The Ni-Ti mixture was placed in a stainless steel cylindrical die and compressed using a carver hydraulic press. Figure 3.7 shows the cylindrical die and Fig. 3.8 displays a typical Ni-Ti sample after the densification process. 


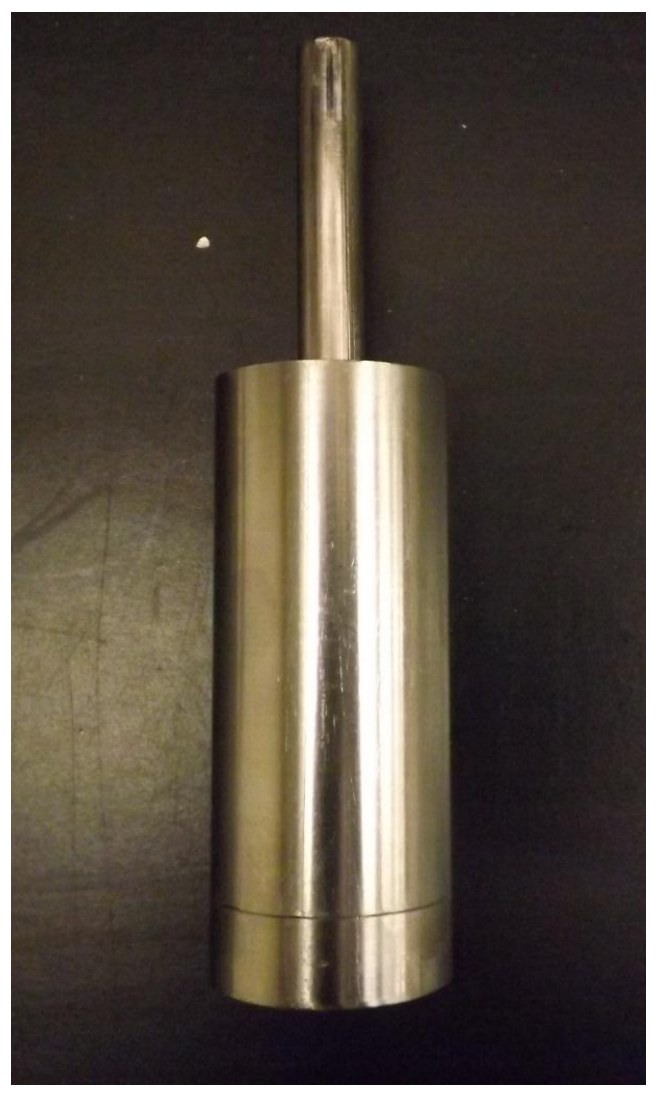

Figure 3.7: Ni-Ti cylindrical die

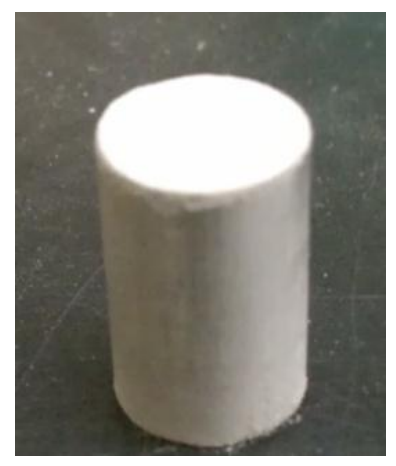

Figure 3.8: Ni-Ti sample after initial densification process 
The densification process was carried out at different pressure values over the range 13000-27000 N. After fabrication each sample was wrapped in individual zip lock bags and then stored in an air tight container. This step was necessary to prevent oxidation of the sample, which would have inhibited successful completion of the combustion process. It was also vital to store the Ni and Ti particles in separate air tight containers again to prevent oxidation of the particles.

\subsubsection{Experimental parameters}

The experimental parameters used in the study include the following: pre-heating temperature, ignition temperature, and particle size. These parameters were varied and analyzed throughout the combustion process. Table 3.3 shows the input parameter values used in the study. Samples were compressed at 13345N, 26689N, 22241N. The first set of samples consisted of a 1:1 mixture of $37 \mu \mathrm{m} \mathrm{Ni}$ and Ti particle size. The second set consisted of a 1:1 mixture of 2.5 $\mu \mathrm{m}$ Ni particle size and $5 \mu \mathrm{m}$ Ti particle size.

Table 3.3 Input process parameters used for sample densification pressures of $13345 \mathrm{~N}, 26689 \mathrm{~N}$, $22241 \mathrm{~N}$.

\begin{tabular}{|c|c|}
\hline Heating Temperature $\left({ }^{\circ} \mathrm{C}\right)$ & Ignition Temperature $\left({ }^{\circ} \mathrm{C}\right)$ \\
\hline$\approx 600$ & $\approx 1100$ \\
\hline$\approx 500$ & $\approx 1100$ \\
\hline$\approx 350$ & $\approx 1100$ \\
\hline$\approx 600$ & $\approx 1050$ \\
\hline$\approx 500$ & $\approx 1050$ \\
\hline$\approx 350$ & $\approx 1050$ \\
\hline$\approx 600$ & $\approx 1000$ \\
\hline$\approx 500$ & $\approx 1000$ \\
\hline$\approx 350$ & $\approx 1000$ \\
\hline
\end{tabular}




\subsubsection{Combustion synthesis}

Ni-Ti samples were placed in the center of the heating coil and pre-heated for 10 minutes. The heating source was then either decreased or completely shut off to prevent melting of the Nichrome wire (melting temperature: $1400{ }^{\circ} \mathrm{C}$ ). The ignition process immediately started after the 10 minute heating period. It usually took approximately 1-3 minutes for the Ni-Ti sample to foam and undergo the combustion process. Argon was allowed to flow throughout the system at optimal flow rate to prevent oxidation of the sample.

\subsubsection{NiTi analysis}

Scanning electron microscope micrographs, area porosity, and pore distribution were analyzed for each NiTi sample. Each sample was cut in both longitudinal and transversal directions using a Buehler diamond saw. A SEM was used to obtain micrographs of each sample. Porosity distribution was then evaluated using the ImageJ imaging software. The software produced sample pore distribution graphs along with area porosity calculations. 


\section{CHAPTER 4: RESULTS AND DISCUSSION}

\subsection{Overview}

This chapter presents the results obtained in this study. The results include the effect on porosity of prescribed densification pressures, particle size, heating temperature and ignition temperature. Porosity distribution and consistency are analyzed by means of data imaging software. A $3 \mathrm{~mm} \times 3 \mathrm{~mm}$ segment of each sample was analyzed for area porosity, pore distribution and characteristics for both $\mathrm{X}$ and $\mathrm{Y}$ segments. The near net shape capabilities of the PACS process is also verified. The samples investigated are designated as A1, A2 and A3 for densification force $13344 \mathrm{~N}, 22241 \mathrm{~N}$, and $26689 \mathrm{~N}$ respectively in order to ease presentation of results.

\subsection{Effect of Processing Parameters}

\subsubsection{Preheat temperature}

The effect of preheat temperature was investigated holding constant the ignition temperature, densification pressure, and particle size. The data obtained are separated by the sample compression pressure to magnify any trends that may appear for the preheat temperature. All samples were ignited at $1100^{\circ} \mathrm{C}$. A $3 \mathrm{~mm}$ x $3 \mathrm{~mm}$ sample size was analyzed for each sample. SEM micrographs for sample A2 are presented in Figs. 4.1 and 4.2 for $\mathrm{X}$ and $\mathrm{Y}$-sections respectively. The corresponding results for sample A3 are shown in Figs. 4.3 and 4.4. In general 
pore sizes in sample A2 are more uniform than those in sample A3. The pores of sample A2 in most cases produce small spherical shaped pores, while sample A3 exhibits large pores. This trend is attributed to the change in densification force. Densification of $\mathrm{Ni}$ and $\mathrm{Ti}$ elemental particles decreases the initial porosity and improves contact of particle surface area. The decrease in the contact area between $\mathrm{Ni}$ and $\mathrm{Ti}$ particles at low compaction force results in insufficient liquid phase that produce large voids. Similar trends also occur for excessively high densification force. In the case of A2 inducing a lower pre-heat temperature causes the least amount of uniformity which can be seen in Figs. 4.1(C) and 4.2 (C).

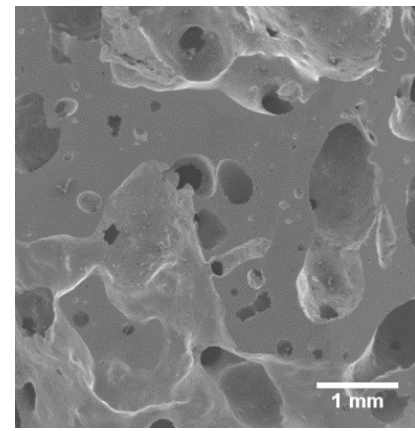

A

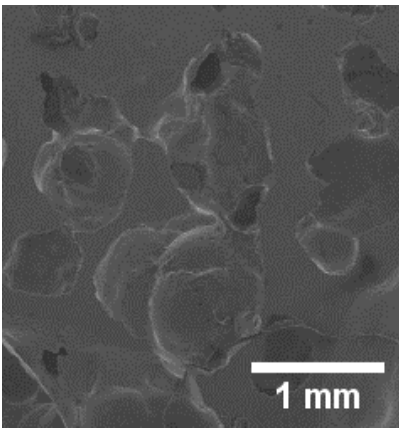

B

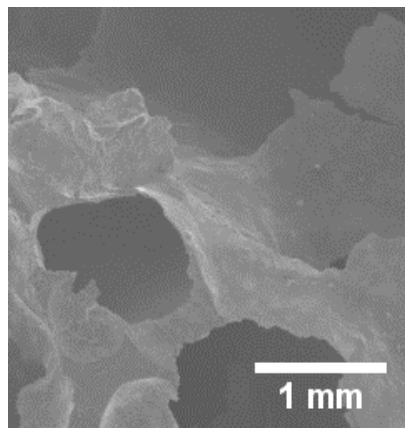

C

Figure 4.1 SEM micrographs for sample A2 (densification force $=22241 \mathrm{~N}$ ) in the $\mathrm{X}$-direction $\left(\mathrm{A}=\right.$ preheat temp. $\approx 600^{\circ} \mathrm{C}, \mathrm{B}=$ preheat temp. $\approx 500^{\circ} \mathrm{C}, \mathrm{C}=$ preheat temp. $\approx 350^{\circ} \mathrm{C}$ ) 


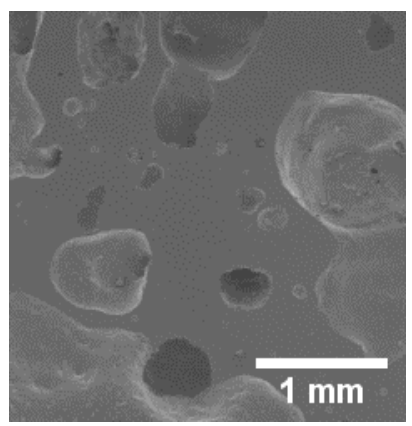

A

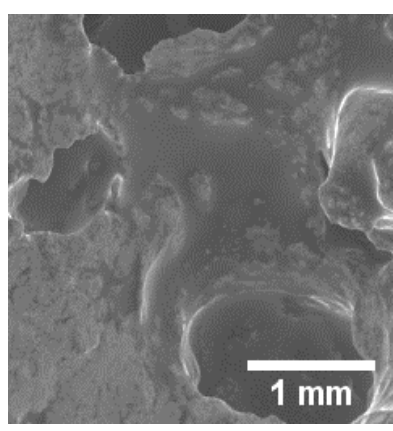

B

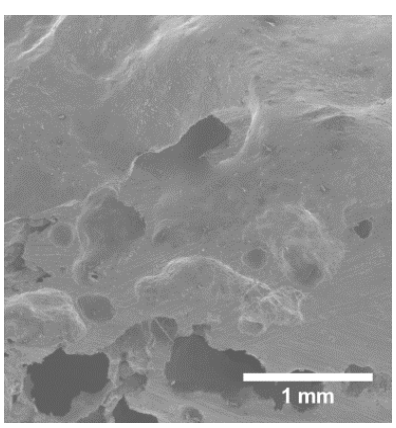

C

Figure 4.2 SEM micrographs for sample A2 (densification force $=22241 \mathrm{~N}$ ) in the Y-direction $\left(\mathrm{A}=\right.$ preheat temp. $\approx 600^{\circ} \mathrm{C}, \mathrm{B}=$ preheat temp. $\approx 500^{\circ} \mathrm{C}, \mathrm{C}=$ preheat temp. $\left.\approx 350^{\circ} \mathrm{C}\right)$

A similar trend can be seen in Figs. 4.3 and 4.4 for sample A3. Figures 4.3A and 4.4A show that smaller pores are obtained at the highest preheat temperature. As the preheat temperature decreases the sample pore size increases. At preheat temperature $\approx 600^{\circ} \mathrm{C}$ (shown in $4.3(\mathrm{~A})$ and 4.4(A)) the pore distribution is more uniform.

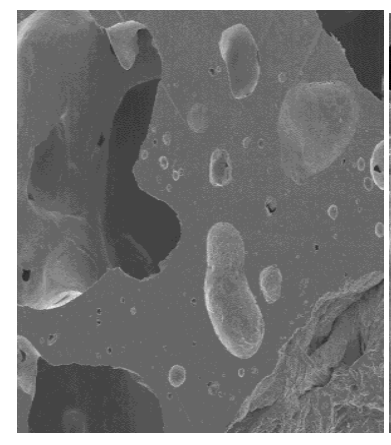

A

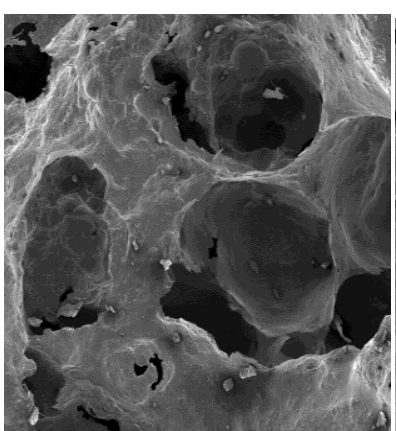

B

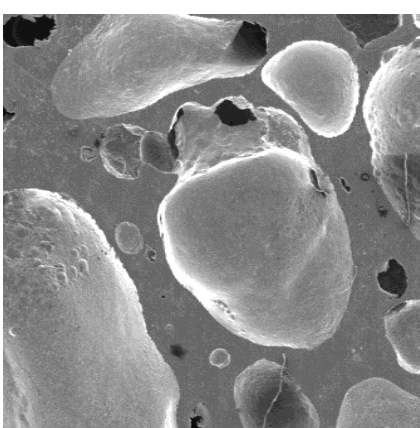

C

Figure 4.3 SEM micrographs for sample A3 (densification force $=26689 \mathrm{~N}$ ) in the X-direction $\left(\mathrm{A}=\right.$ preheat temp. $\approx 600^{\circ} \mathrm{C}, \mathrm{B}=$ preheat temp. $\approx 500^{\circ} \mathrm{C}, \mathrm{C}=$ preheat temp. $\left.\approx 350^{\circ} \mathrm{C}\right)$ 


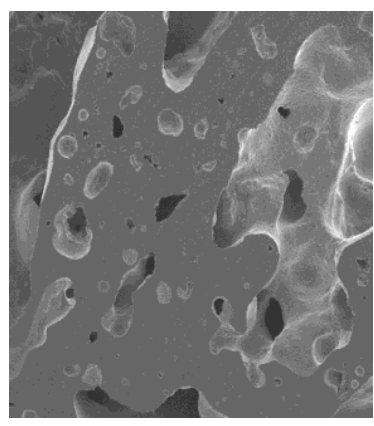

A

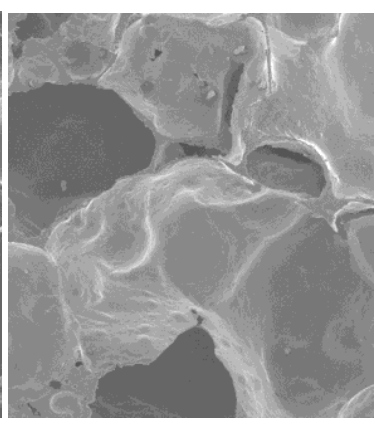

B

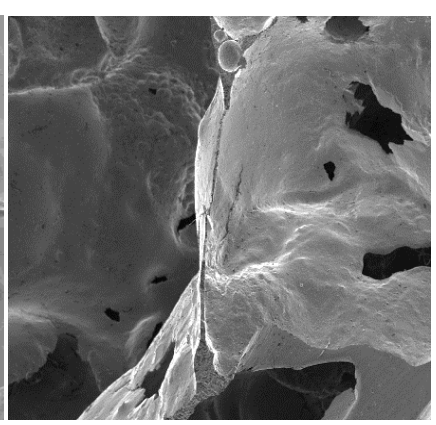

C

Figure 4.4 SEM micrographs for sample A3 (densification force $=26689 \mathrm{~N}$ ) in the Y-direction $\left(\mathrm{A}=\right.$ preheat temp. $\approx 600^{\circ} \mathrm{C}, \mathrm{B}=$ preheat temp. $\approx 500^{\circ} \mathrm{C}, \mathrm{C}=$ preheat temp. $\left.\approx 350^{\circ} \mathrm{C}\right)$

Figures 4.5 and 4.6 show the pore frequency for sample A2 with distance along the $\mathrm{X}$ and Y direction respectively. Specifically the figure shows the amount of pores in a prescribed area by detecting the pixel intensity. Pores in the SEM images generally appear darker than nonporous surfaces. The software uses this principal to calculate a value based on the color and size of the pore. The higher the pore frequency value the higher the number of pores in the area being analyzed. An increase in pixel intensity may also be due to a larger void space. Figs. 4.5 and 4.6 show that pore distribution varies widely on the sample A2 considered. The trends observed in both the $\mathrm{X}$ and $\mathrm{Y}$ directions are however consistent. In Figs. 4.5 and 4.6 the sample processed at $600{ }^{\circ} \mathrm{C}$ appears to have the most uniform porosity distribution. This trend is attributed to the increasing combustion temperature with increasing preheat temperature. Li et. al. [41] used thermodynamic equations to show that a higher preheat temperature leads to a higher combustion temperature. Thus a higher preheat temperature is able 
to improve the overall chemical reaction causing the sample to achieve close to complete liquid phase where new pores are formed. At lower preheat temperatures the reaction is governed by a more solid state reaction meaning the original pores of the green sample are the main source of pores obtained in synthesized products. This observation is also shown in Tables 4.1 and 4.2.

The corresponding pore frequency results for sample A3 are presented in Figs. 4.7 and 4.8. The pores obtained in sample A2 (Figs. 4.5 and 4.6) are observed to be more homogeneous than those of sample A3 (Figs. 4.9 and 4.8). This may be due to the change in densification force. Higher densification force increases the contact area between particles causing the initial porosity to decrease. The decrease in porosity makes it more difficult for liquid to flow when Ni and Ti particles began to melt. This results in porosity having a non-uniform distribution on the sample surface.

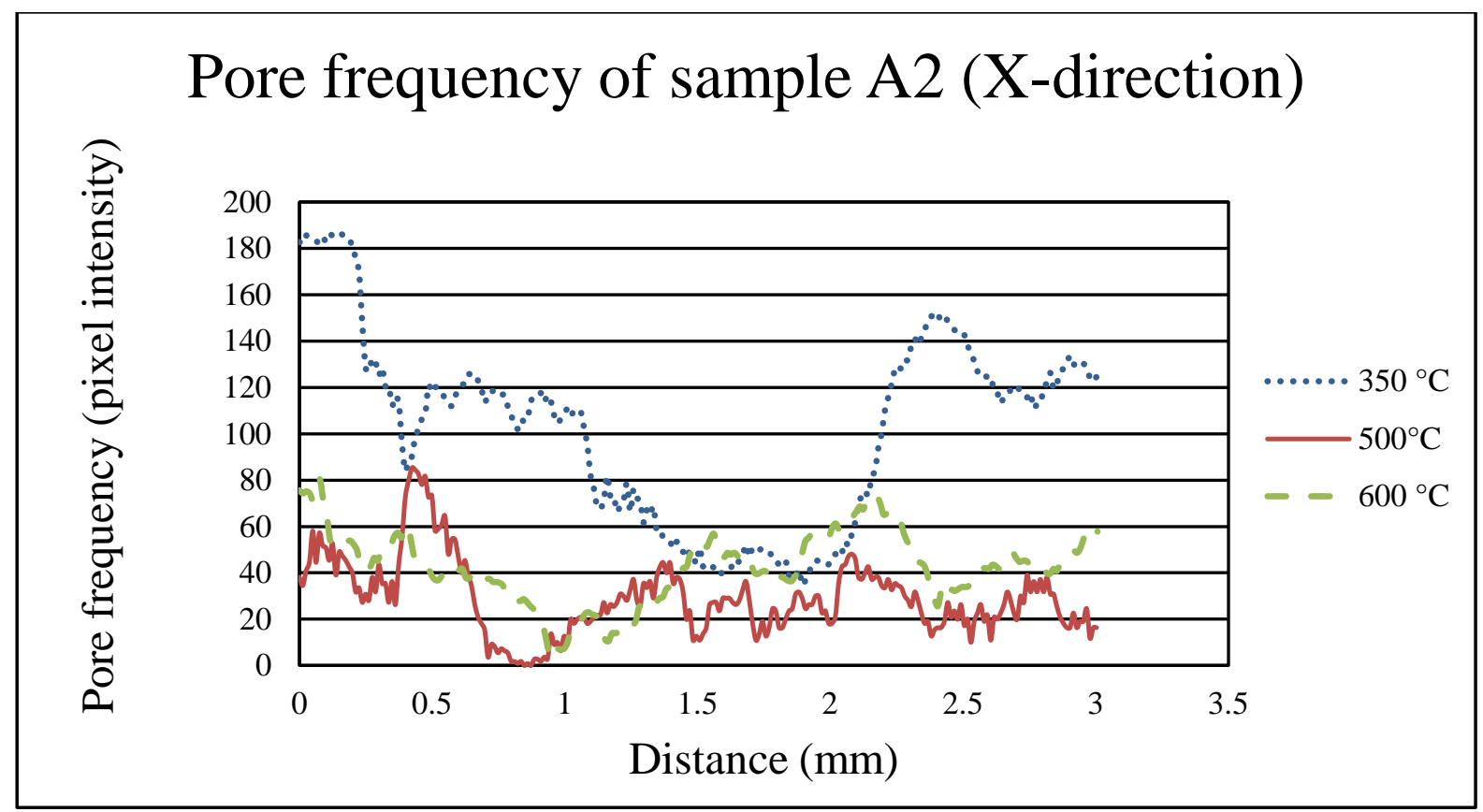


Figure 4.5 Pore frequency analysis of sample A2 in the X-direction

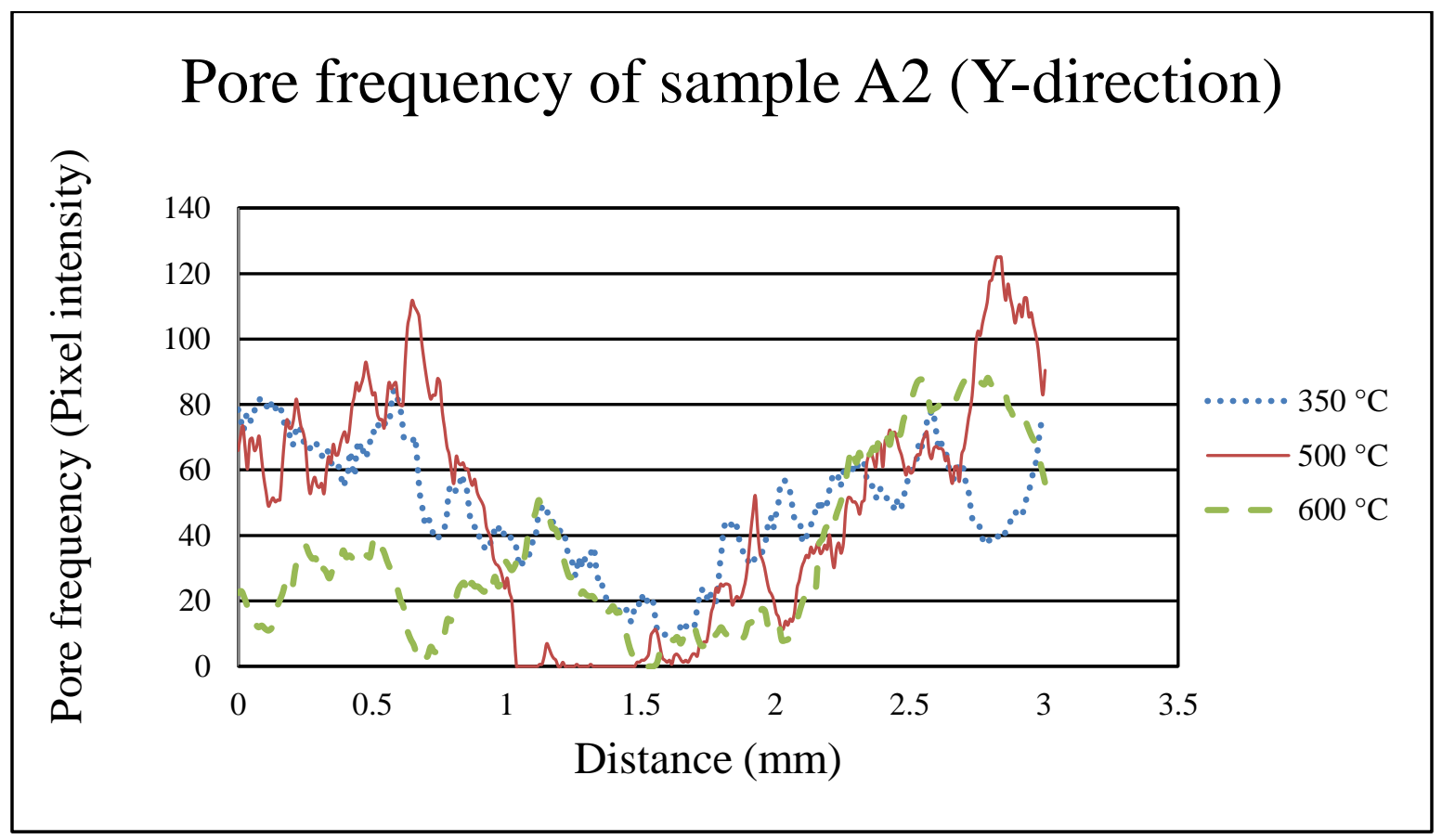

Figure 4.6 Pore frequency analysis of sample A2 in the Y-direction

Figure 4.7 shows that at $600^{\circ} \mathrm{C}$ preheat temperature, the pore frequency is quiet high in the $\mathrm{X}$-direction of the sample. At the same temperature the pore frequency varies from a high value to nearly zero in the Y-direction in Fig. 4.8, rises and then subsequently falls to very low value. The initial high pore frequency is due to the large voids seen in Figs. 4.3 and 4.4. 


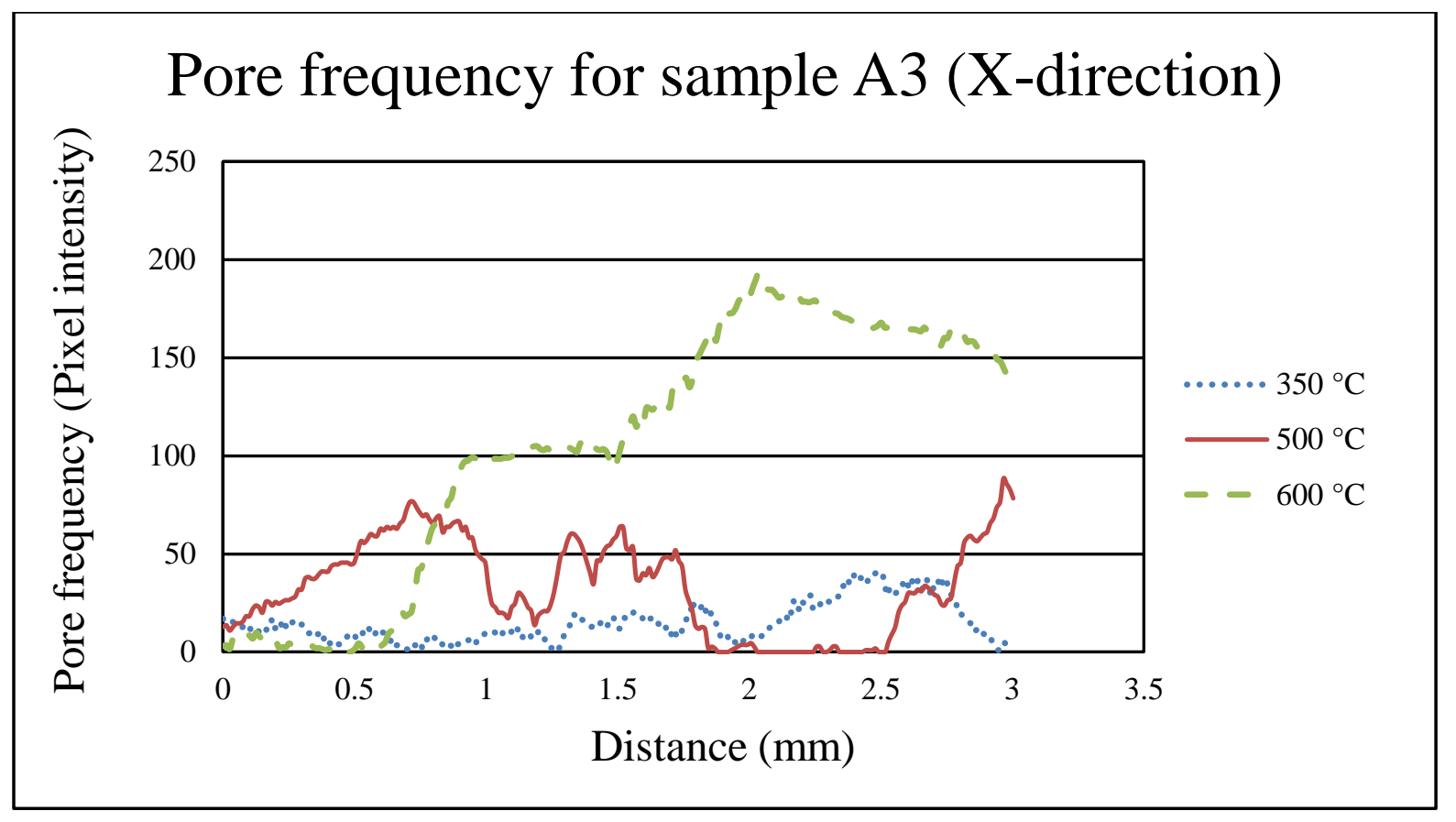

Figure 4.7 Pore frequency analysis of sample A3 in the X-direction 


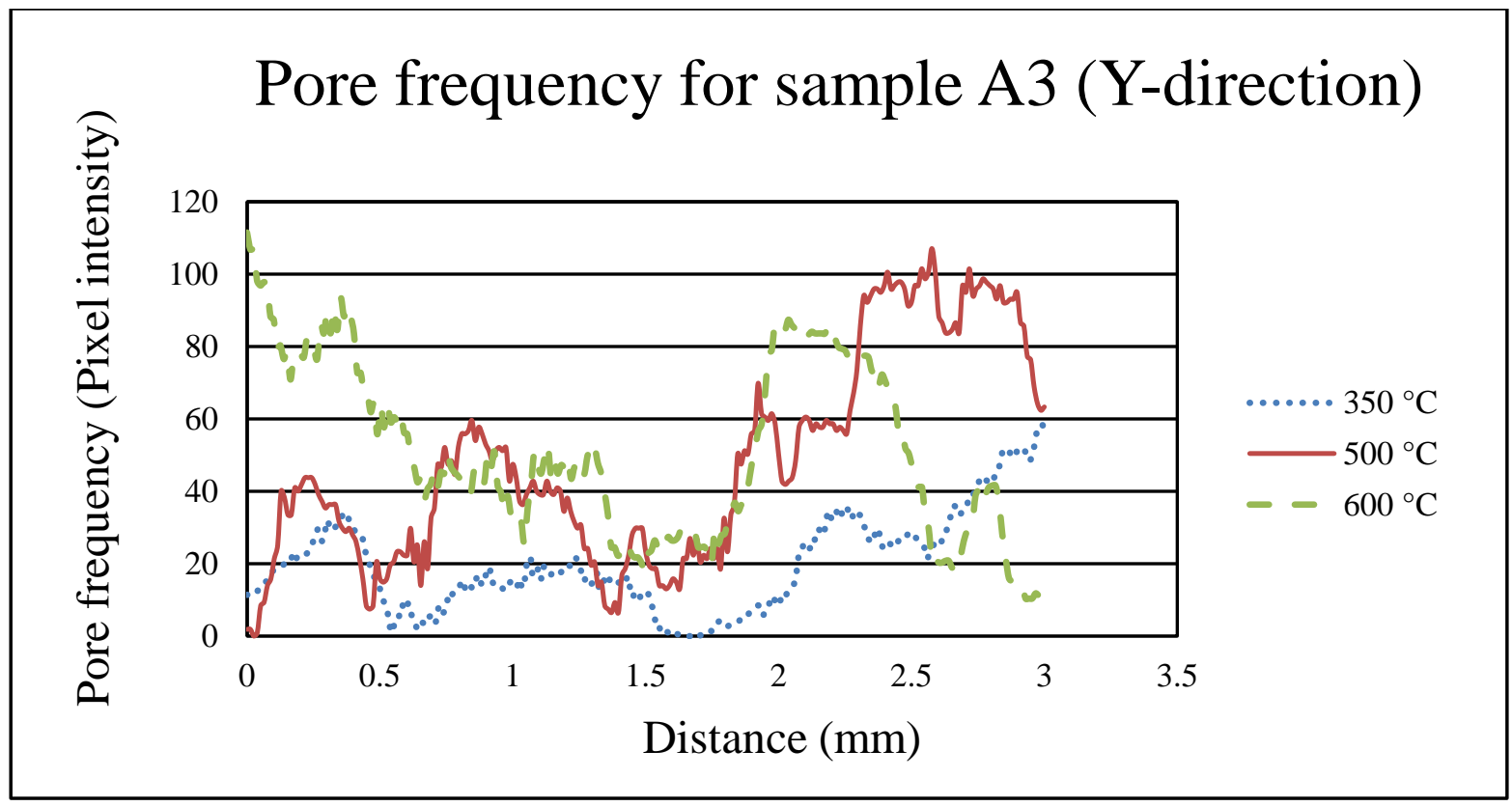

Figure 4.8 Pore frequency analysis of sample A3 in the Y-direction

The changes in area porosity for samples A2 and A3 are examined due to changes with the preheat temperature during the PACS process. Table 4.1 shows data for the sample compressed at $22241 \mathrm{~N}$ (A2) and Table 4.2 displays data for the sample compressed at $26689 \mathrm{~N}$ (A3). Samples A2 and A3 were arbitrarily chosen for analysis. Tables 4.1 and 4.2 in general exhibit a trend of decreasing area porosity with decreasing preheat temperature. This is due to the decrease in the combustion temperature with decreasing preheat temperature. At lower preheat temperatures the solid fraction increases causing the final porosity to decrease. In Table 4.1 sample A2 obtains identical $\mathrm{X}$ and $\mathrm{Y}$ area porosity values are obtained at the lowest preheat temperature. Sample A3 in table 4.2 shows a decrease of porosity with decreasing preheat temperature in the $\mathrm{X}$-direction while for the $\mathrm{y}$ direction at preheat temperature of $500^{\circ} \mathrm{C}$ 
increases. This trend is due to an increase in pore size of the $500^{\circ} \mathrm{C}$ preheat. Visual analyses of sample A3 in Figs. 4.3 and 4.4 confirm the increase in pore size at preheat temperature of $500^{\circ} \mathrm{C}$. Despite the increase in porosity, sample A3 subsequently exhibits decreasing area porosity with decreasing pre-heat temperature.

Table 4.1 Area porosity data for sample A2 with ignition temperature $\approx 1100^{\circ} \mathrm{C}$

\begin{tabular}{|c|c|c|}
\hline $\begin{array}{c}\text { Preheat Temperature } \\
\left({ }^{\circ} \mathrm{C}\right)\end{array}$ & $\begin{array}{c}\text { X-direction Area } \\
\text { Porosity }(\%)\end{array}$ & $\begin{array}{c}\text { Y-direction Area } \\
\text { Porosity }(\%)\end{array}$ \\
\hline$\approx 600$ & 10 & 13 \\
\hline$\approx 500$ & 8 & 10 \\
\hline$\approx 350$ & 5 & 5 \\
\hline
\end{tabular}


Table 4.2 Area porosity data for sample $\mathrm{A} 3$ with ignition temperature $\approx 1100^{\circ} \mathrm{C}$

\begin{tabular}{|c|c|c|}
\hline $\begin{array}{c}\text { Preheat } \\
\text { Temperature }\left({ }^{\circ} \mathrm{C}\right)\end{array}$ & $\begin{array}{c}\text { X-direction Area } \\
\text { Porosity }(\%)\end{array}$ & $\begin{array}{c}\text { Y-direction Area } \\
\text { Porosity }(\%)\end{array}$ \\
\hline$\approx 600$ & 11 & 8 \\
\hline$\approx 500$ & 7 & 12 \\
\hline$\approx 350$ & 3 & 5 \\
\hline
\end{tabular}

\subsubsection{Ignition temperature}

The effect of ignition temperature on the final pore morphology is analyzed in Figs. 4.9 and 4.10 for $\mathrm{X}$ and $\mathrm{Y}$ - directions respectively. All samples were compressed at $22241 \mathrm{~N}$, preheated to $\approx 600{ }^{\circ} \mathrm{C}$ and ignited at 3 different ignition temperatures $\left(\approx 1000{ }^{\circ} \mathrm{C}, \approx 1050{ }^{\circ} \mathrm{C}\right.$, and $\left.\approx 1100{ }^{\circ} \mathrm{C}\right)$. In Fig. 4.9 sample A processed at the lowest ignition temperature $\left(\approx 1000{ }^{\circ} \mathrm{C}\right)$ shows large voids scattered about the sample. The same pore characteristic can be seen in sample B. At the highest ignition temperature $\left(\approx 1100{ }^{\circ} \mathrm{C}\right)$ the pores become more spherically-shaped and obtain a more uniform pore distribution than that of samples A and B. The same trend can be seen in Fig. 4.10 for the Y-direction. From visual observation it can be seen that the effect of ignition temperature on the final pore morphology is similar to the effect of preheat temperature. This is due to the increase in temperature of the overall reaction. Sample C in Figs. 4.9 and 4.10 seems to have a more uniform pore distribution than that of samples A and B. The pore distribution is further analyzed in Figs. 4.11 and 4.12. 


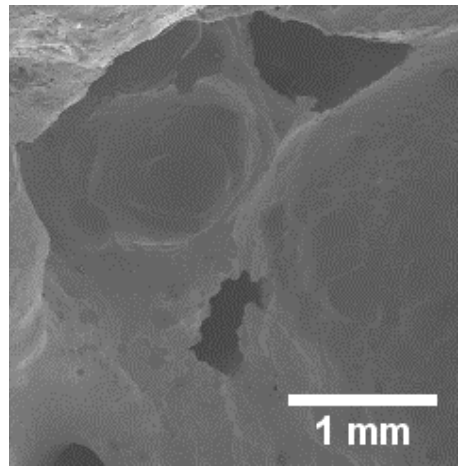

A

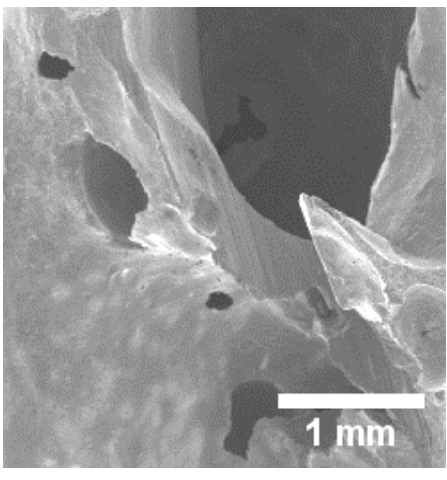

B

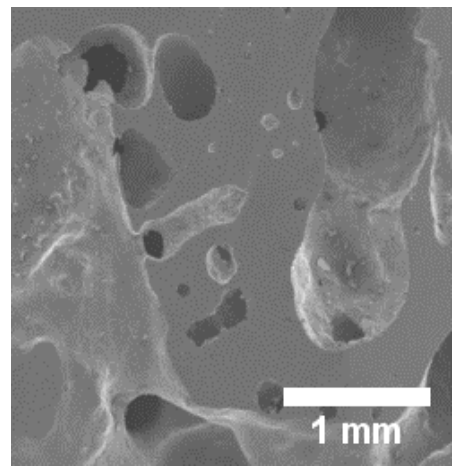

C

Figure 4.9: SEM micrographs showing different pore morphology in the Y-direction for samples processed at preheat temperature $\approx 600^{\circ} \mathrm{C}$ at different ignition temperatures $(\mathrm{A} \approx$ $1000^{\circ} \mathrm{C}, \mathrm{B} \approx 1050^{\circ} \mathrm{C}, \mathrm{C} \approx 1100^{\circ} \mathrm{C}$ )

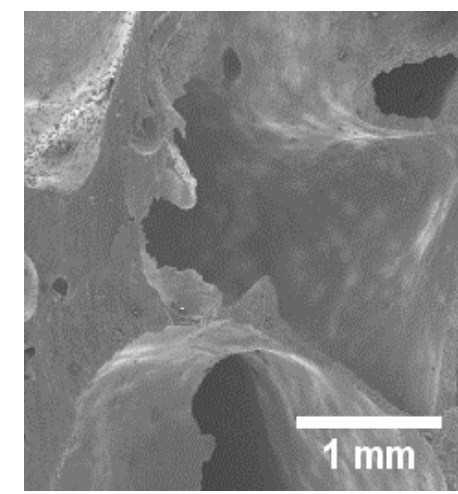

$\mathbf{A}$

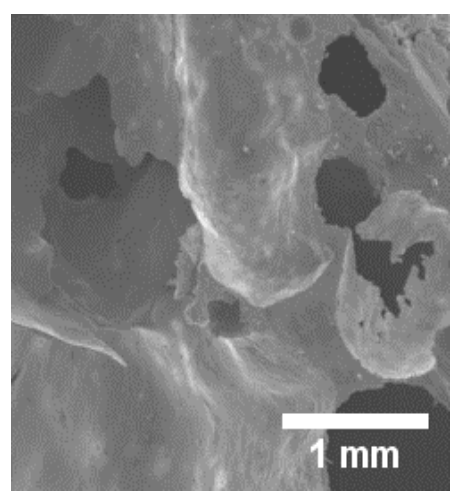

B

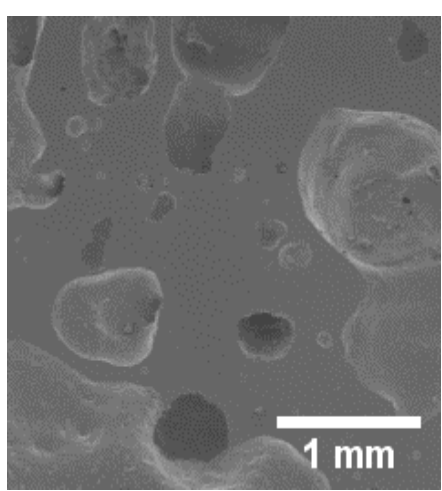

C

Figure 4.10: SEM micrographs showing different pore morphology in the Y-direction for samples processed at preheat temperature $\approx 600^{\circ} \mathrm{C}$ at different ignition temperatures $(\mathrm{A} \approx$ $1000^{\circ} \mathrm{C}, \mathrm{B} \approx 1050^{\circ} \mathrm{C}, \mathrm{C} \approx 1100^{\circ} \mathrm{C}$ )

Figures 4.11 and 4.12 display pore distribution for the $\mathrm{X}$ and $\mathrm{Y}$-directions respectively. As expected sample $\mathrm{C}$ has a more uniform pore distribution than that of samples $\mathrm{A}$ and $\mathrm{B}$. Samples A and B in Figs. 4.11 and 4.12 show segments of high pore frequency due to the large 
voids shown in Figs. 4.9 and 4.10. This trend is due to an increase in the liquid fraction with increasing ignition temperature. At lower ignition temperatures it appears that the area porosity is lower and that is because the liquid fraction is lower at lower temperatures. At higher ignition temperatures the liquid fraction increases causing formation of new pores. This trend is observed in Table 4.3.

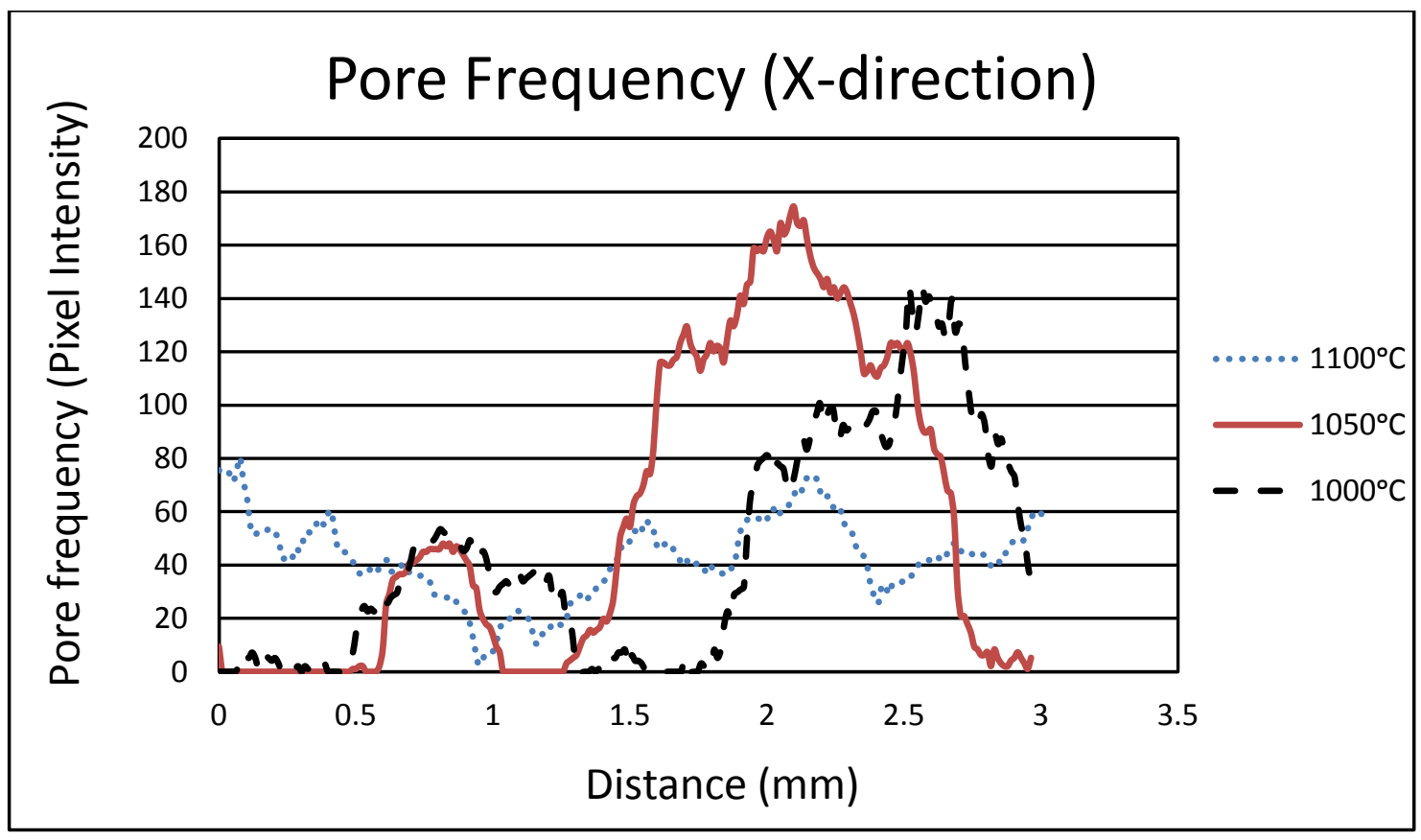

Figure 4.11: Pore distribution in the $\mathrm{X}$-direction for samples processed at preheat temperature $\approx 600{ }^{\circ} \mathrm{C}$ 


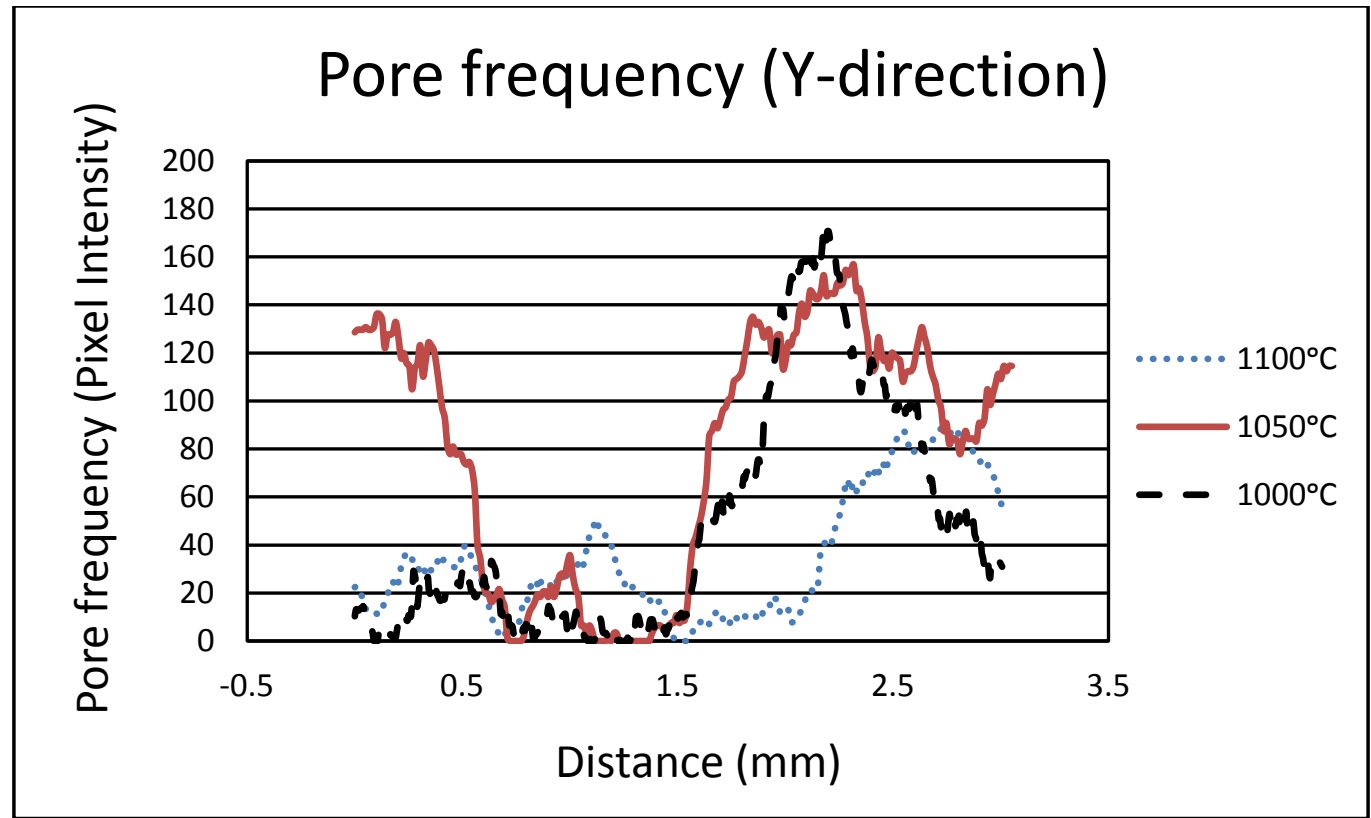

Figure 4.12: Pore distribution in the $\mathrm{Y}$-direction for samples processed at preheat temperature $\approx 600{ }^{\circ} \mathrm{C}$

Table 4.3 displays a trend of increasing area porosity with increasing ignition temperature. The table also shows that samples B and $\mathrm{C}$ have the most uniform area porosity distribution when comparing individual $\mathrm{X}$ and $\mathrm{Y}$ segments.

Table 4.3 Area porosity data for sample A2 processed at preheat temp. $600^{\circ} \mathrm{C}$

\begin{tabular}{|c|c|c|}
\hline Preheat temperature $\left({ }^{\circ} \mathrm{C}\right)$ & $\begin{array}{c}\text { X-direction Area } \\
\text { Porosity }(\%)\end{array}$ & $\begin{array}{c}\text { Y-direction Area } \\
\text { Porosity }(\%)\end{array}$ \\
\hline$\approx 1000(\mathrm{~A})$ & 3 & 8 \\
\hline$\approx 1050(\mathrm{~B})$ & 6 & 7 \\
\hline$\approx 1100(\mathrm{C})$ & 10 & 13 \\
\hline
\end{tabular}




\subsubsection{Densification pressure}

The effect of densification pressure is examined in this section as a control parameter for porous NiTi. The samples were processed at a preheat temperature of $600{ }^{\circ} \mathrm{C}$ and ignition temperature of $1100^{\circ} \mathrm{C}$. As in the previous section A1, A2 and A3 represent samples at different densification pressures.

SEM micrographs are shown in Figs. 4.13 and 4.14. In general porosity distributions in both directions depend on the exerted force. For example, both samples A1 and A2 produced with a relatively smaller force $(13344 \mathrm{~N}$ and $22241 \mathrm{~N})$ have most uniform distribution of porosity which varies transversally and longitudinally in both samples. The pores of sample A1 are large and scattered randomly in the sample due to the relatively small force applied. There are also many isolated small pores spread on the surface of the sample. Specifically, the pore size appears to become more uniform through formation of smaller pores and more spherical-shaped voids. This trend may be attributed to the transient intermediate liquid phase during the combustion synthesis. As mentioned in prior chapter 2, densification of $\mathrm{Ni}$ and $\mathrm{Ti}$ particles decreases the initial porosity and improves contact of particle surface area. This enhances the chemical reaction and reduces final porosity of the final product. Overall, sample A2 appears to have the closest approach to fairly uniform porosity. 


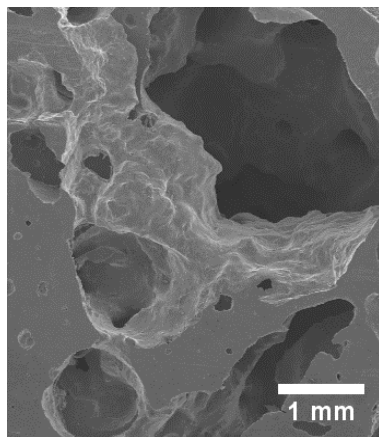

A1

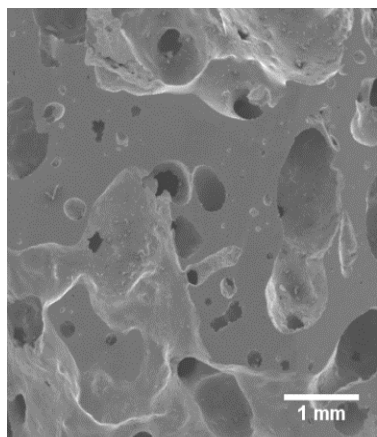

A2

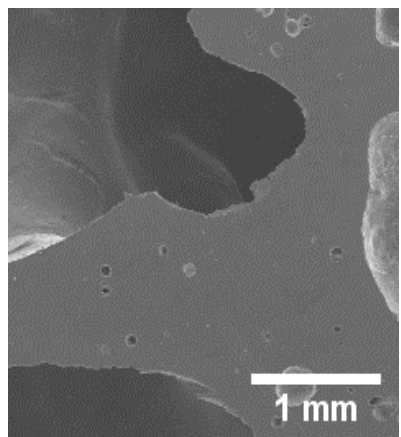

A3

Figure 4.13 SEM micrographs forces applied are A1(13344N), A2(22241N) and A3(26689N) (X-direction) (preheat temp. $\approx 600^{\circ} \mathrm{C}$ ignition temp. $\approx 1100^{\circ} \mathrm{C}$ )

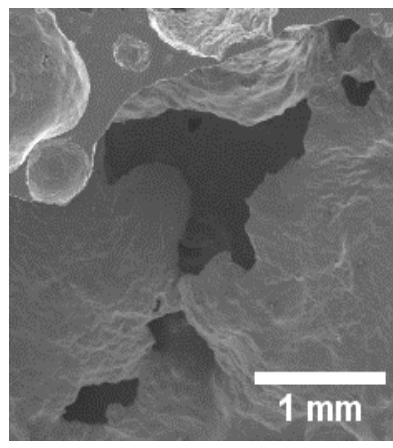

A1

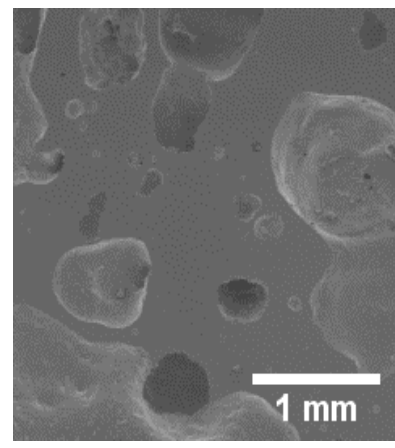

A2

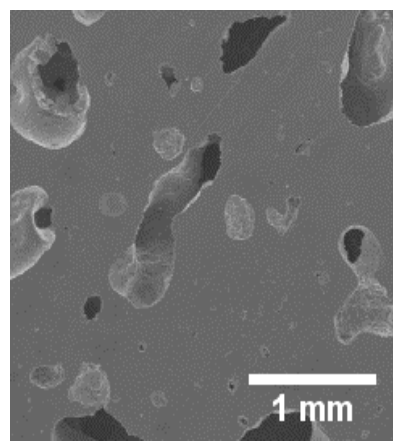

A3

Figure 4.14 SEM micrographs forces applied are A1 (13344N), A2 (22241N) and A3 (26689N) (Y-direction) (preheat temp. $\approx 600^{\circ} \mathrm{C}$ ignition temp. $\approx 1100{ }^{\circ} \mathrm{C}$ )

Table 4.4 shows area porosity of samples A1, A2 and A3 (both $\mathrm{X}$ and Y directions) for respectively. Table 4.4 presents data for samples processed at a preheat temperature of $600{ }^{\circ} \mathrm{C}$ and ignition temperature of $1100{ }^{\circ} \mathrm{C}$ while Table 4.6 shows data for samples processed at a preheat temperature of $500{ }^{\circ} \mathrm{C}$ and ignition temperature of $1100{ }^{\circ} \mathrm{C}$. Table 4.4 shows sample A1 has the highest area porosity, followed by $\mathrm{A} 2$ and $\mathrm{A} 3$ in both the $\mathrm{X}$ and $\mathrm{Y}$ directions. In the 
consensus of the results presented in the previous Figs. 4.13 and 4.14, samples A2 and A3 exhibit the highest uniformity of area porosity. Overall sample A2 has the most consistent pore uniformity. The observed trend of decreasing area porosity with increasing densification pressure may be attributed to the initial porosity of the sample before the PACS process. Densification of sample increases the contact area between elemental $\mathrm{Ni}$ and $\mathrm{Ti}$ which in turn enhances chemical reaction to produce bulk NiTi. Thus in order to produce porosity in the final product, a careful control is desirable between the various input processing conditions.

Table 4.4: Area porosity data for samples A1, A2 (Samples processed at preheat temp. $\approx 600{ }^{\circ} \mathrm{C}$, ignition temp. $\approx 1100^{\circ} \mathrm{C}$ )

\begin{tabular}{|c|c|c|}
\hline Sample (N) & $\begin{array}{c}\text { X-direction Area } \\
\text { Porosity (\%) }\end{array}$ & $\begin{array}{c}\text { Y-direction Area } \\
\text { Porosity (\%) }\end{array}$ \\
\hline $13344($ A1) & 15 & 11 \\
\hline $22241($ A2) & 11 & 8 \\
\hline 26689 (A3) & 10 & 7 \\
\hline
\end{tabular}

Figures 4.15 and 4.16 show porosity distribution in the longitudinal (X) and transversal (Y)-directions respectively. Both figures show the variation of pore frequency with distance across the sample. The pore frequency is measured in pixels and given a value based on color and size of the observed area (The bigger and darker the observed region the higher the pixel value). The dark area on the SEM micrographs generally represents voids within the sample. Figure 4.15 shows sample A3 has the least amount of uniform pore distribution, while A3 has the highest. Sample A3 has virtually no voids at the end but very large voids within the sample, reaching a maximum at about $2 \mathrm{~mm}$ within the sample. 


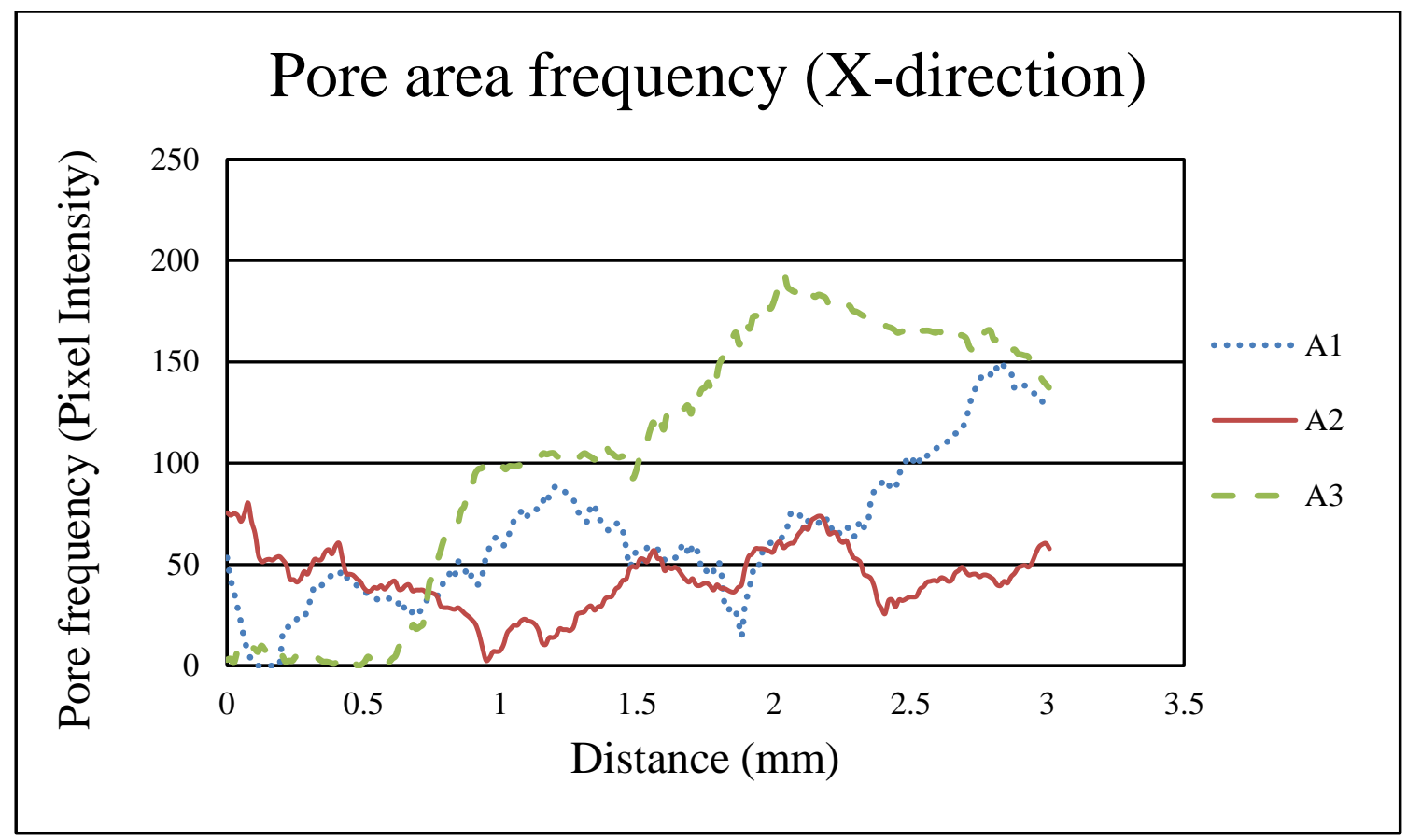

Figure 4.15: Pore intensity for sample in the $\mathrm{x}$-direction (Samples processed at preheat temp. $\approx$ $600^{\circ} \mathrm{C}$, ignition temp. $\approx 1100^{\circ} \mathrm{C}$ )

The corresponding results to Fig. 4.15 is presented in Fig. 4.16 for area porosity in the Ydirection. Samples A1 and A3 again exhibit the least amount of pore uniformity compared to A2. Sample A1 has large voids due to the low densification force applied. The consistent pore uniformity observed for sample A2 in both the X and Y-directions (Figs. 4.15 and 4.16) may be attributed to the compaction force of samples prior to the PACS process. At low densification force pore sizes are larger and not consistent across the sample as seen in Figs. 4.13 and 4.14. The decrease in the contact area between $\mathrm{Ni}$ and $\mathrm{Ti}$ particles at low compaction force results in insufficient liquid phase that produce large voids. Similar trends also occur for excessively high densification force. The increase in compaction force significantly decreases the initial pore size 
thereby almost creating a bulk material. When the liquid phase occurs some of the liquid may either stay in place or fill small voids. Sample A2 appears to have been produced with best densification force among the three forces investigated.

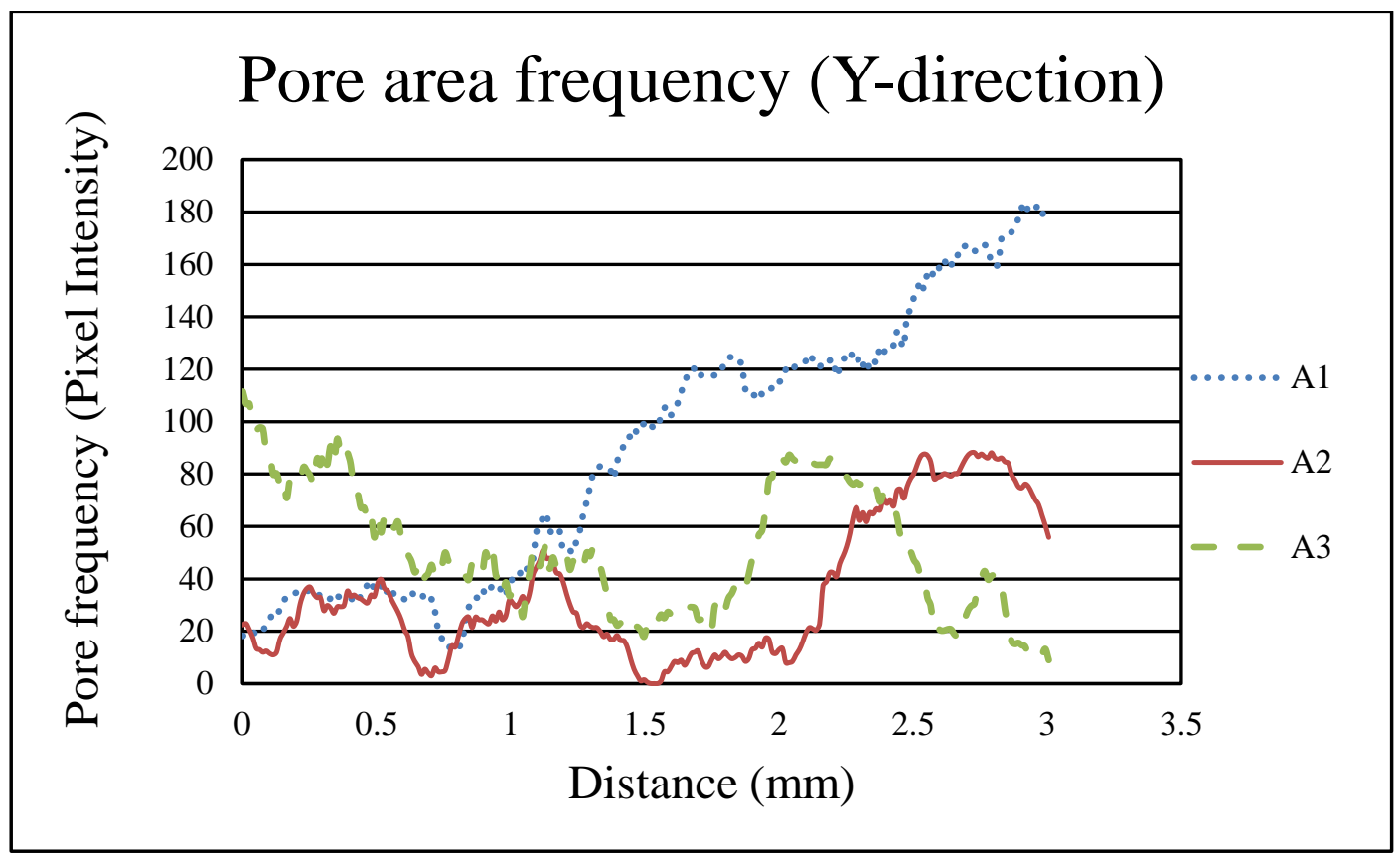

Figure 4.16: Pore intensity for sample set 1 in the Y-direction(Samples processed at preheat temp. $\approx 600{ }^{\circ} \mathrm{C}$, ignition temp. $\approx 1100{ }^{\circ} \mathrm{C}$ )

\subsubsection{Particle size}

This section analyzes the effects of initial particle size on area porosity, pore morphology and distribution. The preheat temperature, ignition temperature and densification force are all kept constant. Two different $\mathrm{Ni}$ and $\mathrm{Ti}$ particle mixture sizes are considered. The samples are produced with a preheat temperature of about $500{ }^{\circ} \mathrm{C}$, ignition temperature of about 
$1050^{\circ} \mathrm{C}$ and a densification force of $22241 \mathrm{~N}$. Sample A2 represents composite with particle sizes of $37 \mu \mathrm{m} \mathrm{Ni}$ and $37 \mu \mathrm{m}$ Ti while A2.1 represents samples fabricated with $2.5 \mu \mathrm{m}$ Ni particle and $5 \mu \mathrm{m} \mathrm{Ti}$.

Figures 4.17 and 4.18 present SEM micrographs of the two particle sizes in the $\mathrm{X}$ and $\mathrm{Y}$ directions respectively. Sample A2 in Fig. 4.17 shows a small pore frequency with pore configurations. On the other hand sample A2.1 displays a moderate pore frequency and spherical-shaped pores.

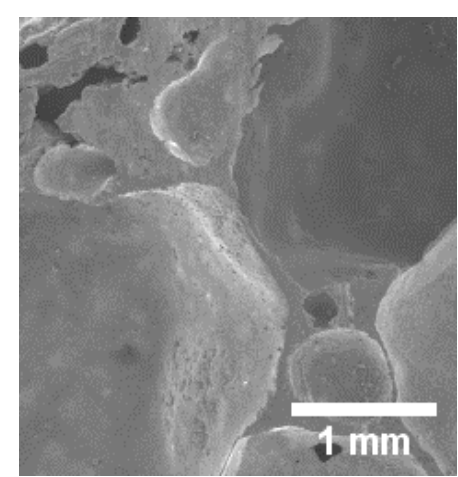

A2

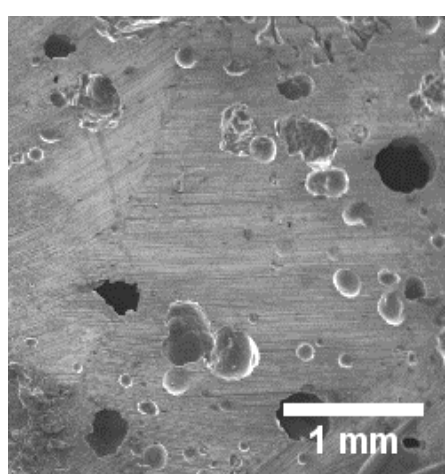

A2.1

Figure 4.17 SEM micrographs of samples A2 and A2.1 in the X-direction processed at a preheat temp. of $500{ }^{\circ} \mathrm{C}$ and ignition temp of $1000{ }^{\circ} \mathrm{C}$.

Figure 4.18 shows A2 with a significant increase in void size than that of Fig. 4.17 A2. There is a signification pore size increase as well as a decrease in the number of pores for the surveyed area. A2.1 also shows a decrease in the amount of pores within the sample. 


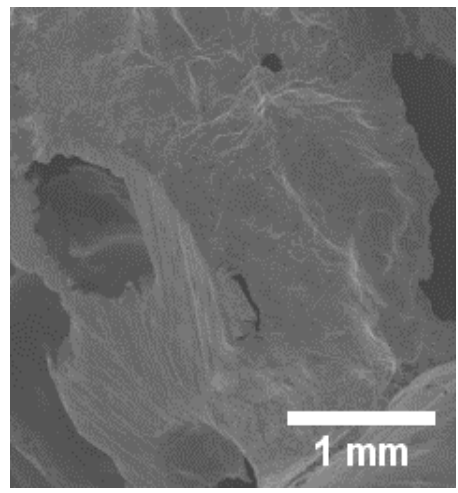

A2

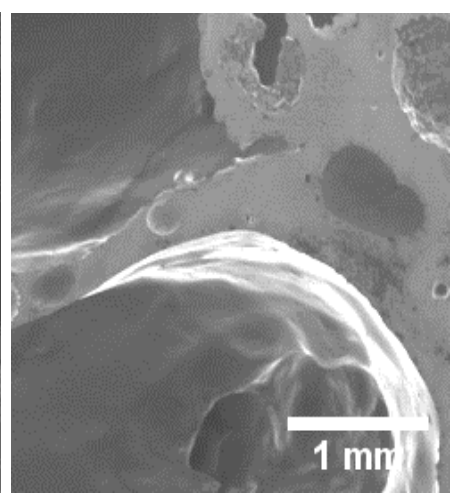

A2.1

Figure 4.18 SEM micrographs of samples A2 and A2.1 in the X-direction processed at a preheat temp. of $500{ }^{\circ} \mathrm{C}$ and ignition temp of $1000{ }^{\circ} \mathrm{C}$.

Table 4.5 presents data for samples compressed at $22241 \mathrm{~N}$ at two different particle sizes. The table shows a reduction in area porosity with decreasing particle size. This trend may be attributed to the increase in available contact area with decrease in particle size. This in turn enhances compaction, promotes chemical reaction and increases the intermediate liquid phase. In effect a portion of the liquid phase may stay place or fill voids thereby reducing the porosity. The effect of particle size decrease is generally similar to the effect of increasing compaction force.

Table 4.5 Area porosity for A2 and A2.1 (Samples processed at preheat temp. $\approx 500{ }^{\circ} \mathrm{C}$ and ignition temp. $\approx 1050{ }^{\circ} \mathrm{C}$ )

\begin{tabular}{|c|c|c|}
\hline Sample (N) & $\begin{array}{c}\text { X-direction Area } \\
\text { Porosity (\%) }\end{array}$ & $\begin{array}{c}\text { Y-direction Area } \\
\text { Porosity (\%) }\end{array}$ \\
\hline (A2) & 8 & 5 \\
\hline (A2.1) & 5 & 3 \\
\hline
\end{tabular}

Figures 4.19 and 4.20 show pore distribution for samples A2 and A2.1 in both the X and Y-directions respectively. In Figure 4.21 sample A2.1 exhibits a significant pore consistency 55 
compared to sample A2. Figure 4.20 shows large voids are concentrated on the left side $(\mathrm{x}=0)$ of sample A2.1 while sample A2 has large voids at both left and right. Observation of the data in Figs. 4.19 and 4.20 show that both samples A2 and A2.1 seem to have better pore distribution transversally (i.e. X-direction).

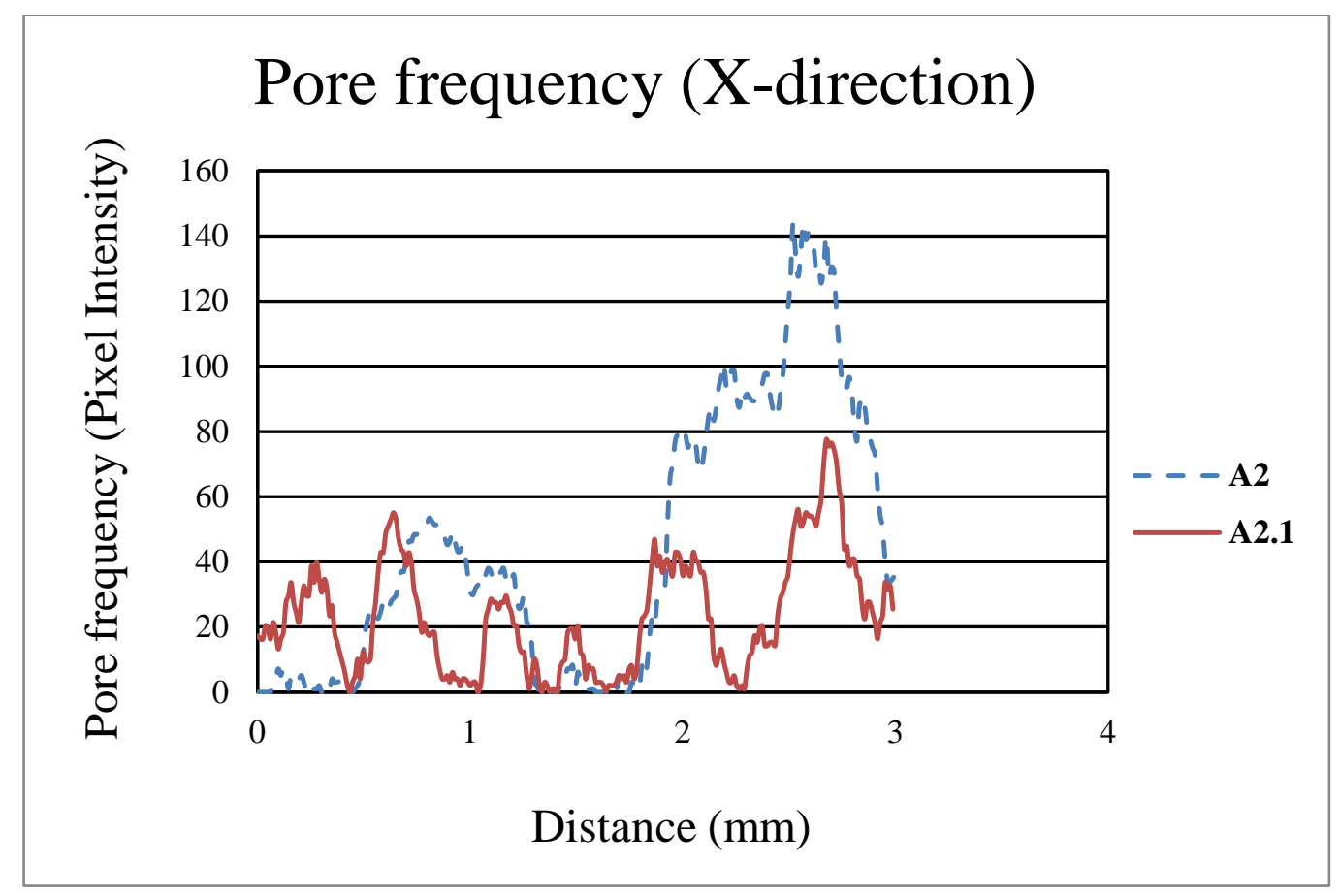

Figure 4.19 Pore distribution for samples A2 and A2.1 in the X-direction (Samples processed at preheat temp. $\approx 500^{\circ} \mathrm{C}$ and ignition temp. $\approx 1050^{\circ} \mathrm{C}$ ) 


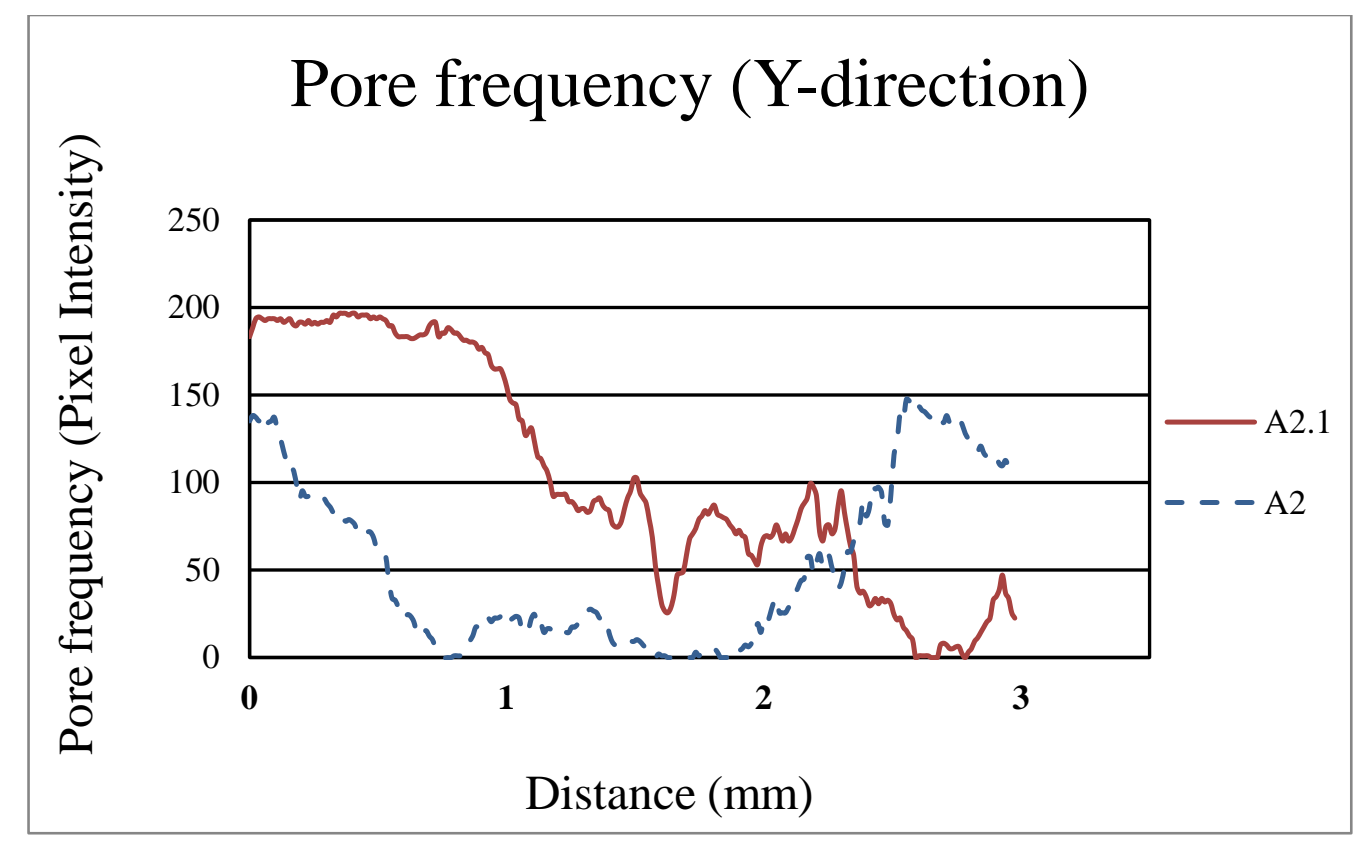

Figure 4.20 Pore distribution for samples A2 and A2.1 in the Y-direction (Samples processed at preheat temp. $\approx 500^{\circ} \mathrm{C}$ and ignition temp. $\approx 1050^{\circ} \mathrm{C}$ )

In summary the particle size affects pore size and frequency within the NiTi samples. Specifically the area porosity decreases with a reduction in particle size. 


\subsection{Near-net Shape Processing}

In this section the foaming behavior of NiTi during the SHS process is combined with shape molding to assess the near-net shape capabilities of PACS process product porous NiTi. Unlike the procedure described in chapter 3 the present approach involves placing the Ni-Ti sample in a mold. Samples were compressed at an arbitrary densification pressure using $37 \mu \mathrm{m}$ $\mathrm{Ni}$ and Ti particle size. Three different molds were fabricated using fire brick and sanding tools to carve out a desired shape. Figure 4.21 illustrates the three different molds utilized in the nearnet shape analysis. Mold A consists of 4 lines carved (using a sanding tool) out from four different sides of the sample. Mold B consist of a square extrusion while mold $\mathrm{C}$ consist of a cylindrical extrusion. Each sample was processed at a preheat temperature of $600^{\circ} \mathrm{C}$ and ignition temperature of $1100^{\circ} \mathrm{C}$.

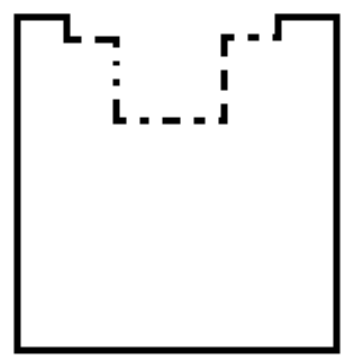

A

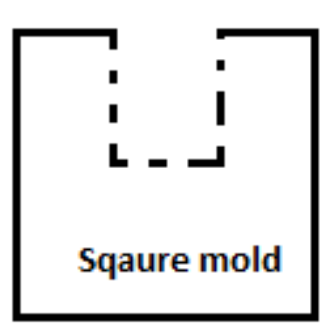

B

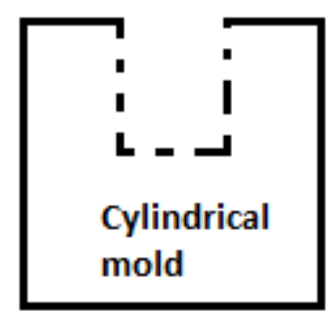

C

Figure 4.21: Ni-Ti molds

Figure 4.22 shows the corresponding results for using the molds in Fig. 4.21. Samples B and $\mathrm{C}$ of Fig. 4.22 appear to match the prescribed molding accurately. However, in Fig. 4.22(A) 
a small amount of material is observed on each of the four sides extruded in the mold. The material does not extend to the full length of the extruded lines of the mold but does mimic the shape.

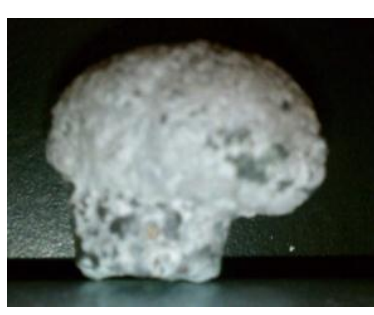

A

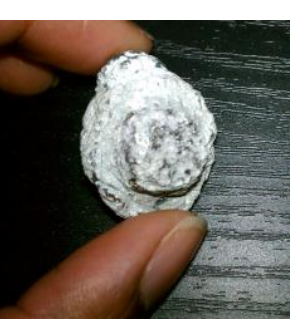

B

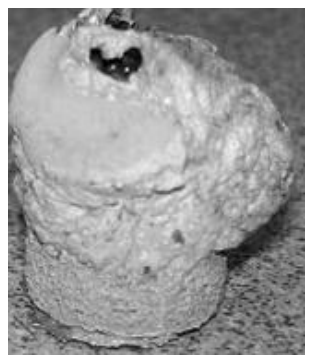

C

Figure 4.22: Sample mold results

In Figure 4.22(C) Combustion channels are observed at the bottom end which is the result of a complete reaction taking place. The other two molds failed to induce a complete chemical reaction for the NiTi samples. This usually results in a hollow synthesized sample at the lower end of the sample. This is due to the sample combustion temperature rising above the melting temperature of NiTi. The firebrick insulation may contribute to a significant increase of heating temperature causing the combustion temperature to rise above the NiTi melting temperature of $1310^{\circ} \mathrm{C}$.

The results of the samples produced in this section indicate that the PACS process has the capability for near-net shape processing depending on the design of the mold. The near-net shape 
capabilities of PACS demonstrated in simple molds. However, some difficulty is observed when using complex molds due to energy of reaction.

\subsection{Summary}

The influence of the preheat temperature, ignition temperature, densification force, particle size and near net shape capabilities of porous NiTi processed utilizing the PACS process have been analyzed. The results show that the processing parameters of the PACS process has a significant impact on size and distribution of pores.

Preheat and ignition temperatures seem to have a similar effect on pore morphology for porous NiTi. Due to an increase in combustion temperature a higher liquid fraction is created during higher ignition and preheat temperatures causing the final area porosity to increase. When preheat and ignition temperatures are lower the liquid fraction is lower resulting in a higher solid fraction causing the main source of pore formation to be due to the samples original pores.

In the case of densification force area porosity decreases with increasing force and shows more uniformity at moderate densification force. The results show that increasing $\mathrm{Ni}$ and $\mathrm{Ti}$ particle contact area decreases the initial porosity and also improves the overall chemical reaction. The same effects are seen in varying the particle size. A small particle size decreases the initial porosity while increasing the particle size increases the initial porosity.

Overall, the results from this study prove the aforementioned processing parameters to be an effective way to vary the final pore morphology of porous NiTi. 


\section{CHAPTER 5: CONCLUSION AND RECOMMENDATIONS}

\subsection{Conclusion}

The combustion synthesis of $\mathrm{Ni}-\mathrm{Ti}$ was investigated experimentally utilizing different processing parameters. Cylindrical samples were utilized and the flame propagation was measured as a function of the preheat temperature and initial sample porosity. The final product was sectioned and analyzed for macro-porosity distribution. The major findings of the study can be summarized thus:

- Area porosity decreases with decreasing preheat and ignition temperatures. It is proven that increasing the heating temperature increases the combustion temperature in the study of Li et al. [41]. This is why increasing the ignition temperature has a similar effect on area porosity.

- Porosity decreases with increasing densification pressure. Lower densification pressures have the ability to result in a more uniform pore distribution. This is due to the increase in force decreasing the initial porosity.

- Higher preheat temperature has the ability to produce a more uniform pore distribution. The porosity distribution in the final product is significantly influenced by the processing conditions.

- The PACS process has the capability for near-net shape processing of porous intermetallic. 


\subsection{Recommendations}

A number of issues were identified in this study to improve the PACS process. These issues are addressed below. The experiment took occurred in an open argon environment of making it very difficult to produce a controlled reaction. Sometimes the same experimental parameter had to be tested several times on different samples because they resulted in a complete foam reaction of the sample. A completely foamed sample would mainly produce material with internal (hollow) void. This outcome hollow center could be due to oxygen getting into the system and igniting the sample to an extremely high temperature. This could in turn cause the

particles to completely burn with no opportunity to participate in the chemical reaction. It is therefore recommended that subsequent experiments should be performed in a reaction chamber.

In addition experiments performed in a closed environment would allow for a more accurate temperature reading and temperature sensor placement. In many instances, considerate time was spent adjusting the temperature sensor to assure a good temperature reading.

Another issue that was eventually addressed visually was the need to provide efficient insulation throughout the combustion process. Initially, minimal insulation was being used which did not allow for the sample to reach its prescribed heating temperature. This development was observed after several failed experiments.

Another parameter that prohibited chemical reaction was the argon flow. This was discovered during depletion of the argon supply while an experiment was being performed. When this occurred, the argon flow rate slightly increased and then slowly decreased from that. The sample created from this experiment resulted in the least amount of foaming which is very 
good for sample analysis. After this analysis the argon flow was slightly decreased and this sufficiently improved the process.

In summary the main improvements or recommendations suggested for this study would be to have experiments occur in a closed environment in which argon flow and temperature are efficiently monitored.

\subsection{Future Work}

The mechanical properties of porous NiTi play a vital role when being applied in the medical field for hard tissue implant. A significantly higher or lower elastic modulus may cause the sample to damage surrounding hard tissue and can be very harmful to the host. Thus it is imperative for NiTi to have similar mechanical properties to that of bone. It is intended to continue this study by carrying out compression test on synthesized NiTi samples. The results will be used to further analyze the effects of the PACS method on porous NiTi. 


\section{APPENDIX A: SEM IMAGES}




\section{Sample A1}
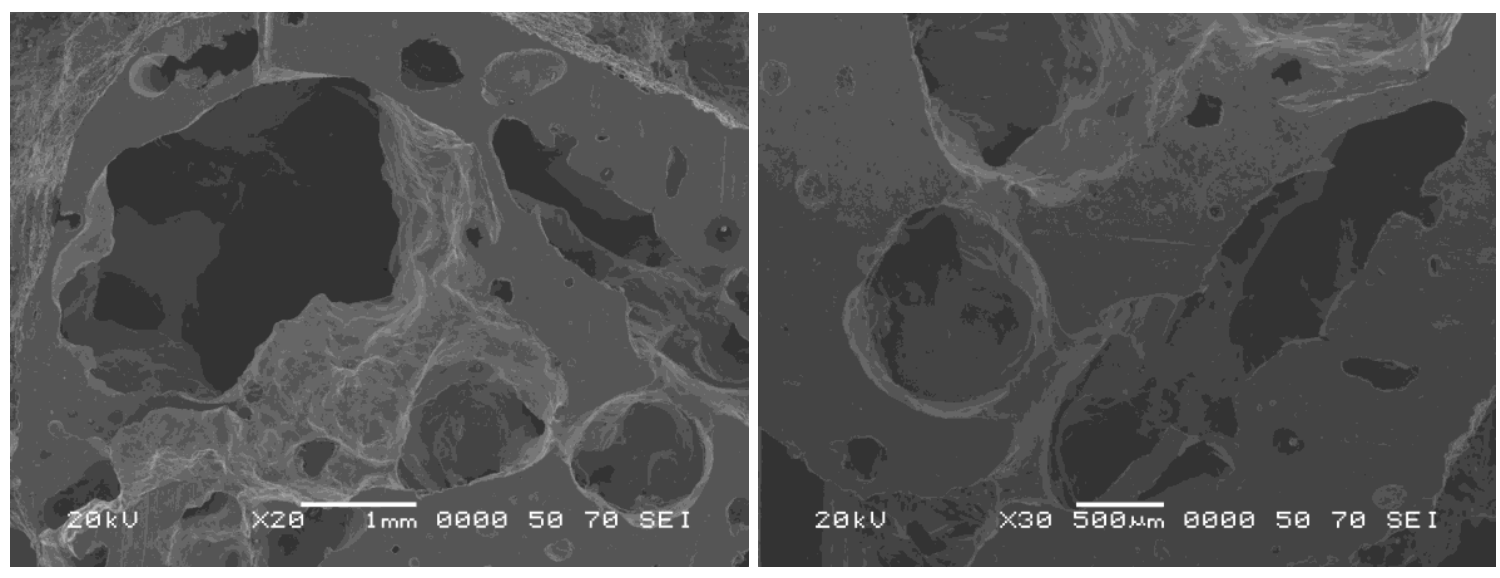

Magnified SEM micrographs of sample A1 (X-direction) processed at $600^{\circ} \mathrm{C}$ preheat temperature and $1100^{\circ} \mathrm{C}$ ignition temperature
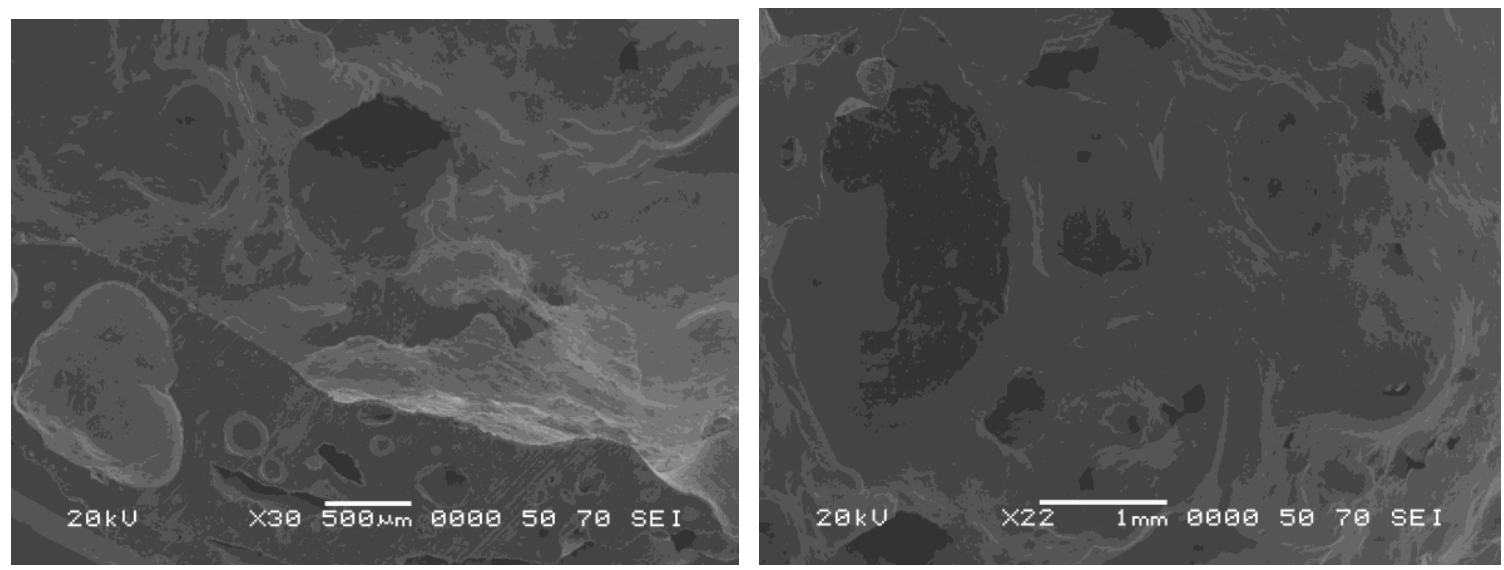

Magnified SEM micrographs of sample A1 (Y-direction) processed at $600^{\circ} \mathrm{C}$ preheat temperature and $1100^{\circ} \mathrm{C}$ ignition temperature 


\section{Sample A2}
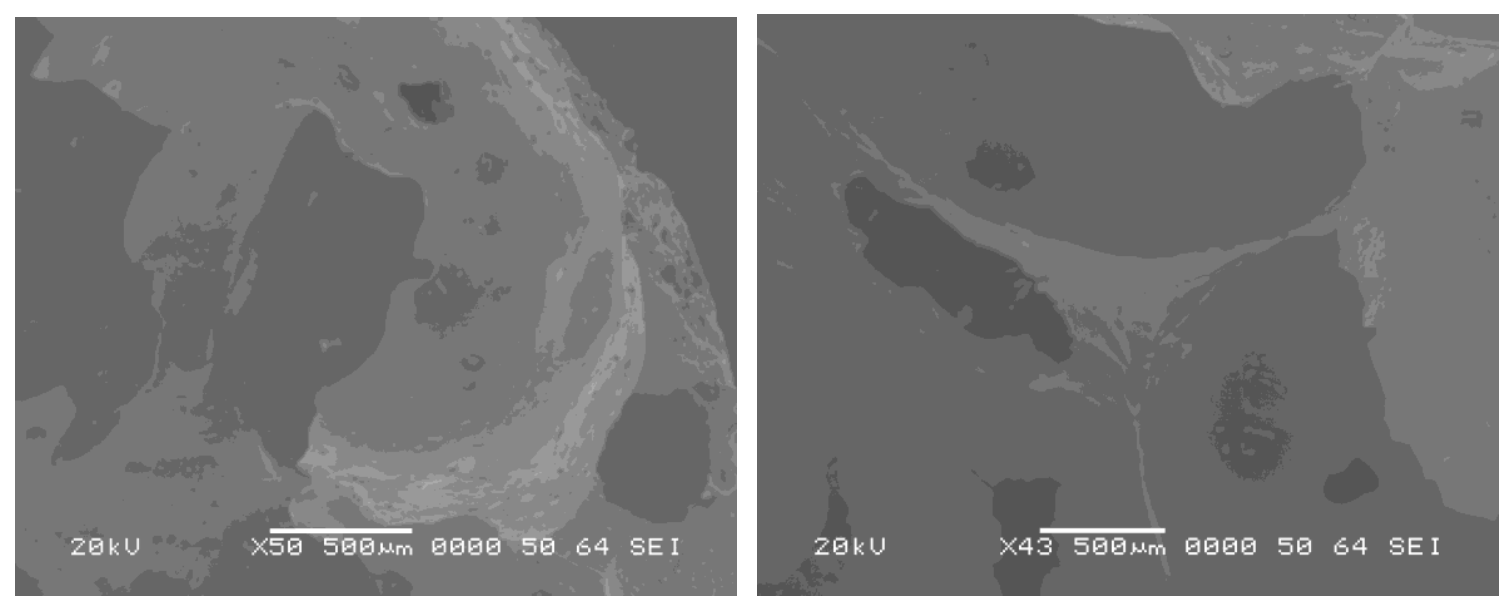

Magnified SEM micrographs of sample A2 (X-direction) processed at $350^{\circ} \mathrm{C}$ preheat temperature and $1100^{\circ} \mathrm{C}$ ignition temperature
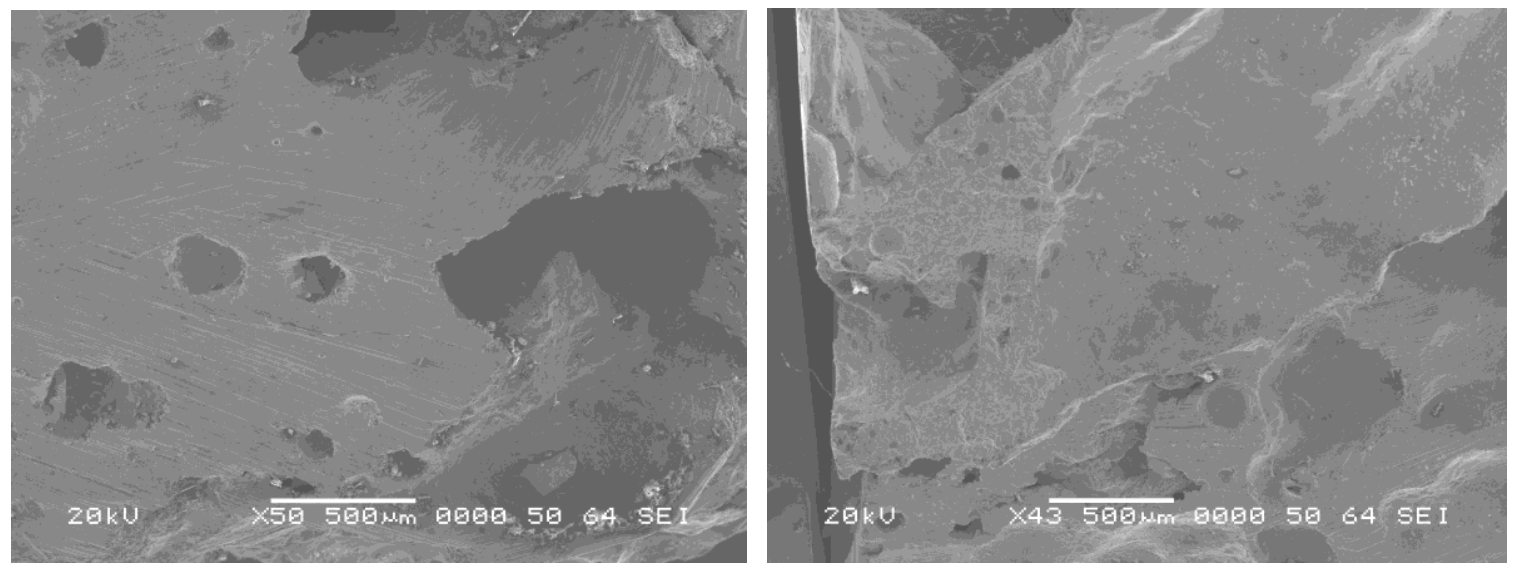

Magnified SEM micrographs of sample A2 (Y-direction) processed at $350^{\circ} \mathrm{C}$ preheat temperature and $1100^{\circ} \mathrm{C}$ ignition temperature 

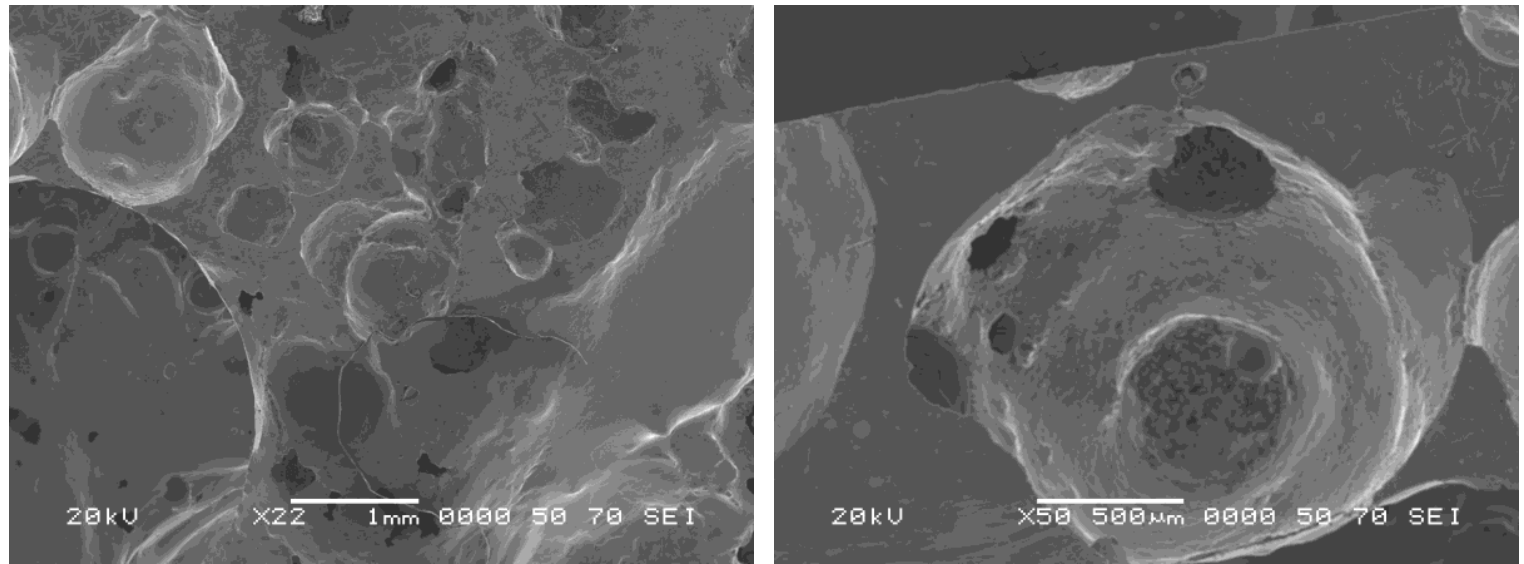

Magnified SEM micrographs of sample A2 (X-direction) processed at $500^{\circ} \mathrm{C}$ preheat temperature and $1100^{\circ} \mathrm{C}$ ignition temperature
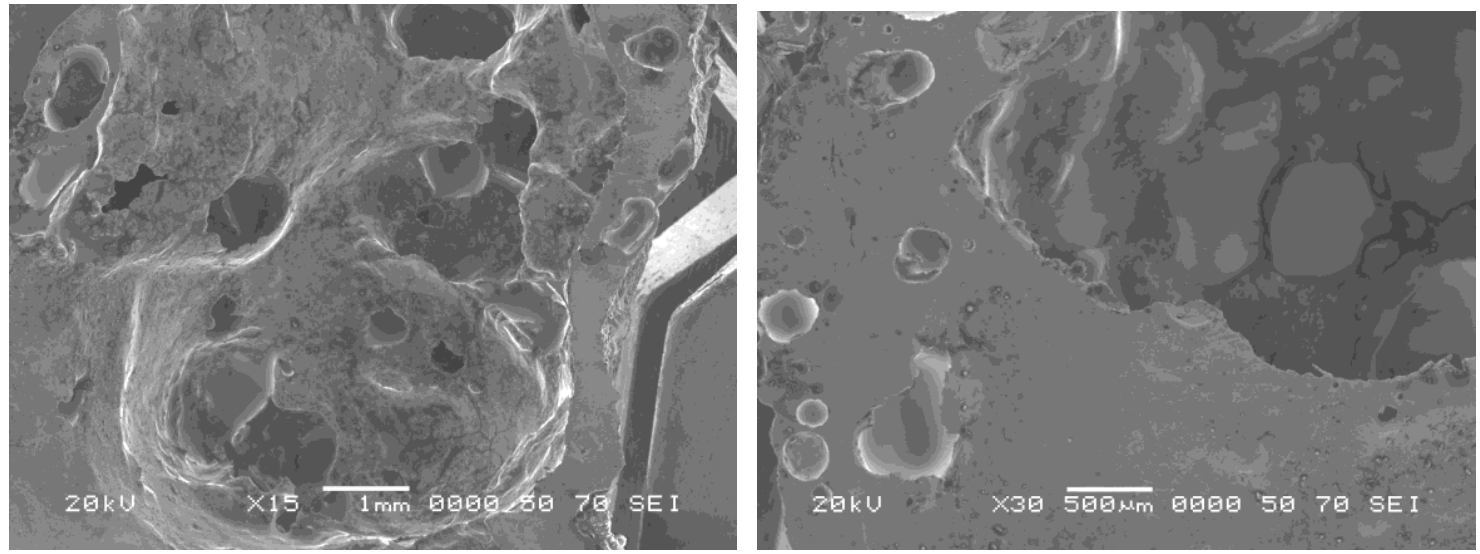

Magnified SEM micrographs of sample A2 (Y-direction) processed at $500^{\circ} \mathrm{C}$ preheat temperature and $1100^{\circ} \mathrm{C}$ ignition temperature 

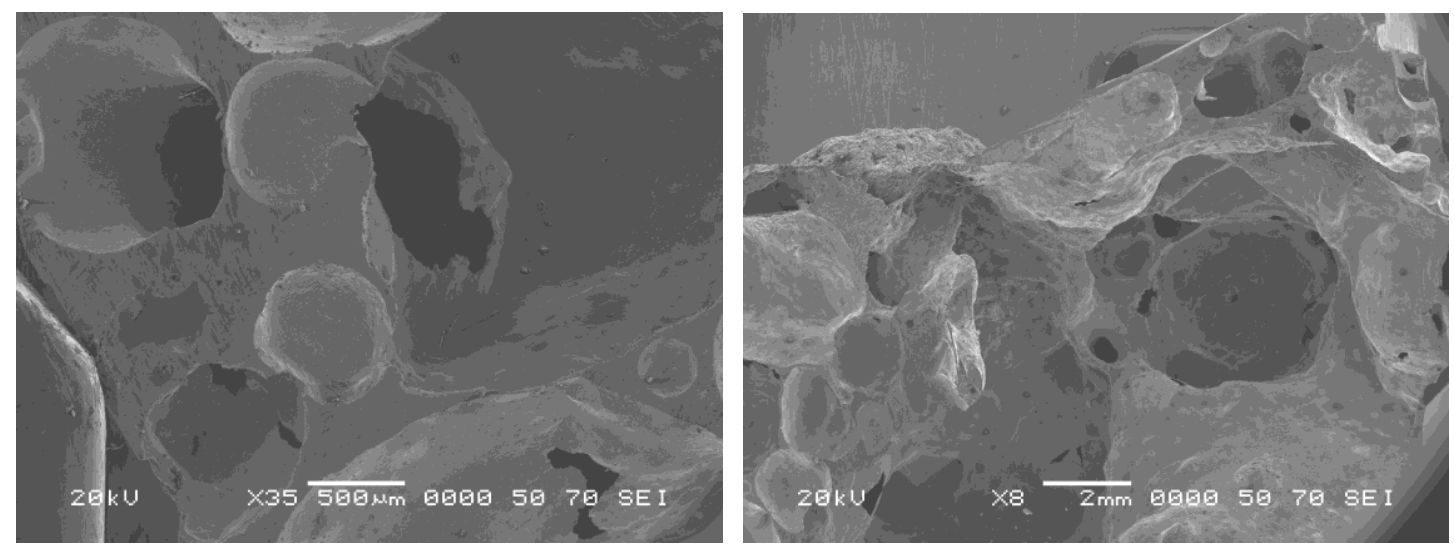

Magnified SEM micrograph of sample A2 (X-direction) processed at $600^{\circ} \mathrm{C}$ preheat temperature and $1000^{\circ} \mathrm{C}$ ignition temperature

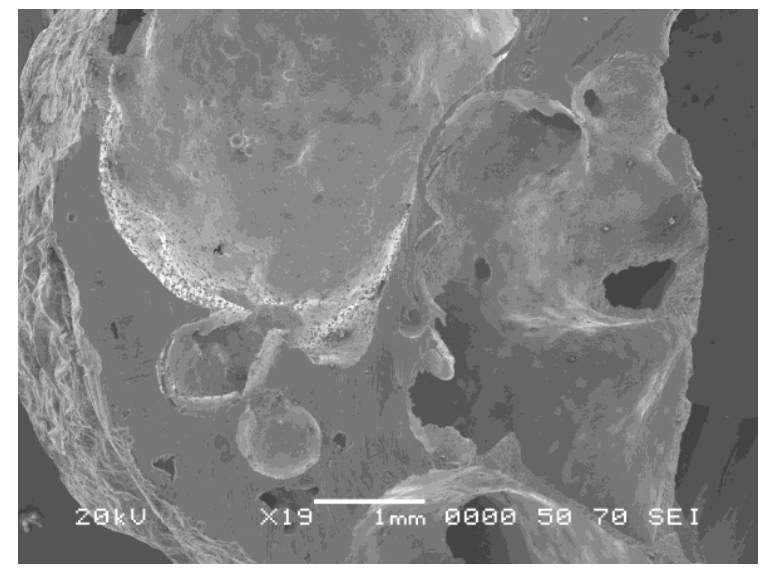

Magnified SEM micrograph of sample A2 (Y-direction) processed at $600^{\circ} \mathrm{C}$ preheat temperature and $1000^{\circ} \mathrm{C}$ ignition temperature 


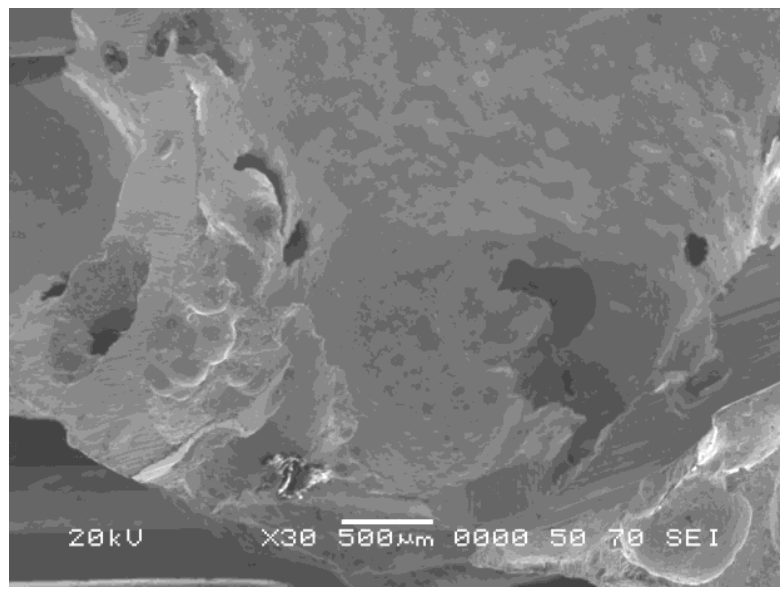

Magnified SEM micrograph taken from an angle of sample A2 (X-direction) processed at $600^{\circ} \mathrm{C}$ preheat temperature and $1050^{\circ} \mathrm{C}$ ignition temperature

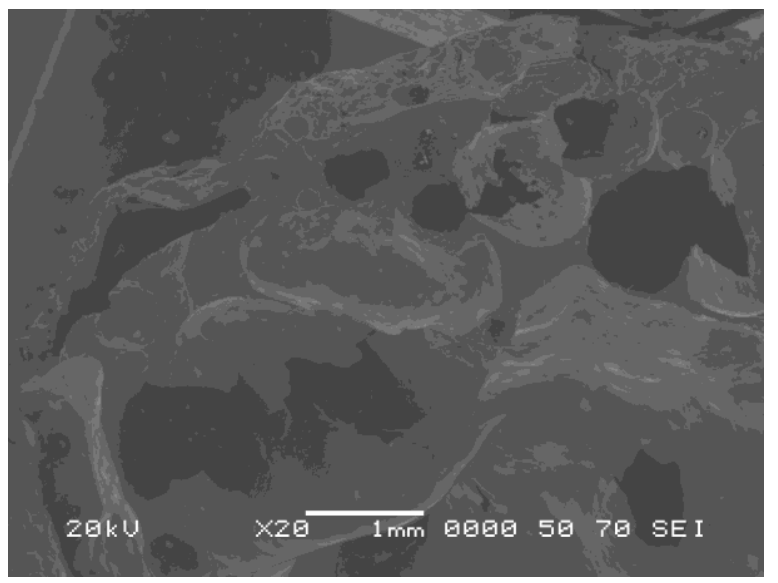

Magnified SEM micrograph taken from an angle of sample A2 (Y-direction) processed at $600^{\circ} \mathrm{C}$ preheat temperature and $1050^{\circ} \mathrm{C}$ ignition temperature 

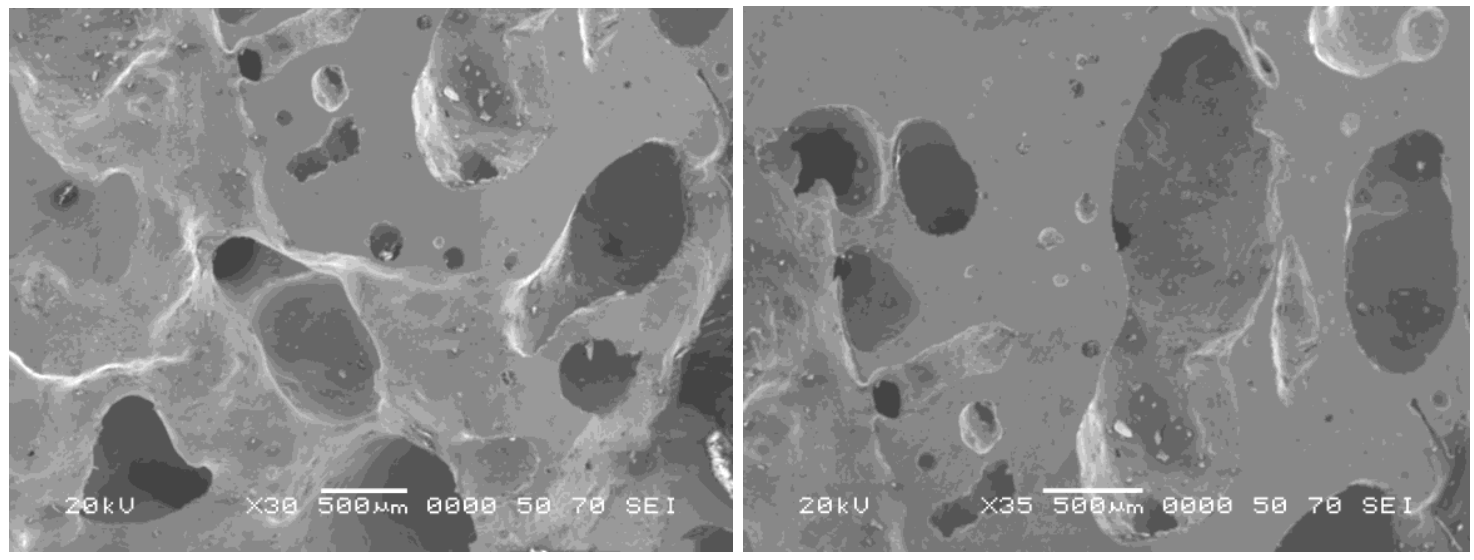

Magnified SEM micrographs of sample A2 (X-direction) processed at $600^{\circ} \mathrm{C}$ preheat temperature and $1100^{\circ} \mathrm{C}$ ignition temperature
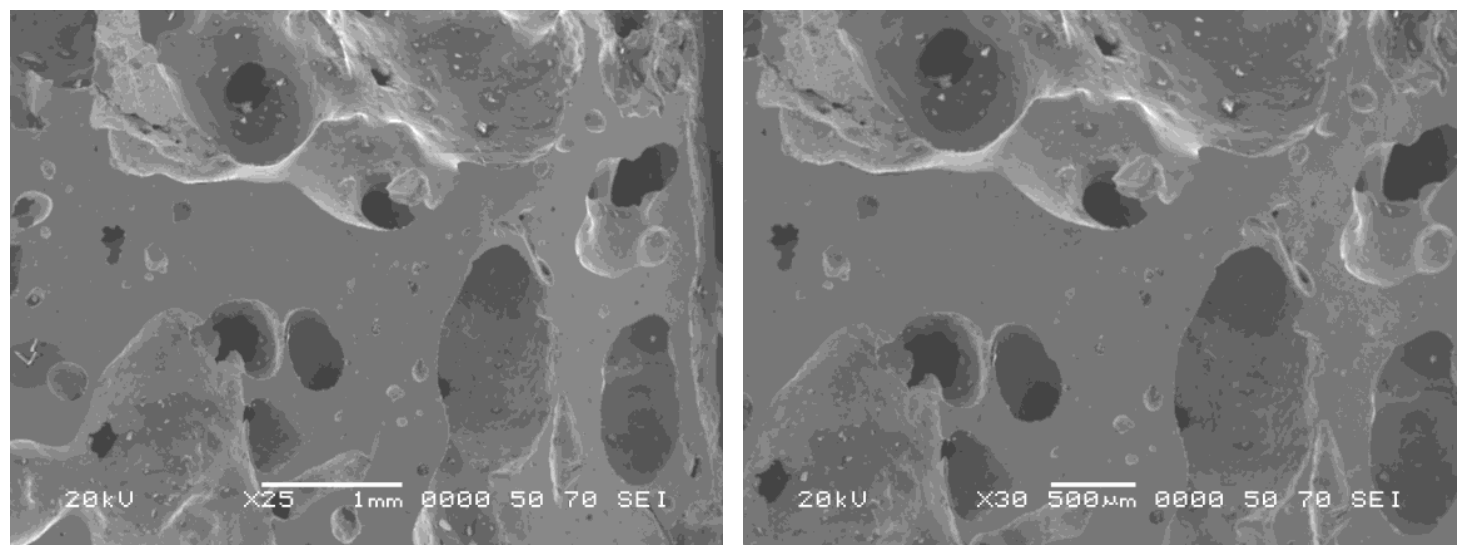

Magnified SEM micrographs of sample A2(X-direction) processed at $600^{\circ} \mathrm{C}$ preheat temperature and $1100^{\circ} \mathrm{C}$ ignition temperature 


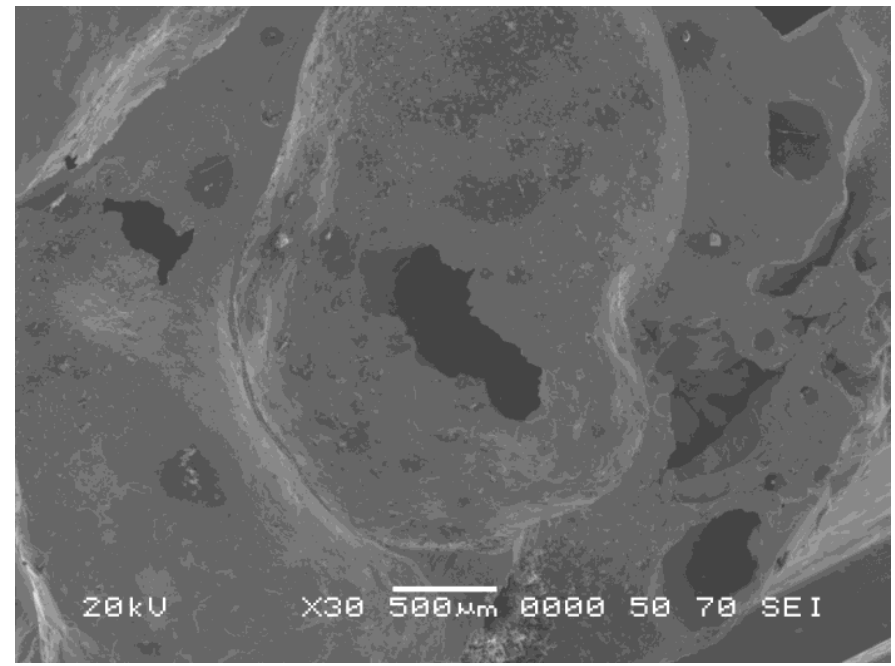

Magnified SEM micrograph of sample A2 (X-direction) processed at $500^{\circ} \mathrm{C}$ preheat temperature and $1000^{\circ} \mathrm{C}$ ignition temperature

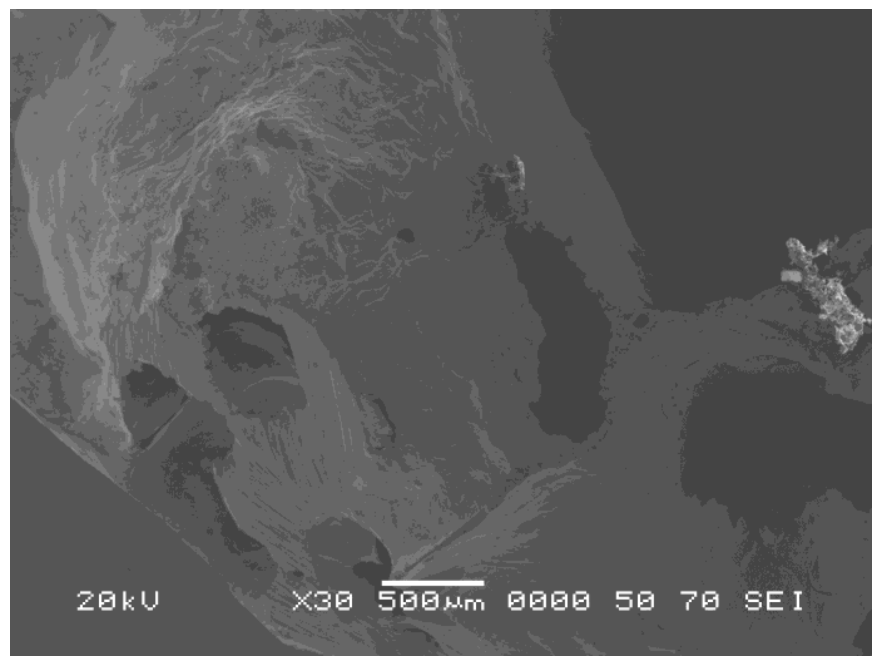

Magnified SEM micrograph of sample A2 (Y-direction) processed at $500^{\circ} \mathrm{C}$ preheat temperature and $1000^{\circ} \mathrm{C}$ ignition temperature 


\section{Sample A3}

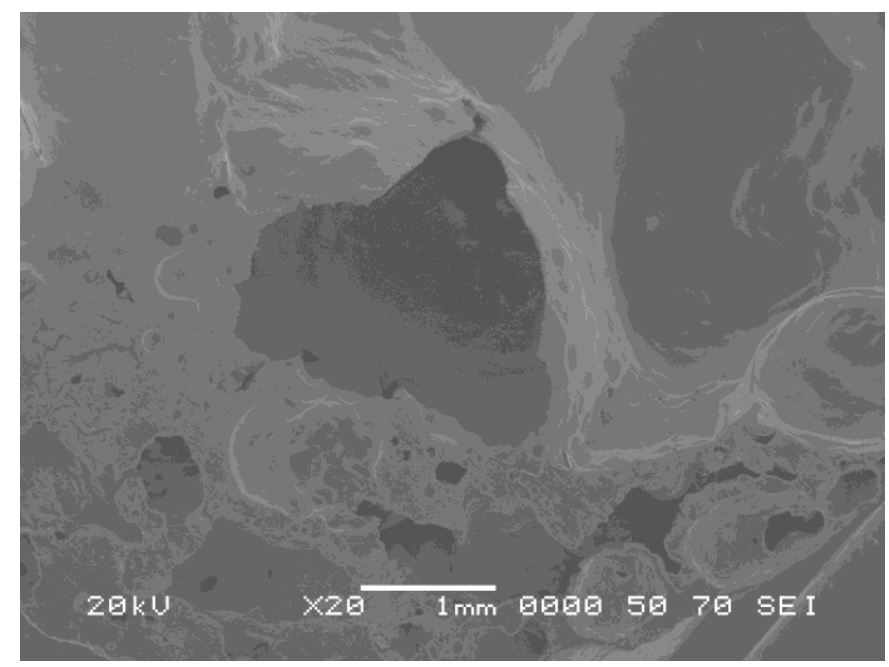

Magnified SEM micrographs of sample A3 (Y-direction) processed at $500^{\circ} \mathrm{C}$ preheat temperature and $1100^{\circ} \mathrm{C}$ ignition temperature
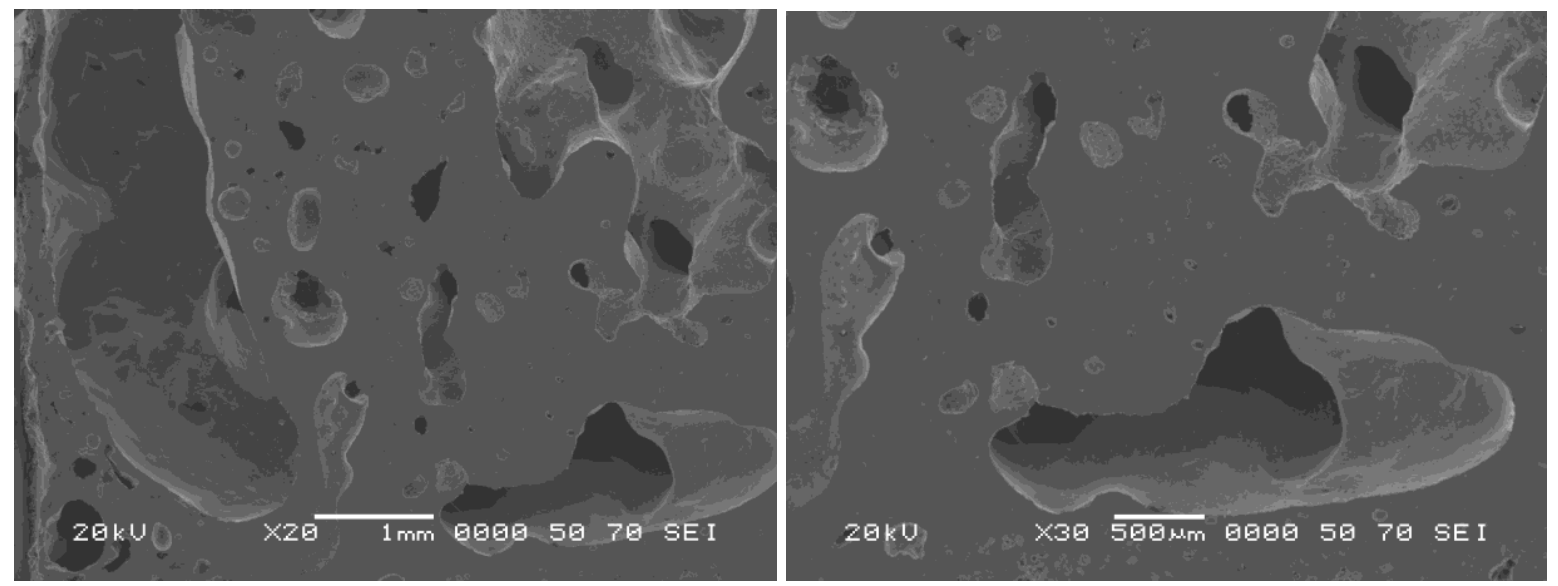

Magnified SEM micrographs of sample A3 (Y-direction) processed at $600^{\circ} \mathrm{C}$ preheat temperature and $1100^{\circ} \mathrm{C}$ ignition temperature 

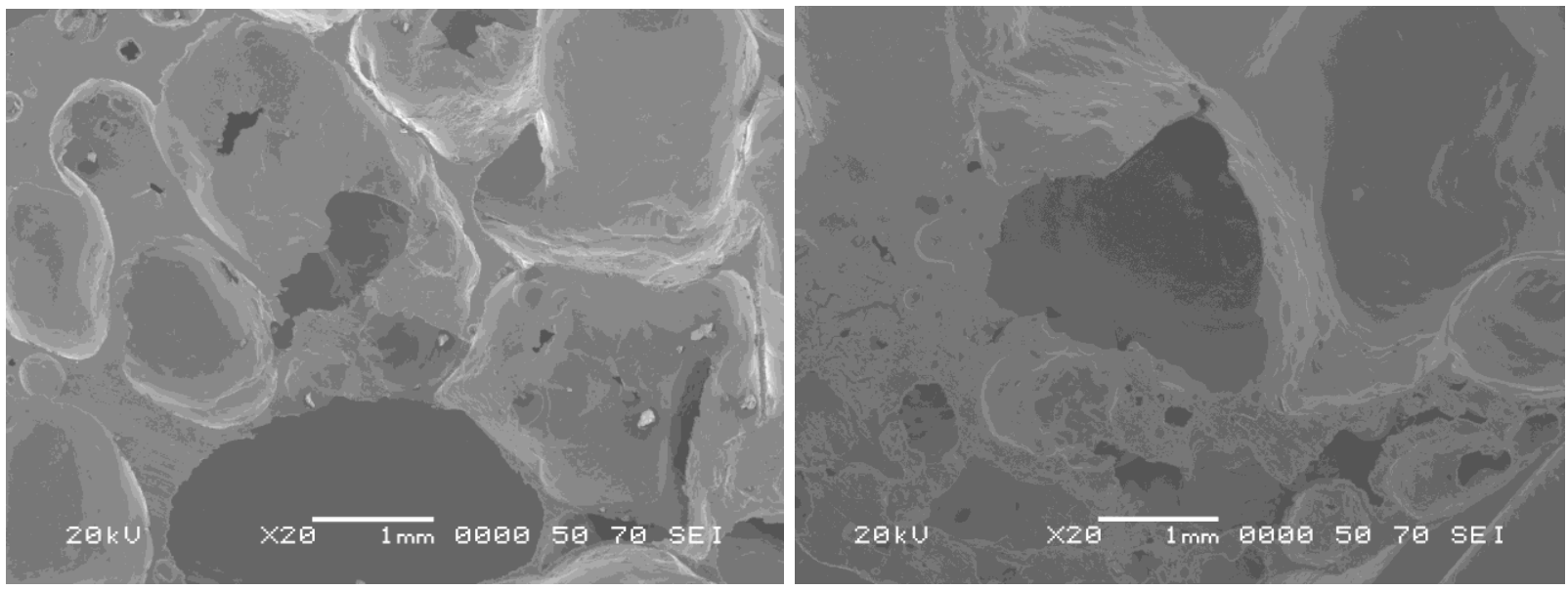

Magnified SEM micrographs of sample A3 (Y-direction) processed at $600^{\circ} \mathrm{C}$ preheat temperature and $1100^{\circ} \mathrm{C}$ ignition temperature 


\section{APPENDIX B: REFERENCE [35] PERMISSION LETTER}




\section{ELSEVIER LICENSE}

Apr 01, 2013

This is a License Agreement between Jessica D Vanterpool ("You") and Elsevier ("Elsevier")

provided by Copyright Clearance Center ("CCC"). The license consists of your order details, the terms and conditions provided by Elsevier, and the payment terms and conditions.

Supplier: Elsevier Limited

The Boulevard,Langford Lane

Kidlington,Oxford,OX5 1GB,UK

Registered Company Number: 1982084

Customer name: $\quad$ Jessica D Vanterpool

Customer address: $\quad 3419$ Saddle Blvd., Orlando, FL 32826

License number: $\quad 3086181207509$

License date: Feb 11, 2013

Licensed content publisher: Elsevier

Licensed content publication Biomaterials

Licensed content title Relationship between osseointegration and superelastic biomechanics in porous NiTi scaffolds

Licensed content author: $\quad$ Xiangmei Liu,Shuilin Wu,Kelvin W.K. Yeung,Y.L. Chan,Tao Hu,Zushun Xu,Xuanyong Liu,Jonathan C.Y. Chung,Kenneth M.C. Cheung,Paul K. Chu Licensed content date: January 2011

Licensed content volume number: 32 
Licensed content issue number:

Number of pages: $\quad 9$

Start Page: $\quad 330$

End Page: $\quad 338$

Type of Use: reuse in a thesis/dissertation

Portionfigures/tables/illustrations

Number of figures/tables/illustrations: 1

Format: electronic

Are you the author of this Elsevier article?: No

Will you be translating?: No

Order reference number: None

Title of your thesis/dissertation: COMBUSTION SYNTHESIS AND CHARACTERIZATION

OF POROUS NITI INTERMETALLIC FOR STRUCTURAL APPLICATION

Expected completion date: Feb 2013

Estimated size (number of pages): $\quad 80$

Elsevier VAT number: GB 494627212 


\section{APPENDIX C: REFERENCE [37] PERMISSION LETTER}




\section{Dear Sir/Madam,}

Thanks for the enquiry. Herewith, we kindly grant you the requested permission to use the paper entitled I"Effect of Preheating Temperature and chamber Pressure on the Properties of Porous NiTi Alloy Prepared by SHS Technique,I" (located World Academy of Science, Engineering and Technology 68 2012) at https://www.waset.org/journals/waset/v68/v68-302.pdf in your thesis.

If you have any questions, please do not hesitate to contact us.

Best regards,

Adam Ariston

Editor-in-Science

International Scientific Council

Tel:++971559099620

http://www.waset.org/ 


\section{APPENDIX D: REFERENCE [41] PERMISSION LETTER}




\section{ELSEVIER LICENSE}

Apr 01, 2013

This is a License Agreement between Jessica D Vanterpool ("You") and Elsevier ("Elsevier")

provided by Copyright Clearance Center ("CCC"). The license consists of your order details, the terms and conditions provided by Elsevier, and the payment terms and conditions.

Supplier

Elsevier Limited

The Boulevard,Langford Lane

Kidlington,Oxford,OX5 1GB,UK

Registered Company Number: 1982084

Customer name: Jessica D Vanterpool

Customer address: 3419 Saddle Blvd., Orlando, FL 32826

License number: 3120040280745

License date: Apr 01, 2013

Licensed content publisher: Elsevier

Licensed content publication: Current Opinion in Solid State \& Materials Science

Licensed content title: The effect of the combustion channels on the compressive strength of porous NiTi shapememory alloy fabricated by SHS as implant material

Licensed content author: Mehmet Kaya,Nuri Orhan,Gül Tosun

Licensed content date: February 2010 
Licensed content volume number: 14

Licensed content issue number: 1

Number of pages: 5

Start Page: 21

End Page: 25

Type of Use: reuse in a thesis/dissertation

Portion: figures/tables/illustrations

Number of figures/tables/illustrations: 2

Format: electronic

Are you the author of this Elsevier article?: No

Will you be translating?: No

Order reference number

Title of your thesis/dissertation : COMBUSTION SYNTHESIS AND CHARACTERIZATION

OF POROUS NITI INTERMETALLIC FOR STRUCTURAL APPLICATION

Expected completion date: Apr 2013

Estimated size (number of pages): 92

Elsevier VAT number: GB 494627212 


\section{REFERENCES}

[1] H.C. Yi and J.J. Moore, "The combustion synthesis of Ni--Ti shape memory alloys", The Journal of the Minerals, Metals, and Materials Society, 42(8):31--35, 1990.

[2] Y. Lu and M. Hirohashi, "Thermal behavior during combustion synthesis of intermetallic compound of Ni--Al system", Journal of Materials Science Letters, 18(5):395--398, 1999.

[3] C. L. Yeh and C.C. Yeh, "Preparation of CoAl intermetallic compound by combustion synthesis in self- propagating mode", Journal of Alloys and Compounds, 288:241-249, 2005.

[4] C. Zanotti, P. Giuliani, A. Terrosu, S. Gennari and F. Maglia, "Porous Ni-Ti ignition and combustion synthesis", Intermetallics, 15:404-412, 2007.

[5]A. Biswas, Acta Mater 53:1415, 2005.

[6]B.-Y. Li, L.-J. Rong, Y.-Y. Li, and V.E. Gjunter, "Fabrication of cellular NiTi Intermetallic compounds," Journal of Materials Research, 15(1):10-13, 2000.

[7] S.B. Margolis, "The asymptotic theory of gasless combustion", Metallurgical Transactions, 23A(1):15--22, 1992.

[8] M. Ballas, Z. Li, O.J. Ilegbusi, "Modeling Reaction Front Propagation and Porosity in Pressure-Assisted Combustion Synthesis of Porous NiTi Intermetallics" JMEPEG, $10.1007 / \mathrm{s} 11665-011-9929-9$

[9] Yong-Hua Li_, Guang-Bin Rao, Li-Jian Rong, Yi-Yi Li, Wei Ke, "Effect of pores on corrosion characteristics of porous NiTi alloy in simulated body fluid," Materials Science and Engineering A363 (2003) 356-359

[10] A. Bansiddhi, T.D. Sargeant, S.I. Stupp, and D.C. Dunan, "Porous NiTi for bone implants: A review,"Acta Biomaterialia 4 773-782, 2008

[11] C.L. Chua, C.Y. Chung, P.H. Lin, S.D. Wang, "Fabrication of porous NiTi shape memory alloy for hard tissue implants by combustion synthesis," Materials Science and Engineering A366 (2004) 114-119

[12] Carlos Oldani, Alejandro Dominguez, "Titanium as a Biomaterial for Implants," 
[13] Y. Zhang and G.C. Stangle, "A micromechanistic model of the combustion synthesis process: Part I. Theoretical development", Journal of Materials Research, 9(10):2592-2604, 1994.

[14] J. Puszynski, V.K. Jayaraman, and V. Hlavacek, "A Stefan problem for exothermic noncatalytic reactions", International Journal of Heat and Mass Transfer, 28(6):1237--1239, 1985.

[15] L. Rao, P. Yu, and R.B. Kaner, "Numerical modeling of combustion synthesis with phase changes", Journal of Materials Synthesis and Processing, 2(6):343--353, 1994.

[16] N. Bertolino, M. Monagheddu, A. Tacca, P. Giuliani, C, Zanotti and U. A. Tamburini, "Ignition mechanism in combustion synthesis of Ti-Al and Ti- Ni systems" Intermetallics, 11:41, 2003.

[17] H.C. Yi and J.J. Moore, "Combustion synthesis of of TiNi intermetallic compounds. Part 1, Determination of heat of fusion of TiNi and heat capacity of liquid TiNi", Journal of Materials Science, 24(10):3449--3455, 1989.

[18] H.C. Yi and J.J. Moore, "Combustion synthesis of of TiNi intermetallic compounds. Part 2. Effect of TiO\$_\$ formation”, Journal of Materials Science, 24(10):3456--3462, 1989.

[19] A.H. Advani, N.N. Thadhani, H.A. Grebe, R. Heaps, C. Coffin, and T. Kottke, "Dynamic modelling of material and process parameter effects on self-propagating high-temperature synthesis of titanium carbide ceramics," Journal of Materials Science, 27:3309-3317, 1992.

[20] A.K. Bhattacharya, "Modelling of the effects of porosity and particle size on the steadystate wave velocity in combustion synthesis," Journal of Materials Science, 27(6):1521$1527,1992$.

[21] A.K. Bhattacharya, "Green density of a powder compact and its influence on the steadystate wave velocity in combustion synthesis of condensed phase," Journal of the American Ceramic Society, 74(9): 2113--2116, 1991.

[22] M.G. Lakshmikantha, A. Bhattacharya, and J.A. Sekhar, "Numerical modeling of solidification combustion synthesis," Metallurgical Transactions, 23A(1):23--34, 1992.

[23] J. Puszynski, J. Degreve, and V. Hlavacek, "Modeling of exothermic solid-solid noncatalytic reactions", Industrial and Engineering Chemistry Research, 26(7):14241434, 1987. 
[24] Z. Li and O. J. Ilegbusi, "Experimental Study of Thermal and Flame front Characteristics in Combustion Synthesis of Porous Ni - Ti Intermetallic Material," Journal of Materials Engineering and Performance, 1059-9495, 2011

[25] W.D. MacDonald, T.W. Eagar, "Transient liquid phase bonding processes," The Mineral, Metals and Materials Society, 1992

[26]Kopeliovich, D "Solid state fabrication of metal matrix composites", http://www.substech.com/dokuwiki/doku.php?id=solid_state_fabrication_of_metalmatrix _composites

[27] "How does plasma welding work", http://www.cmf.fr/news/plasma-arc-welding/ Smith, D "title of article", (Date Published) Retrieved from: http://www.thewebsite.com

[28] M. V. Kuznetsov, I. V. Shishkovsky2, Yu. G. Morozov, and I. P. Parkin, "Design of ThreeDimensional Functional Articles via Layer-by-Layer Laser Sintering of Exothermic Powder Mixtures," Materials and Manufacturing Processes, 23: 571-578, 2008

[29]B.Y. Tay,, C.W. Goh, Y.W. Gu, C.S. Lim, M.S. Yong, M.K. Ho, M.H. Myint, "Porous NiTi fabricated by self-propagating high-temperature synthesis of elemental powders," Journal of Materials processing Technology, 202: 359-364, 2008

[30]Epstein NE. A review of interspinous fusion devices: High complication, reoperation rates, and costs with poor outcomes. Surg Neurol Int 2012;3:7

[31]Health wise staff, "CoronaryAngioplasty," http://www.sutterhealth.org/health/healthinfo/index.cfm?A=C\&type=info\&hwid=zm263 $3 \&$ popup $=1$

[32] “Angioplasty and Vascularstenting," http://www.radiologyinfo.org/ en/info. cfm?pg $=$ angioplasty

[33] "Medical applications of Nitinol http://www.nickeltitanium.com/dosya/Seminar\%20 Genera $1 \% 20$ Applications\%20of\% 20NiTi\%20Shape\%20 Memory\%20 Alloys \%20\% 28 dilibal $\%$ 29.pdf

[34] Lagoudas, D. (2008) Shape memory alloys. London: Springer, p.20. 
[35] Xiangmei Liu, Shuilin Wu, KelvinW.K. Yeung, Y.L. Chan, Tao Hub, Zushun Xu, Xuanyong Liu, Jonathan C.Y. Chung, Kenneth M.C. Cheung, Paul K. Chu, "Relationship between osseointegration and superelastic biomechanics in porous NiTi scaffolds," Biomaterials 32 (2011) 330e338

[36] S. L. Zhu, X. M. Wang, F. X. Qin, M. Yoshimura and A. Inoue, "New TiZrCuPd Quaternary Bulk Glassy Alloys with Potential of Biomedical Applications," Materials Transactions, Vol. 48: 2445-2448, 2007

[37] Wisutmethangoon S., Denmud N., Sikong L., "Effect of Preheating Temperature and chamber Pressure on the Properties of Porous NiTi Alloy Prepared by SHS Technique," World Academy of Science, Engineering and Technology 682012

[38] B. Y. Li, L. J. Rong, Y. Y. Li, and V. E. Gjunter, "Synthesis of Porous Ni-Ti Shape Memory Alloys by Self Propagated High-Temperature Synthesis: Reaction Mechanism and Anisotropy In Pore Structure," in Acta Materialia, 48, pp. 3895-3904, 2000.

[39] Xiangmei Liu, Shuilin Wu, K.W.K. Yeung, Z.S. Xu, C.Y. Chung, and Paul K. Chu, "Superelastic Porous NiTi with adjustable porosities synthesized by Powder Metallurgical Method,” JMEPEG (2012) 21:2553-2558

[40] Dimitris c. Lagoudas, Eric L. Vandygriff, "Processing and Characterization of NiTi Porous SMA by Elevated Pressure Sintering," Structures Journal of Intelligent Material Systems and structures, 2002 13: 837 DOI: 10.1177/1045389X02013012009

[41] Mehmet Kaya, Nuri Orhan, Gül Tosun, "The effect of the combustion channels on the compressive strength of porous NiTi shape memory alloy fabricated by SHS as implant material," Current Opinion in Solid State and Materials Science 14 (2010) 21-25

[42] H.C. Man, S. Zhang, F.T. Cheng, X. Guo, "Laser fabrication of porous surface layer on NiTi shape memory alloy," Materials Science and Engineering A 404 (2005) 173-178.

[43] B. Y. Li, L. J. Rong, Y. Y. Li, V. E. GJunter, "Synthesis of porous Ni-Ti shape-memory alloys by self propagating high-temperature synthesis," Acta materialia Acta mater. 48 (2000) 3895-3904

[44] Rasband, W.S., ImageJ, U. S. National Institutes of Health, Bethesda, Maryland, USA, http://imagej.nih.gov/ij/, 1997-2012. 